\title{
CHANGING CHARACTERISTICS OF HIGH ACCIDENT DRIVERS OVER A FIVE YEAR PERIOD
}

SEPTEMBER 1972 - NUMBER 29

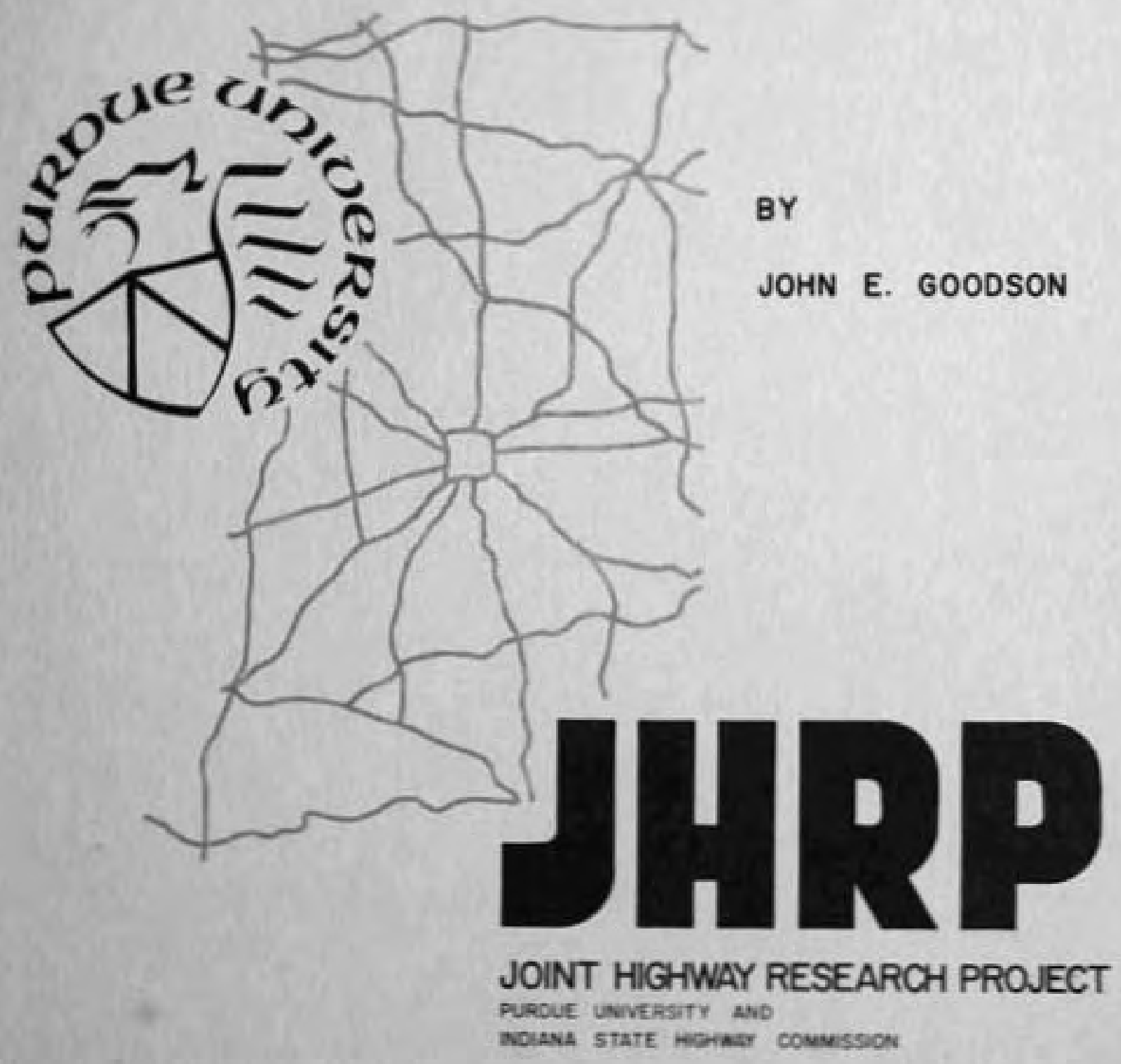


Final Report

CHANGING CHARACTERISTICS OF HIGH ACCIDENT

DRIVERS OVER A FIVE YEAR PERIOD

\author{
by \\ John E. Goodson \\ Graduate Assistant in Research
}

Joint Highway Research Project

Project No.: C- $36-150$

File No.: $8-5-15$

\begin{abstract}
Conducted By
Joint Highway Research Project

Engineering Experiment Station

Purdue University

In Cooperation With

Indiana State Highway Commission
\end{abstract}

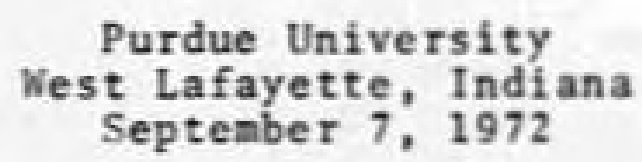


Final Report

\section{CHANGING CHARACTERISTICS OF HIGH ACCIDENT \\ DRIVERS OVER A FIVE YEAR PERIOD}

T0: J. F. McLaugh1in, Director

Joint Highway Research Project

FROM: H. L. Michae1, Associate Director Joint Highway Research Project
September 7, 1972

Project: C-36-150

File: $8-5-15$

The attached Final Report "Changing Characteristics of High Accident Drivers Over a Five Year Period" is submitted as fulfillment of the objectives of the research proposal approved by the Board. The Report was written and the research conducted by $\mathrm{Mr}$. John E. Goodson, Graduate Assistant in Research on our staff, under the direction of Professor H. L. Michael.

The report notes that alnost all individuals who had three or more accidents in the year 1967 had a much decreased accident rate in each of the following four years. Only a very few drivers continued to exhibit high accident rates for the next four years and driver or accident characteristics exhibited in 1967 would not have enabled selection of these drivers. There was an indication, however, that following several years of continued accident history an extremely small number of drivers could have been noted who would probably continue to have accidents at a high rate.

The Report is presented to the Board for acceptance as fulfillment of the objectives of the study.

Respectfully submitted,
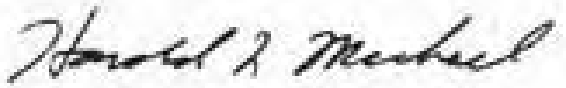

Harold L. Michael

Associate Director

HLM:ms

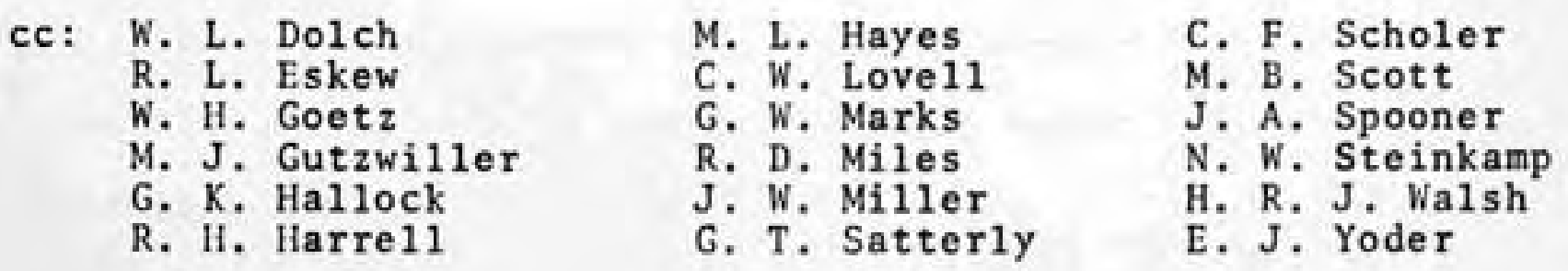




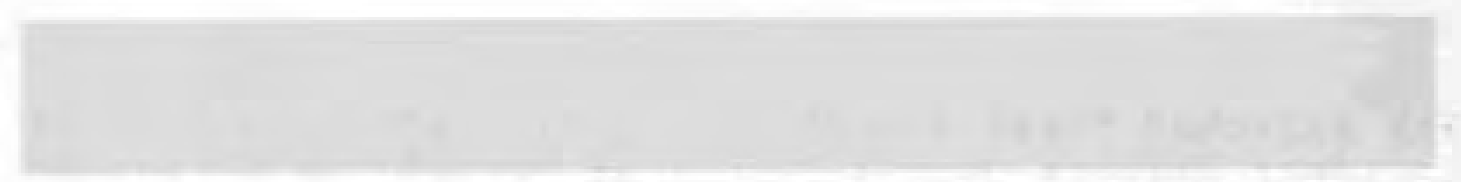

Digitized by the Internet Archive in 2011 with funding from

LYRASIS members and Sloan Foundation; Indiana Department of Transportation

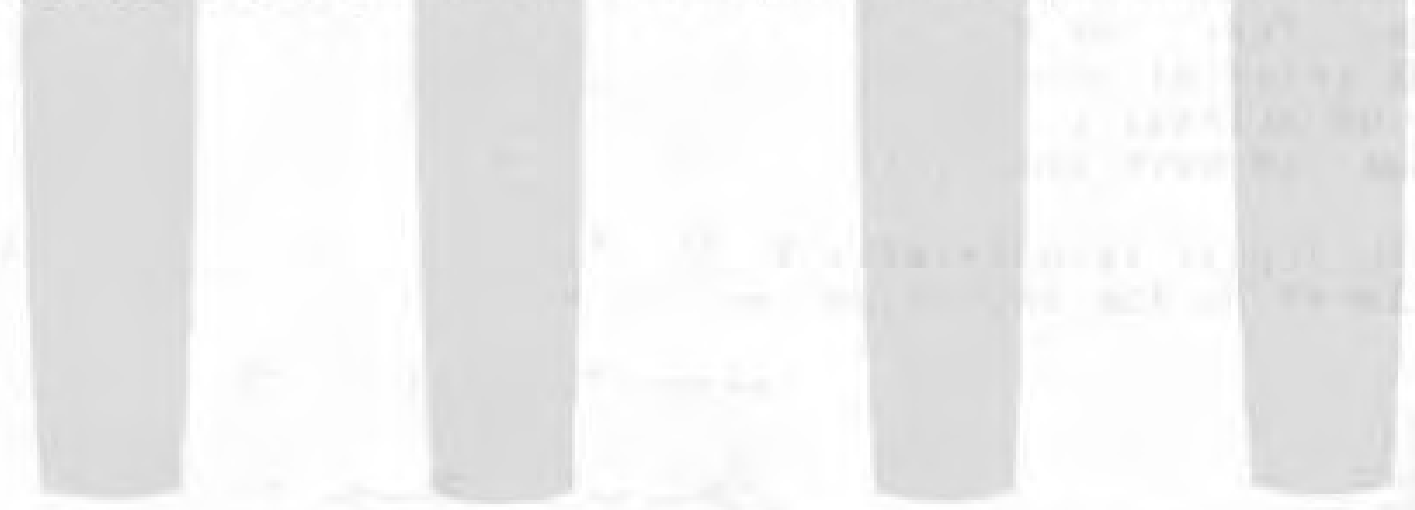




\section{ACKNOWLEDGEMENTS}

The author wishes to express his sincere appreciation to Professor Harold L. Michael, Associate Director of the Indiana Joint Highway Research Project, for his guidance in selecting the topic, performing the research and his review of the manuscript; to Professor William L. Grecco of the School of Civil Engineering for his advice and review of the manuscript; and to Professor Leonard z. Breen of the Sociology Department for his advice and review of the manuscript.

The author is very grateful for the cooperation of the Indiana State Police and the generous assistance provided by Major C. W. McCarter, Lieutenant J. H. Romack, Sergeant J. S. Kinder, and the rest of the staff of the Accident Records Department.

Acknowledgement is also given to the Indiana Bureau of Motor Vehicles and in particular to Mr. Morris Carter, Mrs. M. H. Smith, and Mrs. Alberta Bauer for their assistance in providing and interpreting the driver record summaries.

Special thanks are extended to Dr. Edward Kannel for his valuable assistance during all phases of the research; to Miss Kathy DeWald; and to the many other individuals who participated in the study.

The author is especially grateful to his wife for her countless hours of assistance and encouragement. 
TABLE OF CONTENTS

Page

LIST OF TABLES ................... . . $v$

LIST OF FIGURES. . . . . . . . . . . . . . . . vii

ABSTRACT ................... vili

INTRODUCTION . . . . . . . . . . . . . . 1

PURPOSE. . . . . . . . . . . . . . . 5

DATA COLLECTION. . . . . . . . . . . . . . . 6

High Accident Driver . . . . . . . . . . . 7

The Control Driver Group . . . . . . . . . . . . 12

Additional Data. . . . . . . . . . . . . 13

ANALYSIS OF DATA . . . . . . . . . . . 15

High Accident Driver ......... . . . . . 15

The Control Driver Group . . . . . . . . . . . . 19

Final Data Groups. . . . . . . . . . . . 19

RESULTS. . . . . . . . . . . . . . . 20

The Accident Picture . . . . . . . . . . . 20

Seriousness of the Accidents . . . . . . . . 27

Where the Accidents Occurred . . . . . . . . . 30

Driver Characteristics............. 35

License TYpe . . . . . . . . . . . . . . . . . 39

The Driving Record............... 41

The Combined Characteristics as Accident

CONSEQUENCES OF LICENSE SUSPENSION OR REVOCATION . • 51

Drivers Having Three Accidents During

the Year 1967 . . . . . . . . . . . . 51

Drivers Having Four Accidents During

the Year 1967 . . . . . . . . . . . . 54

Drivers Having Five Accidents During

the Year 1967 ... . . . . . . . . 56

Drivers Having Six or More Accidents During

the Year 1967............. 56 
Page

CASE HISTORIES OF SELECTED HIGH ACCIDENT DRIVERS . . . . 59

Clear Driving Record . . . . . . . . . . . 59

Drivers With Improved Driving Records After 1967.61 Three Accidents in 1967 and Continued High

Accident Rate Afterward . . . . . . . . . . . . 64

Drivers With Multiple Suspensions. . . . . . . . . 68

Fifteen or More Accidents During the Five Year

Study Period. . . . . . . . . . . . . . 74

Summary Comments... . . . . . . . . . . 80

CONCLUSIONS. . . . . . . . . . . . . . . . . . . 82

RECOMMENDATIONS. . . . . . . . . . . . . . . . . 84

LIST OF REFERENCES . . . . . . . . . . . . . . . 86

APPENDICES

Appendix A: State Record Summaries. . . . . . 90

Appendix B: Driving Regulations . . . . . . . 102

Appendix C: Data Collection Forms and

Related Information ...... . . 104

Appendix D: Driver Characteristics. . . . . . 108 


\section{LIST OF TABLES}

Table

Page

1. 1967 Multiple Accident Drivers . . . . . . . 20

2. Total Accident Involvement During Five Year Study Period 1967-1971 By Drivers Involved in Three or More Accidents in 1967. . . . . .

3. Sumary Statistics. .............. 23

4. Number of Accidents in 1967 in Relation to Number of Accidents in the Following Four Year Period 1968-1971............ 2. 25

5. Type of Accident. . . . . . . . . . . . 29

6. Accident Involvement in Five Indiana Cities . . 31

7. Residence of Drivers for Pive Indiana Cities. . 32

8. Age Distribution. . . . . . . . . . . 36

9. 1967 Violation Citations. . . . . . . . . . 42

10. 1967 Serious Violations . . . . . . . . . . 44

11. 1967 License Suspensions. . . . . . . . . . . . 45

12. 1967 Suspensions for Driving While Intoxicated. 46

13. Additional Accidents During 1968-1971 by Drivers with Three Accidents During 1967. . . . . . 53

14. Additional Accidents During 1968-1971 by Drivers with Four Accidents During 1967 . . . . . . 55

15. Additional Accidents During 1968-1971 by Drivers with Five Accidents During $1967 . . .+. .+57$

16. Licenses on File in Indiana ............ 91

17. Standard Summary of Motor Vehicle Traffic Accidents ....................

18. Age and Sex Related to Total Accident Involvement............... 109 
19. License Restrictions Related to Total

Accident Involvement. . . . . . . . . . 111

20. Weight/Height Index in Relation to Total

Accident Involvement. . . . . . . . . 113

21. Residence of Drivers. . . . . . . . . . 115

22. Accident Involvement by City. . . . . . . 118 


\section{LIST OF FIGURES}

Figure Page

1. Seriousness of Accidents in Relation to Total Accident Involvement . . . . . . . . 28

2. Residence and Accident Occurrence in Indianapolis in Relation to Total Accident: Involvement. .....................

3. Residence and Accident Occurrence in Fort Wayne in Relation to Total Accident Involvement. . 34

4. Results of Automatic Interaction Detector Program. 49

5. Excerpts from Indiana Driver's Manual. . . . . . . 103

6. Accident Record . . . . . . . . . . . 105

7. Driver Record . . . . . . . . . . . . . 106

8. Soundex Code . . . . . . . . . . . . . . . 107 


\section{ABSTRACT}

Goodson, John Earl. MSCE, Purdue University, August, 1972. Changing Characteristics of High Accident Drivers Over a Five Year Period. Major Professor: Harold I. Michael.

The purpose of this research was to determine the number and characteristics of drivers who had a high accident involvement during a particular year. Then, using information available in the accident and driver record files, the changes in their characteristics and accident involvement during the following four year period were determined.

Accident record summaries were collected for the years 1967 through 1971 for all drivers who were identified as having been involved in three or more accidents during the year 1967. Driver record summaries were collected for drivers involved in three or more accidents during the year 1967 and a total of five or more accidents during the entire five year study period. Included in the final analysis were 776 drivers for which both driver and accident record summaries had been obtained and an additional 1288 drivers for which only accident records were collected.

It was found that the accident records of most of the drivers studied exhibited much improvement during the four year period following the base year. Approximately forty 
percent of the drivers who were involved in three or more accidents during the base year were identified as having no additional reported accidents during the following four year period.

Using only information available in the accident and driver record files, it was found that it is difficult to predict, with any degree of accuracy, which drivers who were high accident drivers during a particular year would continue to be excessive accident repeaters during following years. Two characteristics studied that appeared to have the greatest value as accident predictors were the number of accidents during a year and the type of license. For the average driver of a high accident group, it was found that as the number of accidents in which he was involved during the base year increased, the probability of his being involved in additional accidents during the following years also increased. Persons with chauffeur's licenses and particularly public passenger chauffeur's licenses were found to share a much greater proportion of the high accident groups than their proportions of the licensed drivers would indicate.

In general, the accident record of a driver during one year, even when combined with information available in the Indiana Drivers Records, does not enable a reasonable prediction of the drivers accident record for future years. 


\section{INTRODUCTION}

In order to develop an effective accident prevention program it is necessary to know the characteristics of all of the system components involved: the environment, the vehicle, and the driver. The characteristics that are least understood and the most difficult to predict are those of the individual driver, and it is the driver who is held responsible for the great majority of traffic accidents.

Various research reports in this field have presented contradictory statements regarding the characteristics of drivers involved in accidents. For example, according to Waller (18), "Two fallacies have seriously hampered meaningful programs against traffic accidents. The first is the belief that traffic accidents happen to almost everyone. The second is the attitude that most accidents are the result of voluntary violation of traffic laws, and are subject to correction by the issuance of citations." Evidence given by Crancer $(4,5,6)$ indicates that it is the non-average driver that is involved in fatal accidents, while Goldstein (7) states that most accidents occur to normal, average people.

Penn's report (13) summarizes that "The accident process is stated to consist essentially of a driver breakdown of some sort which allows the underlying accident potential 
to come into play. In the case of a large body of drivers, this breakdown factor is probably temporary; in other groups of operators, it is more enduring."

Each year a small percentage of drivers are involved in an excessive number of accidents. Very little is known about the characteristics of these drivers or how their accident histories vary over periods of time longer than a year. In a 1946 report by Johnson (9), it was stated that "Operators who are accident-repeaters in one period tend to regress toward the average of the group in another period." This temporary nature of accident proneness is further reinforced by more recent reports of Schuster and Guilford (14) and Campbe11 (1), but is contradicted by Shaw and Sichel (16) who say, "... The man whose past record has been unsatisfactory is unlikely to improve, punishing him will have very little effect, and retraining him means throwing good money after bad. The only practical way of insuring that he does not have accidents is to prevent him from driving."

It is very probable that the accident-repeater is not the average driver nor the average person. According to Penn (13) "The person likely to become involved in an accident is a disturbed person, at odds with the world around him." It may be that the conditions or circumstances that plague the accident-repeater and involve him in several collisions are the same, at least temporarily, for the average person or driver who has an accident. By studying the records of the accident-repeater, determining his 
characteristics and how they change with time, it should be possible to determine accident causative factors that apply to the entire population of drivers. Some such factors may be difficult to pinpoint in the driver that is only occasionally involved in an accident, but may be more apparent in the accident-repeater.

It is recognized that one method of possibly reducing accidents would be to restrict the driving liberty of those who could be classified as accident repeaters. But to provide such restrictions, good evidence of the benefits to society will be necessary. It would be desirable to know the answer to several questions, for example; Why do some individuals have more accidents than other drivers? Does an individual's relative accident involvement rate in one year remain the same in succeeding years or does it increase or decrease? If improvements or deteriorations are noted, what are the causative factors of these changes?

In 1967 there were about 2.7 million drivers licensed in the State of Indiana. During that year, 301,921 drivers were involved in 175,886 reported motor vehicle accidents within the state. During that same year more than two thousand drivers were involved in three or more accidents. It was found that 2064 of these drivers were involved in a total of 6573 reported accidents. Thus less than one tenth of one percent of the total licensed drivers were involved in over 3.7 percent of the accidents that were reported during the year 1967 . 
While 3.7 percent is not a very large proportion of the total accidents, it is a substantial number. If it could be determined that these high accident drivers were going to continue to become involved in such a large number of accidents during the following years, it would be foolish to allow them to continue as a threat to society. Therefore, this study was directed toward those 2064 individuals who were involved in three or more accidents during the year 1967. 


\section{PURPOSE}

The objectives of this study were to:

1. Determine the number and characteristics of drivers who had an excessively high accident involvement during a particular year.

2. Evaluate the records of these drivers for a period of years beyond the base year to determine changes which take place over time in accident involvement and in their characteristics.

3. From information available in the accident and driver record files, correlate changes in accident involvement with present or possible corrective procedures, such as revocation of operators permit, drivers training courses, etc. 
DATA COLLECTION

A driving record of all persons licensed by the State of Indiana to drive a motor vehicle is maintained by the Bureau of Motor Vehicles. This driving record includes information about the personal characteristics, type of license, and violation citations of each driver. Accidents in which a person is involved are not recorded on the driver record unless the driver was proven responsible for the accident .

A completely separate record of all reported accidents is maintained by a completely separate organization: the Indiana State Police. This record includes driver identification and date, location and type of accident.

Data were collected for two groups of drivers for the purpose of this study. The first group of drivers included all persons who were identified as being involved in three or more accidents during the year 1967. Complete accident record summaries were collected for this group for the years 1967 through 1971. In addition, driver record summaries were collected for all drivers in this group who had a total of five or more accidents during the entire five year study period.

The second group of drivers was selected randomly from the entire population of Indiana drivers. This group of 
drivers was selected to serve as a control group to which the multiple accident driver could be compared. Complete accident record summaries for the years 1967 through 1971 were collected for all drivers in the control group. Driver record summaries were also collected for all control group drivers.

\section{High Accident Driver}

Accident Record Summaries

Indiana State Law requires that a written report be filed with the State Police within five days of an accident in the event of a death, injury or over fifty dollars damage. The State Police maintain a record of all reported motor vehicle accidents. Unlike the driver record which files all infractions to a particular driver, the accident record treats each accident individually. In other words, a listing is not maintained for each driver giving his individual accident history.

Each year a name listing of drivers involved in traffic accidents during the year is prepared. These name listings identify drivers by their last name, first name and middle initial. Since the year 1967 , the name listings have further identified drivers by their date of birth. The last name of each driver is Soundex Coded so that all names that are spelled identically or that sound the same are grouped together. (A more detailed explanation of the Soundex Code will be found in Appendix $C$ ). The first name and middle initial are listed alphabetically within each Soundex group. 
For each reported accident that a driver has during a particular year, he is listed once in that years accident name listing. Therefore, to determine which drivers had multiple accidents during a particular year it is necessary to search the name listing for that year for multiple listings of drivers with the same identification.

Since 1967 was the first year that accident name listings were maintained that included the date of birth of the driver, that year was selected as the base year for this study. The date of birth was required for the purpose of making positive identification of the drivers. There are approximately one hundred licensed drivers in Indiana that have the same first and last name and middle initial and the same date of birth as another licensed driver. These drivers are distinguished by the notation "Suffix 1" or "Suffix 2 " on their driver record. None of these drivers were involved in this study as high accident drivers (three or more accidents in 1967 and five or more accidents 19671971).

State Police records show that 301,921 drivers were involved in 175,886 motor vehicle accidents in Indiana during the year 1967 (See Appendix A). A preliminary sampling of the 1967 Accident Name Listing was made to determine the frequency at which multiple accident listings occurred. This preliminary review indicated that roughly one driver had three or more accidents for every one hundred-fifty 
accident listings. On this basis the decision was made to limit this study to only those drivers who had three or more reported accidents during the year 1967.

Each of the 301,921 accident name listings for the year 1967 was checked name by name for multiple listings of three accidents or more. Those names found three or more times were then checked for identical birthdates. Once a driver was positively identified as having been involved in three or more accidents during the year 1967, the following information was recorded from the accident name listing (See Appendix C for sample data collection form):

1. Driver's last name, first name, and middle initial;

2. Driver's date of birth;

3. Residence of driver at time of accident;

4. Age of driver at time of accident;

5. City or township in which accident occurred;

6. County in which accident occurred;

7. Date that accident occurred;

8. Type of accident (property damage, injury, or fatal);

9. State Police accident code identification number. Information was recorded on 2093 drivers who had three or more accidents during the year 1967. Some drivers were found in the accident name listing that appeared to have three or more accidents but no date of birth was listed. Under these circumstances positive identification of the driver was not possible and these names were not included in 
the study. It is also possible that a few drivers who had three or more accidents might have been missed due to human error. However, the search for multiple accident drivers was very thorough and if any drivers were missed, the number is very few.

Once the base sample of drivers for the year 1967 was complete, a thorough search was made of the Accident Name Listings for the years 1968, 1969, 1970, and 1971, to determine the additional accidents in which these drivers were involved. Once a driver from the 1967 base sample was positively identified as having been involved in one or more additional accidents during the following four year period, the same accident information was recorded as was for the year 1967 .

\section{Driver Record Summaries}

of the base sample of drivers who had three or more accidents in 1967,805 had a total of five or more accidents during the five year study period. These drivers were selected for a study of their driver record. The names and birthdates of these drivers were submitted to the Bureau of Motor Vehicles. The Bureau then provided copies of the driver record summary for 799 of the 805 drivers. No record could be found for the remaining six drivers. The names and birthdates of these six drivers were rechecked for correctness and then resubmitted to the Bureau of Motor Vehicles. Another search of their files was still unsuccessful in identifying these drivers. 
Each driver record summary contains the following information (See Appendix $C$ for sample driver record sumary):

1. Residence of driver;

2. Type of license (learner permit, driver education permit, probation operator, chauffeur, public passenger chauffeur);

3. Color of hair and eyes;

4. Sex:

5. Date of birth;

6. Weight and height of driver;

7. Date last license was applied for;

8. Date re-exan due;

9. Date license expires.

In addition to the above information which is recorded on every driver record summary, the following data are recorded where applicable:

1. License restrictions (required to wear glasses, required to have outside rearview mirror, daylight driving only, etc.);

2. Date and changes of license type (operator to chauffeur, driver education to operator, etc.);

3. Convictions for moving violations, type of violation, violation points and date;

4. Convictions for failing to appear for driver instruction, interview or court appearance;

5. Actions taken against drivers (interviews, probation, suspension of 1icense, etc.); 
6. Date suspension or probation is closed;

7. If driver has reported an out of state move, date of move and place to where he moved;

8. Deceased drivers noted;

9. Current driving status (clear, on probation, suspended, total active violation points).

The Control Driver Group

In order to have a basis of comparison, a control group of drivers was selected randomly from the entire population of Indiana drivers. This was accomplished through the use of Bureau of Motor Vehicle records.

Accident Record Summaries

A search was made of the accident name listings for each driver in the control group to determine his accident history during the five year study period. When the records indicated that a control driver had been involved in one or more accidents at any time during the five year study period, the same information was recorded as was for the high accident driver.

\section{Driver Record Summaries}

Copies of driver record summaries were obtained for each control group driver from the Bureau of Motor Vehicles. The summaries contained the same type of information as those collected for the high accident driver. Complete accident and driver records were collected for a control group of 367 drivers. 


\section{Additional Data}

Additional statistical information used in this study was taken from the "Standard Summary of Motor Vehicle Traffic Accidents in Indiana." This report is prepared annually by the Indiana State Police. Information was taken from the reports for the years 1967 through 1971. Information concerning total licensed drivers in the state for the years 1967 through 1971 comes from reports prepared by the Bureau of Motor Vehicles (Copies of these reports will be found in Appendix A).

Due to the confidential nature of accident reports and State Laws protecting their confidentiallity, no names or other identifying information were taken from the offices of the State Police. Therefore, once all the data had been collected and assembled, drivers names and other traceable identifying information were removed from the information collected and case study numbers were assigned.

It must be observed that the information recorded on the driver and accident records conveys only a small amount of information about that person's driving performance. Furthermore, a driver may continuously violate traffic laws but will receive a citation which will be recorded on his record only when observed by a law enforcement official or perhaps when involved in an accident. A driver may be involved in many potential accidents-near misses-but is recorded as having an accident only when an accident actually 
occurs and damage over fifty dollars results and/or an injury or fatality occurs. Even then it is possible that a driver may have one or more accidents that go unreported. 


\section{ANALYSIS OF DATA}

\section{High Accident Driver}

Drivers in the high accident group were placed into two categories: those who had a total of five accidents or more and for which driver records had been obtained and those who had a total of three or four accidents and for which driver records had not been obtained. The driver record summary of each person in the first group was examined to determine if that person was an Indiana driver during the entire five year study period. When it could be determined from the record that a person was an Indiana driver for less than fifty-four months of the sixty month study period, that driver was eliminated from the study. Methods of determining that a person was not an Indiana driver for the full study period included record notations that indicated he had moved out of state, his license had expired and had never been renewed, or he had died. However, if it was noted that a driver that had moved out of state had subsequent notations on his records for accidents, citations, license renewal, or other reasons, and if any such notation was within six months of his date of move, it was assumed that he had returned to Indiana and he was included in the study. Drivers were not removed from the study due to license suspensions. Twenty three drivers were removed for not being an Indiana 
driver for the five year study period.

of the original 799 drivers for which both driver and accident records were obtained, this total was now reduced to 776. All of these drivers had a total of five or more accidents during the five year study period of which at least three occurred during the year 1967. The following information from the driver and accident records of these drivers was coded and punched onto computer cards:

1. Case number of the driver;

2. Residence of the driver;

3. Index of weight/height of the driver;

4. Age of driver at the time of first accident during the year 1967;

5. Sex:

6. License type;

7. License restrictions;

8. License changes and date of changes;

9. Total violation points during five year period, (An explanation of the violation point system will be found in Appendix $B$ );

10. Total license suspensions during five year period;

11. Total months license was suspended;

12. Total license suspensions during five year period for:

(a) Driving while intoxicated;

(b) Failure to appear; 
(c) Responsibility for an accident;

(d) Leaving the scene of an accident;

(e) Violation of Implied Consent law;

13. Type, date, and number of points of each violation eitation;

14. Date, place, and type of each accident.

Once a11 of the data were coded, punched onto cards. and verified, computer programs were written to determine the following additional characteristics of each driver:

1. Mean tine in days between accidents;

2. Total number of accidents during the five year period;

3. Mean time in days between violation citations;

4. Total violation citations during the five year period;

5. Number of fatal accidents during the five year period;

6. Number of injury accidents during the five year period;

7. Number of property damage only accidents during the five year period;

8. Number of accidents during the year 1967;

9. Number of each of the following during the year 1967:

(a) Total license suspensions;

(b) License suspensions for driving while intoxicated; 
(c) License suspensions for failure to appear;

(d) License suspensions for responsibility for an accident;

10. Number of violation citations during the year 1967;

11. Number of serious violation citations during the year 1967.

For the purpose of this study a serious violation was defined as a violation that requires mandatory license suspension or carries five or more violation points. This definition is not intended to convey the idea that other violations are not serious. It is intended to distinguish between violations that may occur accidently or through driver inattention and violations that are nearly always willful. Examples of the possible accidental type of violation include driving the wrong way on a one way street and running a stop sign or traffic signal. Examples of the willful violation, the one being defined as serious, include "drag racing", reckless driving, leaving the scene of an accident, and driving while license is suspended.

License types were initially coded into six categories: operator's license, chauffeur's license, public passenger chauffeur's license, learner's permit, driver education permit, and probation operator's license. In the final analys is the learner's permit, driver education permit, and probation operator's license were all combined under the operator's license category. Thus the final categories of 
1icense type that appear in the analysis are the operator's license, the chauffeur's license, and the public passenger chauffeur's license.

\section{The Control Driver Group}

The driving records of all control group drivers were examined using the same criteria as for the high accident driver. A total of forty-one drivers were removed from the control group because it was determined that they were Indiana drivers for less than fifty-four months of the sixty month study period. This left a control group of 326 drivers. With the exception of age, the information was then coded and punched onto computer cards in the exact format as for the high accident driver. The age of the driver was coded as his age on January 1, 1967.

\section{Final Data Groups}

The final data for which both accident and driver records were available were organized into four groups as follows:

Group

Control Group

5 Accident Tota 1

6-7 Accident Total

$\geq 8$ Accident Total
Number of Drivers in Group

326

361

288

127

In addition to these four main groups, information concerning accident records and age and residence of drivers was available for drivers who had three and four accidents. 
RESULTS

The Accident Picture

The search of the 1967 accident records produced 2064 drivers who had three or more accidents in Indiana during that year and who are believed to have been Indiana drivers for most of the five year study period. The number of accidents in which these drivers were involved during that single year ranged from three to nine accidents as shown in Table 1. The group as a whole were involved in a total of 6573 accidents during the year.

Table 1. 1967 Multiple Accident Drivers.

Number of Accidents Per Driver During The Year 1967

$\begin{array}{cc}\text { Number } & \text { Total } \\ \text { of } & 1967 \\ \text { Drivers } & \text { Accidents }\end{array}$

Total Additional Accidents During Following Four Year Period 1968-1971

\begin{tabular}{rrrr}
\hline 3 & 1763 & 5289 & 2102 \\
4 & 241 & 964 & 393 \\
5 & 46 & 230 & 131 \\
6 & 10 & 60 & 56 \\
7 & 3 & 21 & 11 \\
9 & 0 & 9 & 3 \\
\hline
\end{tabular}


Looking at the accident record of this same group of drivers for the entire five year study period, 1967 through 1971, it was found that the number of accidents in which the individual drivers were involved ranged from a low of three, all in 1967, to a high of twenty-nine accidents (See Table $2)$. The group as a whole were involved in 9269 reported accidents during the entire five year study period.

Taken as a group, it is clear that the accident record of these 2064 drivers underwent much improvement during the four year period following the 1967 base year. In 1967, the group had an average of 3.18 accidents per driver while the average per year for the following four year period was 1.30 accidents per driver. In comparison, the control driver was found to have an average of 0.09 accidents per year. This latter figure is shown in Table 3, a summary of important statistics of the drivers in the control group and in the study group. Therefore, taken as a group, the drivers who had three or more accidents in 1967 showed improvement in their accident record during the following four year period, but they still had more than ten times the number of accidents as the average driver would be expected to have.

Table 4 presents some interesting statistics on the accident picture over the 5-year period of the drivers in the study group. Of the group of 1763 drivers who had three accidents in 1967,728 or 41.3 percent of the group had no additional accidents during the following four year period. 
Table 2. Total Accident Involvement During Five Year Study Period 1967-1971 By Drivers Involved in Three or More Accidents in 1967.

\begin{tabular}{|c|c|c|c|c|c|}
\hline \begin{tabular}{l}
\multicolumn{1}{c}{ Total } \\
Accidents \\
Per Driver \\
$1967-1971$
\end{tabular} & $\begin{array}{c}\text { Number } \\
\text { of } \\
\text { Drivers }\end{array}$ & $\begin{array}{c}\text { Total } \\
\text { Accidents }\end{array}$ & $\begin{array}{r}\text { Tc } \\
\text { Acci } \\
\text { Per } \\
1967\end{array}$ & $\begin{array}{l}\text { tal } \\
\text { idents } \\
\text { oriver } \\
-1971\end{array}$ & $\begin{array}{l}\text { Cumu- } \\
\text { lative } \\
\text { Number } \\
\text { of Drivers }\end{array}$ \\
\hline 3 & 728 & 2184 & $\geq$ & 3 & 2064 \\
\hline 4 & 560 & 2240 & $\geq$ & 4 & 1336 \\
\hline 5 & 361 & 1805 & $\geq$ & 5 & 776 \\
\hline 6 & 195 & 1170 & $\geq$ & 6 & 415 \\
\hline- & 93 & 651 & $\geq$ & 7 & 220 \\
\hline 8 & 50 & 400 & 2 & 8 & 127 \\
\hline 9 & 38 & 342 & $\geq$ & 9 & 77 \\
\hline 10 & 13 & 130 & $\geq$ & 10 & 39 \\
\hline 11 & 9 & 99 & $\geq$ & 11 & 26 \\
\hline 12 & 7 & 84 & $\geq$ & 12 & 17 \\
\hline 13 & 4 & 52 & $\geq$ & 13 & 10 \\
\hline 14 & 2 & 28 & 3 & 14 & 6 \\
\hline $\begin{array}{l}15 \\
. \\
. \\
.\end{array}$ & 1 & 15 & $\geq$ & 15 & 4 \\
\hline $\begin{array}{r}17 \\
. \\
. \\
.\end{array}$ & 1 & 17 & $\geq$ & 17 & 3 \\
\hline $\begin{array}{r}23 \\
. \\
. \\
.\end{array}$ & 1 & 23 & $\geq$ & 23 & 2 \\
\hline 29 & 1 & $\frac{29}{9269}$ & $\geq$ & 29 & 1 \\
\hline
\end{tabular}


Table 3. Summary Statistics.

Numbers in Parentheses refer to number of drivers, suspensions or violations upon which percentage or mean is based.

\begin{tabular}{|c|c|c|c|c|}
\hline & $\begin{array}{l}\text { Control } \\
\text { Group } \\
326 \\
\text { Drivers }\end{array}$ & $\begin{array}{l}5 \\
\text { Accident } \\
\text { Group } \\
361 \\
\text { Drivers } \\
\end{array}$ & $\begin{array}{l}6-7 \\
\text { Accident } \\
\text { Group* } \\
288 \\
\text { Drivers }\end{array}$ & $\begin{array}{l}\text { Accident } \\
\text { Group } \\
127 \\
\text { Drivers } \\
\end{array}$ \\
\hline ercent Male & $\begin{array}{l}59.2 \\
(193)\end{array}$ & $\begin{array}{l}95.6 \\
(345)\end{array}$ & $\begin{array}{l}94.8 \\
(273)\end{array}$ & $\begin{array}{l}97.6 \\
(124)\end{array}$ \\
\hline Mean Age & 38.7 & 29.6 & 29.9 & 32.3 \\
\hline Median Age & 36.6 & 25.1 & 25.3 & 27.9 \\
\hline $\begin{array}{l}\text { icense Type } \\
\text { Percent } \\
\text { Operator }\end{array}$ & $\begin{array}{l}90.5 \\
(295)\end{array}$ & $\begin{array}{l}70.9 \\
(256)\end{array}$ & $\begin{array}{l}67.0 \\
(193)\end{array}$ & $\begin{array}{l}58.3 \\
(74)\end{array}$ \\
\hline $\begin{array}{l}\text { Percent } \\
\text { Chauffeur }\end{array}$ & $\left(\begin{array}{l}7.7 \\
25\end{array}\right)$ & $\begin{array}{l}24.7 \\
(89)\end{array}$ & $\begin{array}{l}26.0 \\
(75)\end{array}$ & $\begin{array}{l}23.6 \\
(30)\end{array}$ \\
\hline $\begin{array}{l}\text { Percent } \\
\text { Public Passenger } \\
\text { Chauffeur }\end{array}$ & $\begin{array}{r}1.8 \\
(\quad 6)\end{array}$ & $\begin{array}{r}4.4 \\
(16)\end{array}$ & $\begin{array}{l}7.0 \\
(20)\end{array}$ & $\begin{array}{l}18.1 \\
(23)\end{array}$ \\
\hline $\begin{array}{l}\text { Percent of Drivers } \\
\text { With One Or More } \\
\text { Violation Citations } \\
\text { in } 1967\end{array}$ & $\begin{array}{r}4.9 \\
\quad(16)\end{array}$ & $\begin{array}{l}42.1 \\
(152)\end{array}$ & $\begin{array}{l}41.0 \\
(118)\end{array}$ & $\begin{array}{l}45.7 \\
(58)\end{array}$ \\
\hline $\begin{array}{l}\text { Mean Number of } \\
\text { Violation Citations } \\
\text { Per Driver in } 1967\end{array}$ & $\begin{array}{l}0.055 \\
(18)\end{array}$ & $\begin{array}{l}0.620 \\
(224)\end{array}$ & $\begin{array}{l}0.670 \\
(193)\end{array}$ & $\begin{array}{l}0.653 \\
(83)\end{array}$ \\
\hline 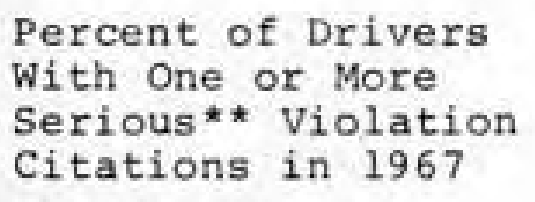 & $\begin{array}{l}1.2 \\
(4)\end{array}$ & $\begin{array}{l}12.5 \\
(45)\end{array}$ & $\begin{array}{l}13.5 \\
(39)\end{array}$ & $\begin{array}{l}11.8 \\
(15)\end{array}$ \\
\hline $\begin{array}{l}\text { Mean Number of } \\
\text { Serious Violation } \\
\text { Citations Per } \\
\text { Driver in } 1967\end{array}$ & $\begin{array}{l}0.012 \\
(\quad 4)\end{array}$ & $\begin{array}{l}0.161 \\
(58)\end{array}$ & $\begin{array}{l}0.170 \\
(49)\end{array}$ & $\begin{array}{r}0.142 \\
(18)\end{array}$ \\
\hline $\begin{array}{l}\text { Percent of Drivers } \\
\text { With One or More } \\
\text { License Suspension } \\
\text { in } 1967\end{array}$ & $\begin{array}{l}0.3 \\
(\quad 1)\end{array}$ & $\begin{array}{l}3.0 \\
(11)\end{array}$ & $\begin{array}{r}2.4 \\
(7)\end{array}$ & $\begin{array}{r}3.1 \\
(\quad 4)\end{array}$ \\
\hline $\begin{array}{l}\text { Mean Number of } \\
\text { License Suspensions } \\
\text { Per Driver in } 1967\end{array}$ & $\begin{array}{l}0.003 \\
(1)\end{array}$ & $\begin{array}{l}0.050 \\
(18)\end{array}$ & 0.038 & $\begin{array}{l}0.032 \\
(4)\end{array}$ \\
\hline
\end{tabular}


Table 3. (Continued)

\begin{tabular}{|c|c|c|c|c|}
\hline & $\begin{array}{l}\text { Control } \\
\text { Group } \\
326 \\
\text { Drivers }\end{array}$ & $\begin{array}{c}5 \\
\text { Accident } \\
\text { Group* } \\
361 \\
\text { Drivers } \\
\end{array}$ & $\begin{array}{l}6-7 \\
\text { Accident } \\
\text { Group } \\
288 \\
\text { Drivers }\end{array}$ & $\begin{array}{l}\text { Accident } \\
\text { Group* } \\
127 \\
\text { Drivers }\end{array}$ \\
\hline $\begin{array}{l}\text { Percent of Drivers } \\
\text { With One or More } \\
\text { Suspensions for } \\
\text { Driving While } \\
\text { Intoxicated in } 1967\end{array}$ & $\begin{array}{r}0.3 \\
(1)\end{array}$ & $\begin{array}{l}1.7 \\
(\quad 6)\end{array}$ & $\begin{array}{l}1.0 \\
(\quad 3)\end{array}$ & $\begin{array}{r}2.4 \\
(\quad 3)\end{array}$ \\
\hline $\begin{array}{l}\text { Mean Number of } \\
\text { Suspensions For } \\
\text { Driving While } \\
\text { Intoxicated in } 1967\end{array}$ & $\begin{array}{c}0.003 \\
(1)\end{array}$ & $\begin{array}{c}0.022 \\
(8)\end{array}$ & $\begin{array}{l}0.010 \\
(3)\end{array}$ & $\begin{array}{l}0.024 \\
(3)\end{array}$ \\
\hline $\begin{array}{l}\text { Percent of Drivers } \\
\text { With One or More } \\
\text { Suspensions For } \\
\text { Failing to Appear } \\
\text { in } 1967\end{array}$ & $\begin{array}{l}0 \\
(0)\end{array}$ & $\begin{array}{r}0.6 \\
(\quad 2)\end{array}$ & $\begin{array}{r}0.7 \\
(\quad 2)\end{array}$ & $\begin{array}{r}0.8 \\
(\quad 1)\end{array}$ \\
\hline $\begin{array}{l}\text { Mean Number of } \\
\text { Suspensions For } \\
\text { Failing to Appear } \\
\text { in } 1967\end{array}$ & $\begin{array}{l}0 \\
(0)\end{array}$ & $\begin{array}{l}0.006 \\
(\quad 2)\end{array}$ & $\begin{array}{l}0.007 \\
(\quad 2)\end{array}$ & $\begin{array}{l}0.008 \\
(\quad 1)\end{array}$ \\
\hline $\begin{array}{l}\text { Percent of Drivers } \\
\text { With One or More } \\
\text { Suspensions for } \\
\text { Leaving the Scene } \\
\text { of an Accident } \\
\text { in } 1967\end{array}$ & $\begin{array}{l}0 \\
(0)\end{array}$ & $\begin{array}{l}1.1 \\
(\quad 4)\end{array}$ & $\begin{array}{l}0.7 \\
(\quad 2)\end{array}$ & $\begin{array}{l}0 \\
(\quad 0)\end{array}$ \\
\hline $\begin{array}{l}\text { Mean Number of } \\
\text { Suspensions for } \\
\text { Leaving the Scene } \\
\text { of an Accident } \\
\text { in } 1967\end{array}$ & $\begin{array}{l}0 \\
(\quad 0)\end{array}$ & $\begin{array}{l}0.014 \\
(\quad 5)\end{array}$ & $\begin{array}{l}0.010 \\
(3)\end{array}$ & $\begin{array}{l}0 \\
(\quad 0)\end{array}$ \\
\hline $\begin{array}{l}\text { Mean Number of } \\
\text { Accidents in } 1967\end{array}$ & $\begin{array}{l}0.080 \\
(26)\end{array}$ & $\begin{array}{l}3.216 \\
(1161)\end{array}$ & $\begin{array}{l}3.403 \\
(980)\end{array}$ & $\begin{array}{l}3.850 \\
(489)\end{array}$ \\
\hline $\begin{array}{l}\text { Mean Number of } \\
\text { Accidents During } \\
\text { Entire Study } \\
\text { Period } 1967-1971\end{array}$ & $\begin{array}{l}0.454 \\
(148)\end{array}$ & $\begin{array}{l}5.000 \\
(1805)\end{array}$ & $\begin{array}{l}6.323 \\
(1821)\end{array}$ & $\begin{array}{r}9.578 \\
(1219)\end{array}$ \\
\hline
\end{tabular}

* Total accidents during the five year study period.

** Serious violation refers to a violation with a point count of five or more or a violation that requires mandatory license suspension. 


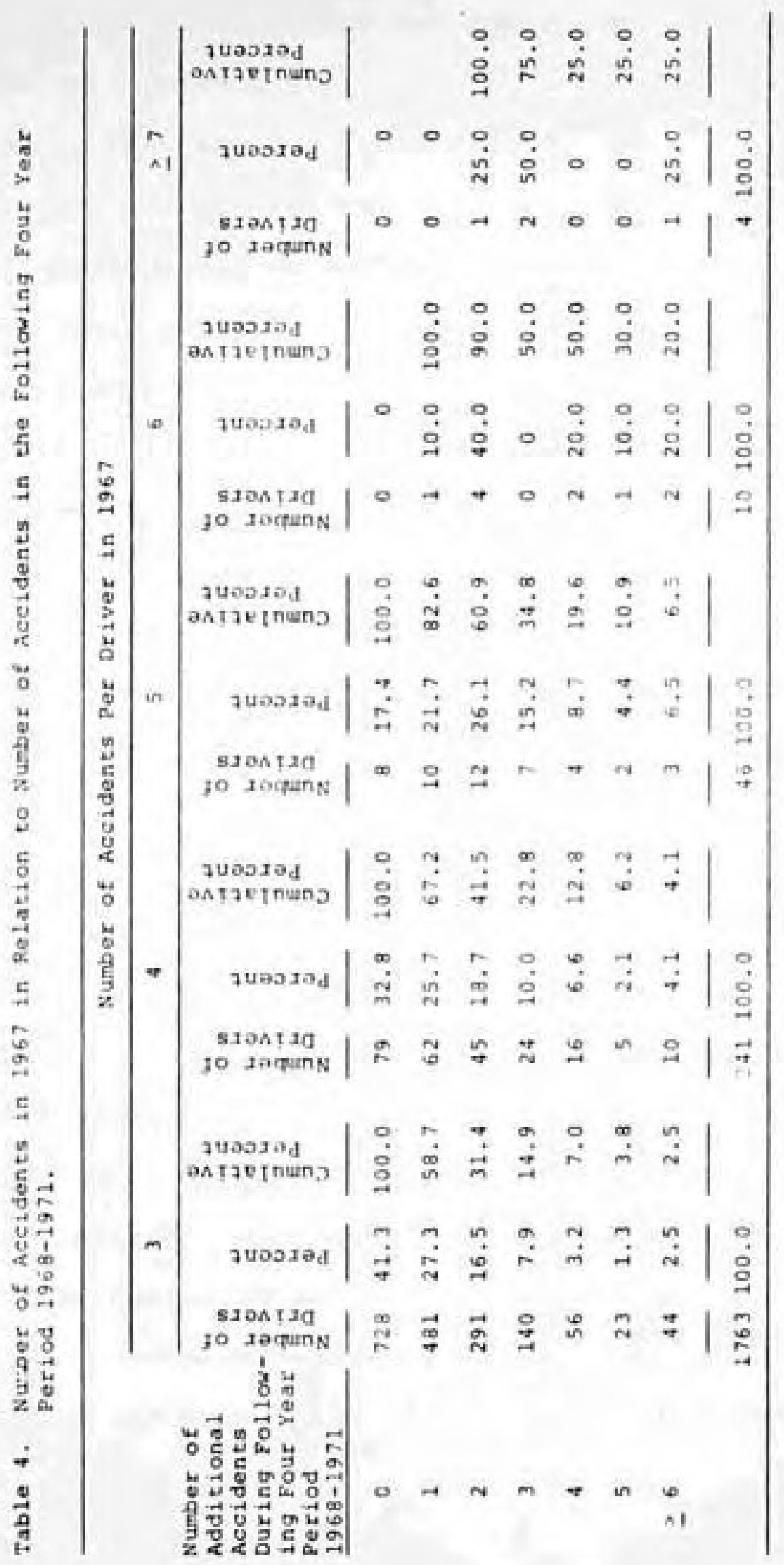


of that same group, 58.7 percent had one or more additional accidents and 31.4 percent had two or more additional accidents during the same four year period.

of that group of 241 drivers who had four accidents in $1967,32.8$ percent had no additional accidents during the following four year period. Of that same group, 67.2 percent had one or more additional accidents and 41.5 percent had two or more additional accidents during the following four year period.

of that group of forty-six drivers who had five accidents during the year 1967 , only eight drivers, or 17.4 percent of the group remained accident free during the following four year period. Of that same group, 82.6 percent had one or more additional accidents, 60.9 percent had two or more additional accidents, and 34.8 percent had three or more additional accidents, all during the same four year period. of the ten drivers who were found that had six accidents during the year 1967, all had at least one accident during the following four year period. Nine drivers or 90.0 percent of the group had two or more accidents during the same four year period. Half of the drivers in this group had four or more accidents during this same four year period.

Only four drivers were found that had seven or more accidents during the year 1967. All four of these drivers 
had two or more accidents during the following four year period.

It is clear that the greater number of accidents that a driver has during a particular year increases the probability that he will have additional accidents during the following years.

\section{Seriousness of the Accidents}

State Police records classify accidents into three categories based on the type of accident. These categories are property damage only for accidents in which fifty dollars or more damage results and no one is killed or injured; injury accidents in which someone sustains a personal injury; and fatality accidents in which a death results.

Using these three categories as a criterion on which to base the seriousness of an accident, the data indicates that, in general, the more accidents that a driver has, the less serious the accidents are. As shown in Pigure 1 and Table 5, about twenty-seven percent of the reported accidents in which the three-accident driver group were involved were either injury or fatality accidents. In comparison, less than ten percent of the reported accidents in which the eight or more accident group were involved were injury or fatality accidents. 


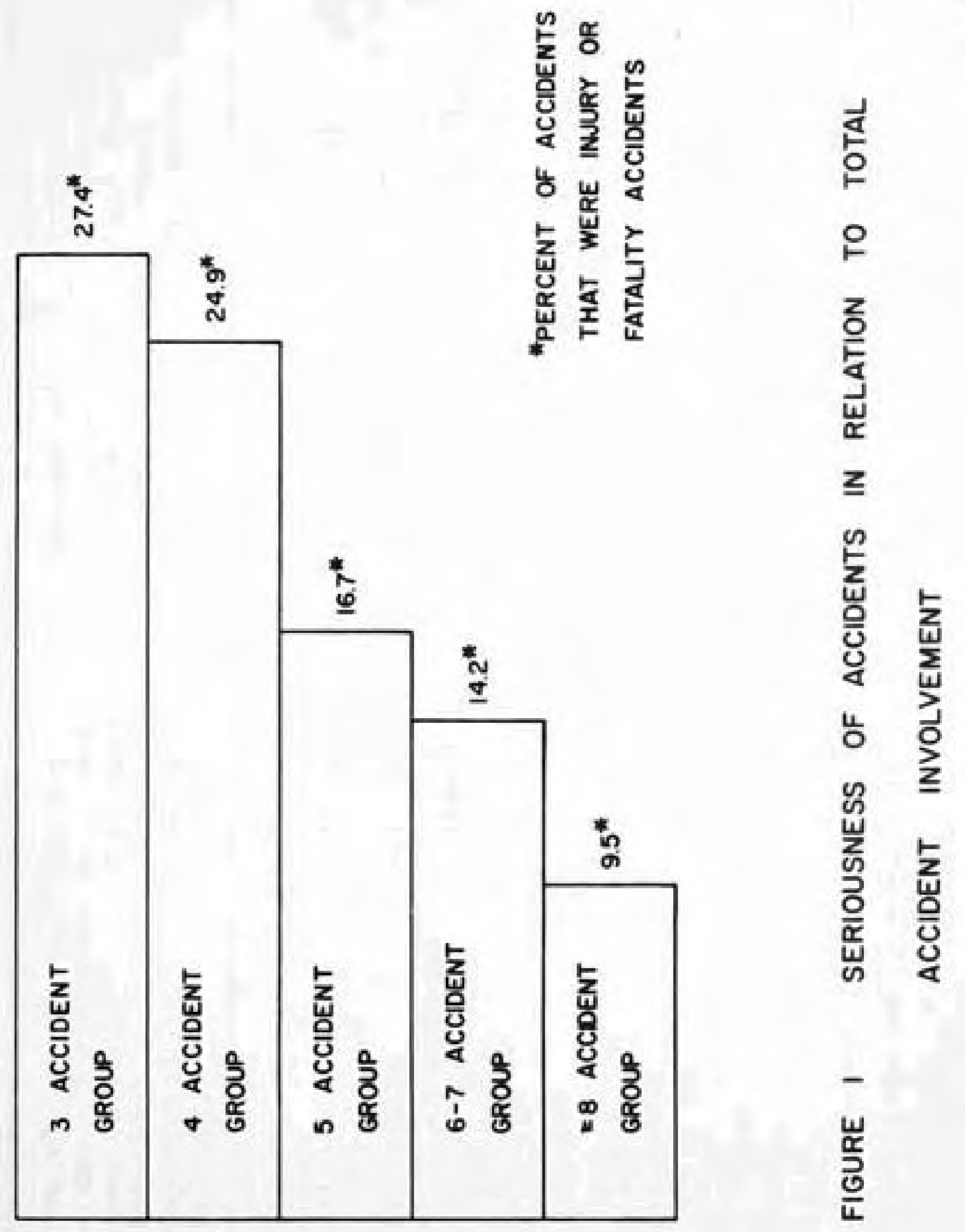




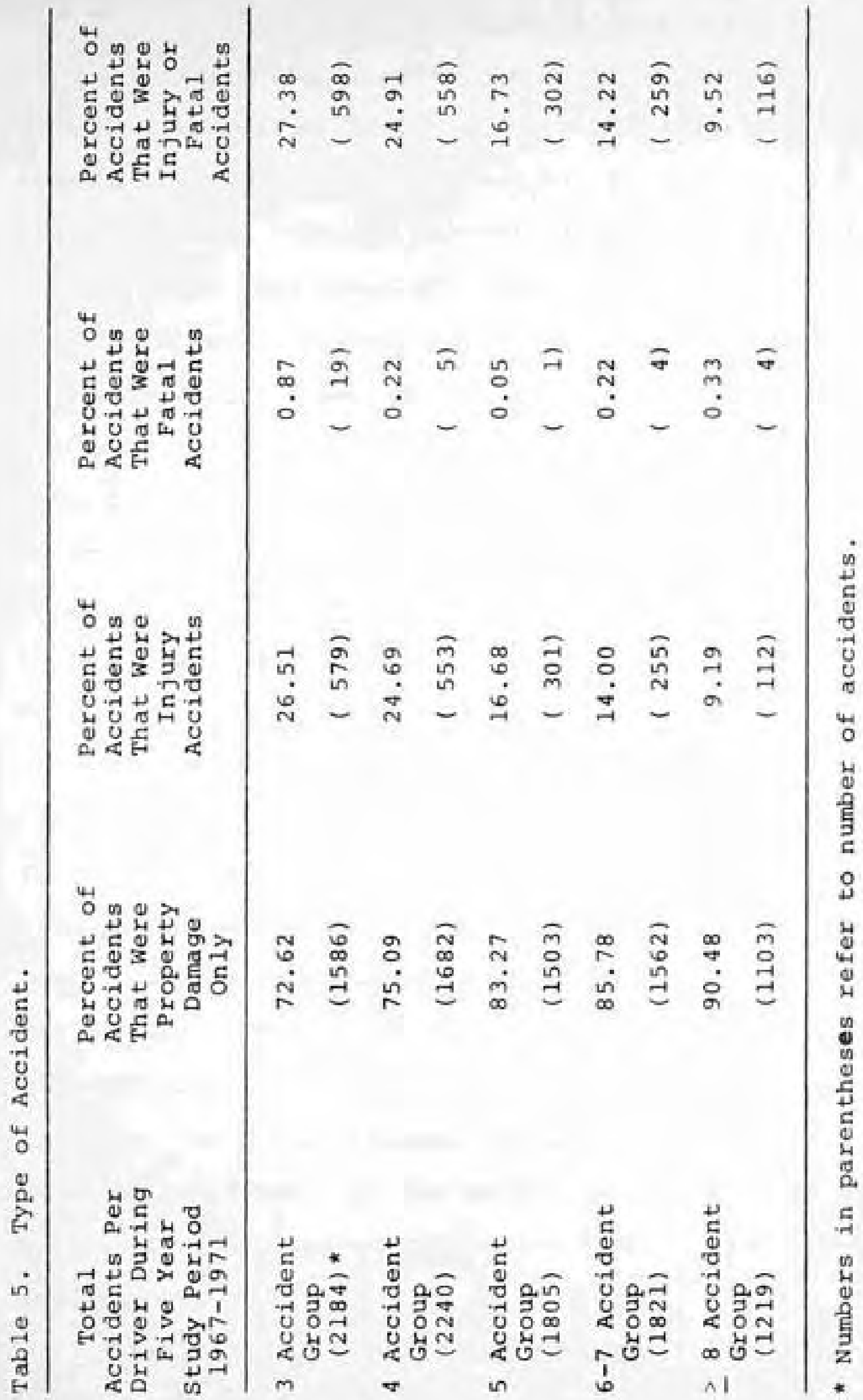




\section{Where the Accidents Occurred}

A definite relationship was found between the number of accidents that a driver had and his residence and the location of the accidents. As shown in Tables 6 and 7 and Figure 2, about thirteen percent of the drivers in the control group were found to reside in Indianapolis while more than twenty-nine percent of the drivers in the eight or more accident group resided in Indianapolis. About fourteen percent of the accidents incurred by the drivers of the control group took place in Indianapolis. More than thirty-two percent of the accidents of the eight or more accident driver group occurred in Indianapolis.

Similar results were found for the city of Fort Wayne. As shown in Figure 3 and Tables 6 and 7 , about seven percent of the drivers and about seven percent of the accidents of the control driver group occurred in Fort Wayne. of the group of drivers who had eight or more accidents during the five year study period, fifteen percent of the drivers were residents of Fort Wayne and more than fourteen percent of the accidents in which this group of drivers were involved occurred in Fort Wayne.

Over forty-six percent, or nearly half of all accidents in which the drivers of the group who had eight or more accidents were involved occurred either in Fort Wayne or Indianapolis.

These findings seem to suggest that the high accident driver, one involved in multiple accidents in a given year, 


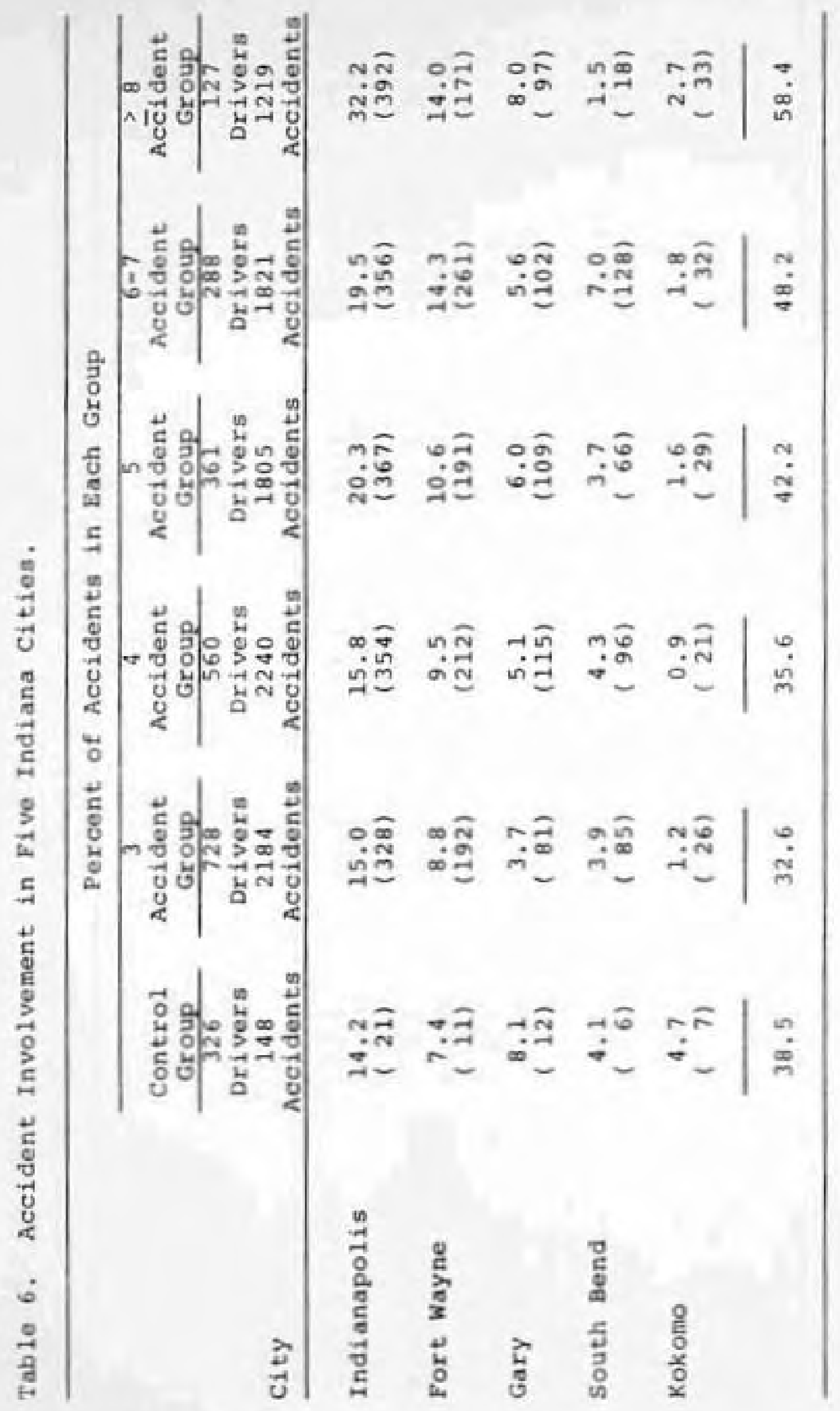




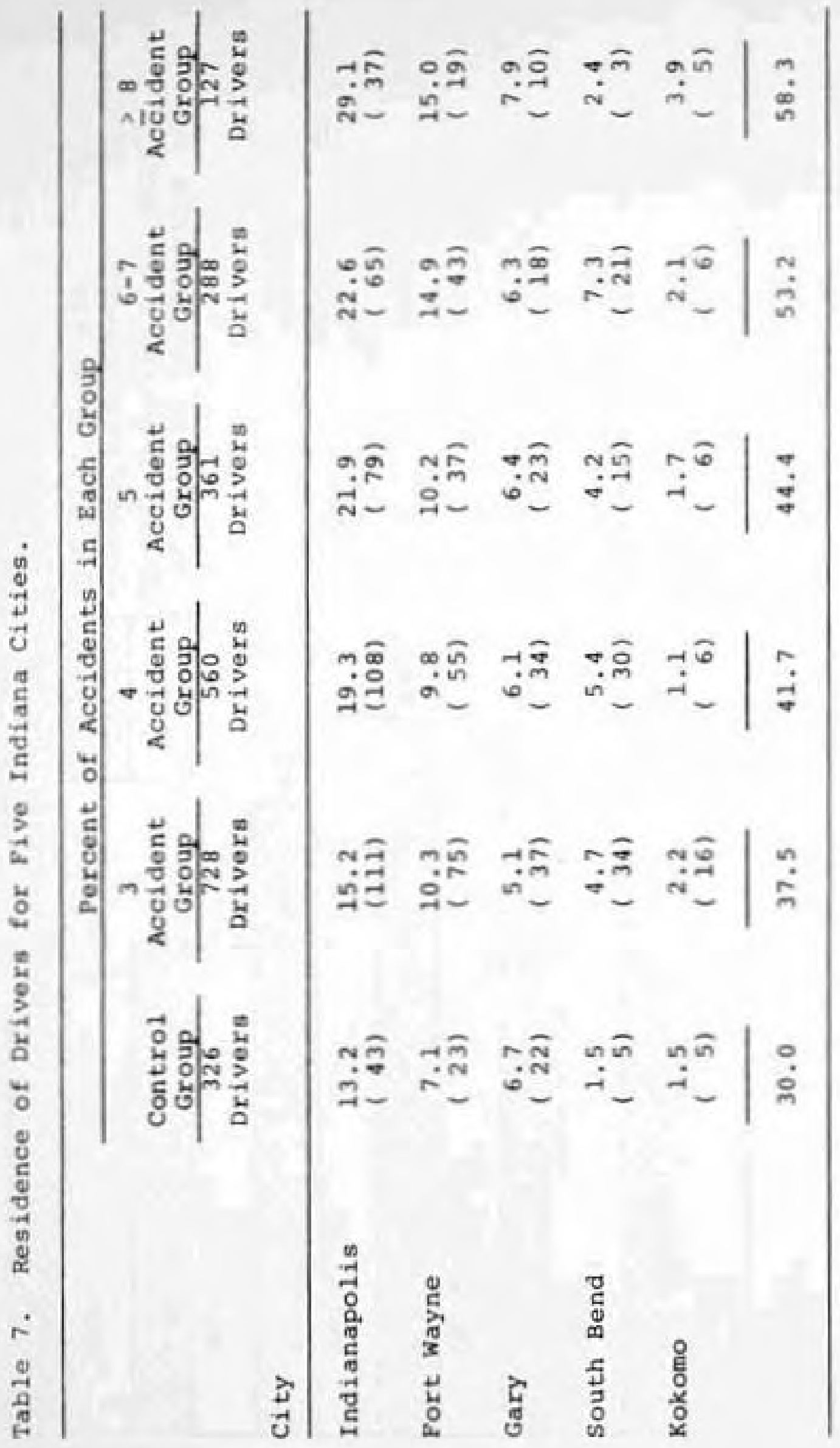




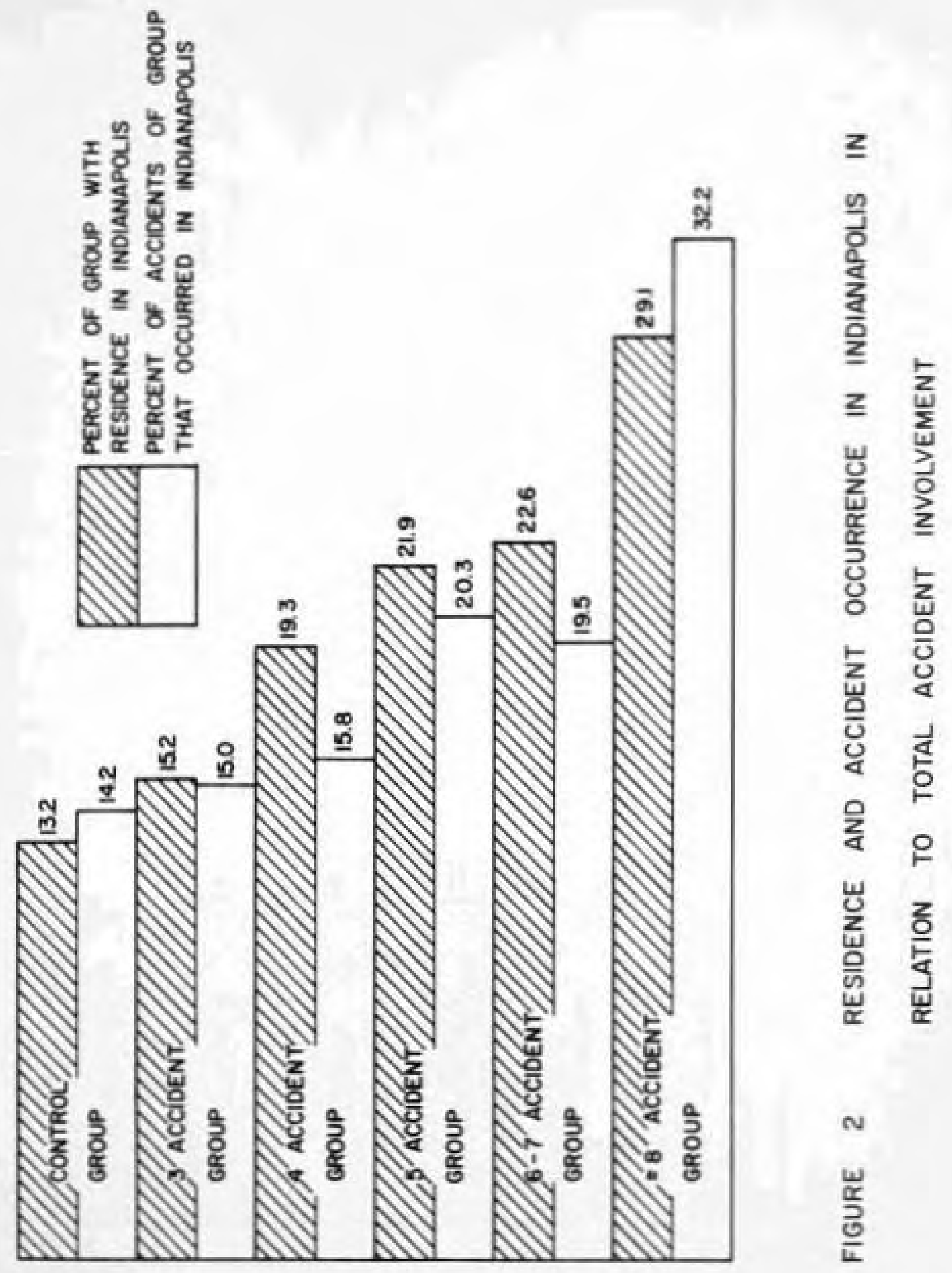




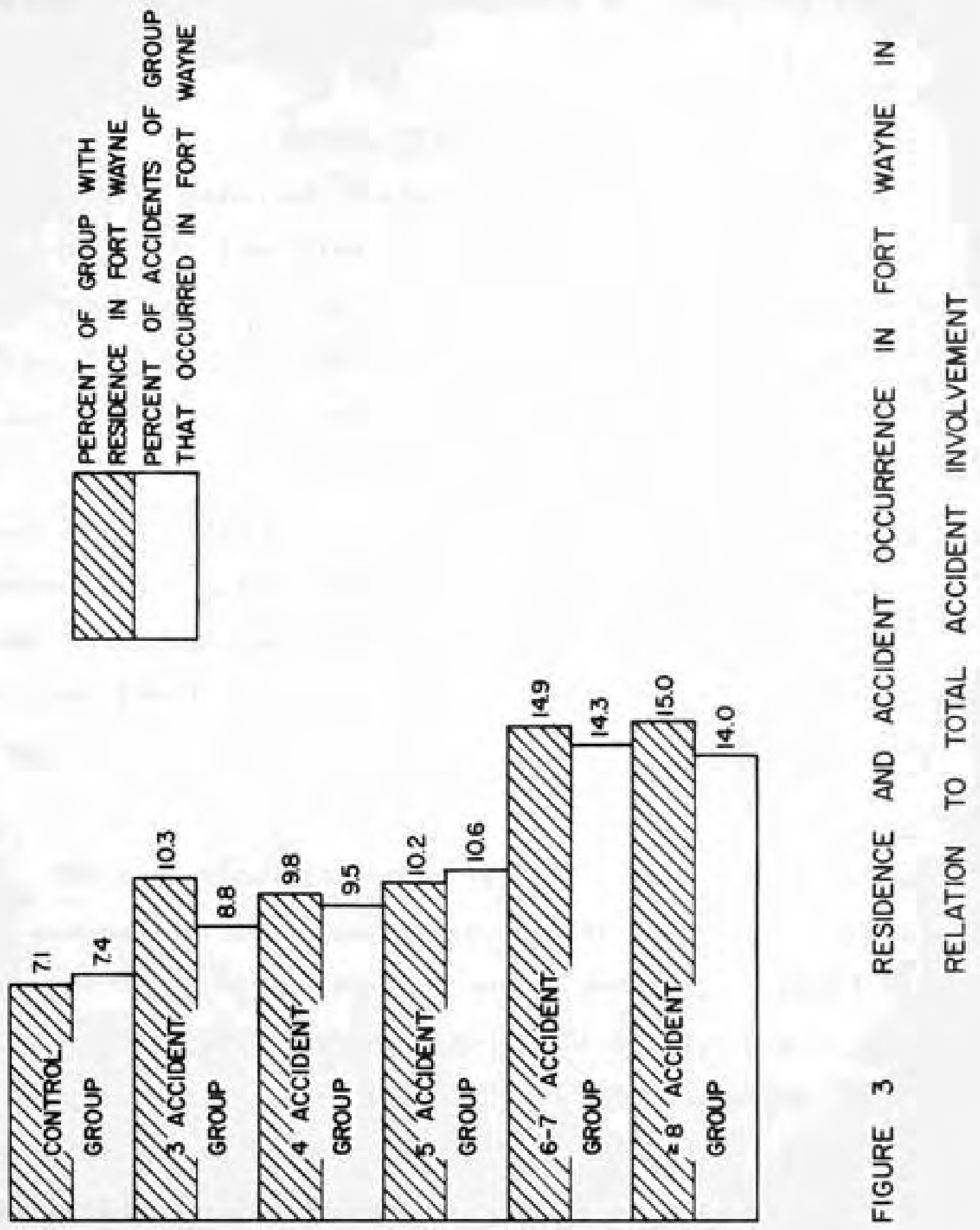


is most likely to be a resident of a large urbanized, more densely populated area. This seems reasonable since there are more vehicles and pedestrians in these areas, more congestion, and thus many more conflicts and opportunities for accidents to occur.

\section{Driver Characteristics}

Several personal characteristics of the drivers were available from the driver and accident records. These characteristics include age, sex, weight and height of the driver, and license restrictions. It would have been informative to have additional information on the drivers such as occupation, economic status and education, but limitations of the data prevented this. Much might also have been learned about driver attitudes if it would have been possible to interview some of the drivers. This, however was not possible due to the confidential nature of the accident records.

Age

The high accident driver is, in general, younger than the average driver. The control driver was found to have a mean age of 38.65 years and a median age of 36.6 years as shown in Table 8. The mean age of the high accident driver ranged from 29.59 years for the five accident group to 32.46 years for the three accident group. The median age for the high accident driver ranged from 25.1 years for the five accident group to 27.9 years for the eight or more accident group. 


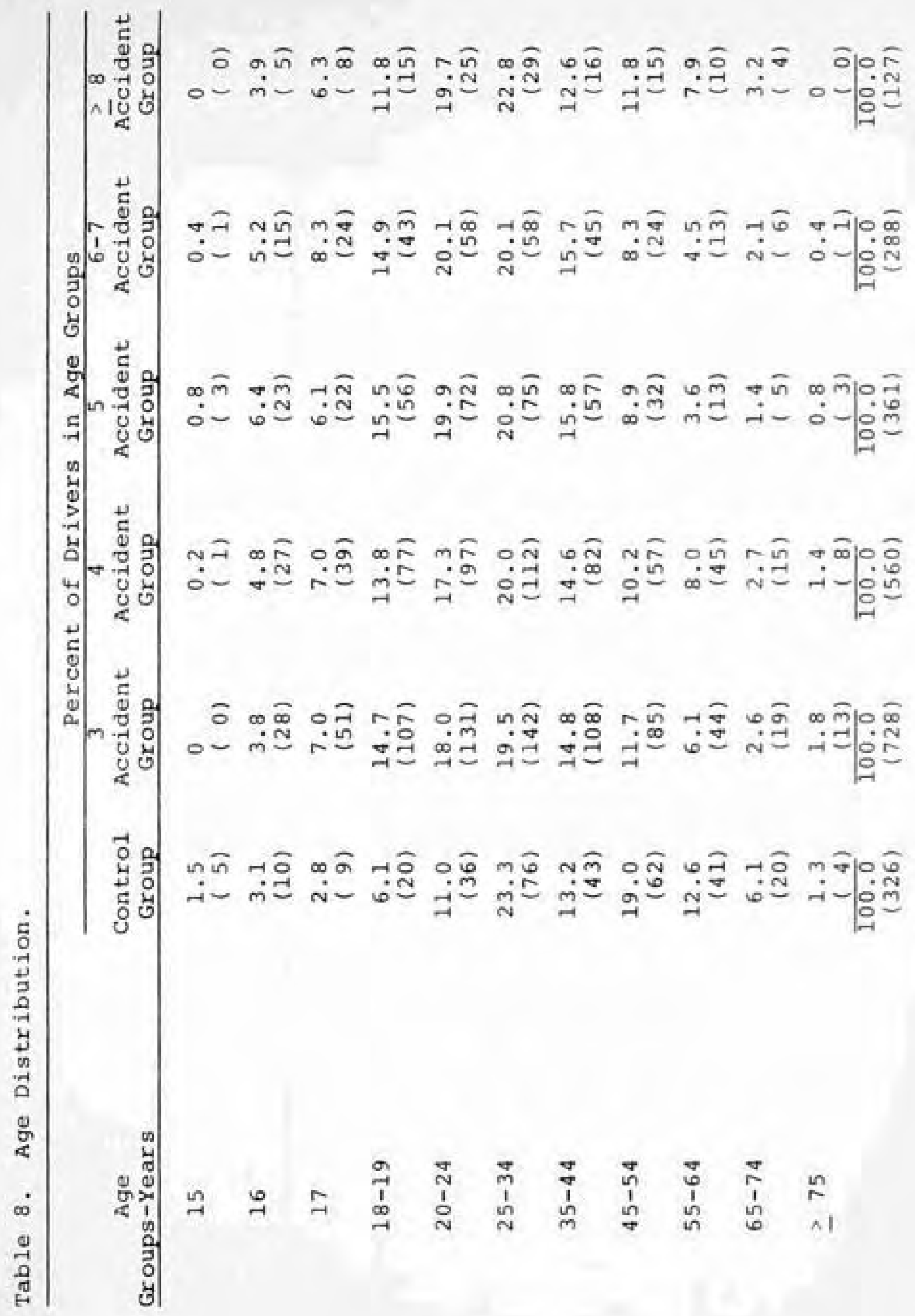




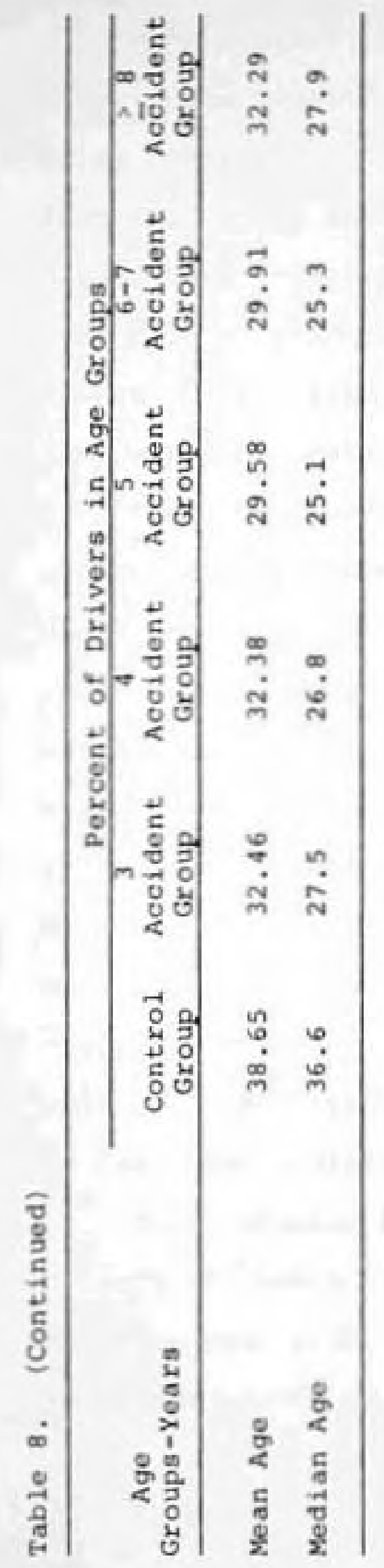


Many studies have noted that certain age groups, most notably the younger drivers, have a higher probability of being involved in accidents $(8,10,11,12,19,20)$. The data from this study agrees with this finding. However, in most cases, this study indicates that age has little value as a predictor of which drivers who are high accident drivers during a particular year will continue to have accidents during the following years.

The 728 drivers who had three accidents in 1967 and no additional accidents during the following four year period had a mean age of 32.46 years and a median age of 27.5 years as indicated in Table 8. In contrast, the 127 drivers who had eight or more accidents during the five year study period had a mean age of 32.29 years and a median age of 27.9 years. There is less than half a years difference between either the means or medians of the ages of these two driving groups. Clearly the age of the driver who had already had three or more accidents during a particular year will, in most cases, be of little use in predicting whether he will have additional accidents during following years. The remaining driver characteristics studied are for drivers who had a total of five or more accidents during the five year study period with at least three of these accidents occurring during the year 1967. 
Sex

While it is well established that male drivers have a greater accident involvement than females, the results of this study are striking. As indicated in Table 3, less than sixty percent of the licensed drivers in Indiana are male; however, male drivers account for over ninety-four percent of the drivers with three or more accidents during the year 1967 and a total of five or more accidents during the entire five year study period. Of the 776 drivers in this group of drivers, only thirty-four were female.

\section{Other Driver Characteristics}

The results of this study found little difference between the control driver group and any of the high accident groups for the variables: index of weight/height or license restrictions. Findings for this phase of the analysis will be found in Appendix $D$.

\section{License Type}

It is unfortunate that no information was available concerning the exposure rate of the drivers under study. The number of miles that a person drives and the circumstances under which they are driven should undoubtedly be an important consideration in this type of an accident study. It is probable that a person who holds a chauffeur or public passenger chauffeur's license is driving more than the average person with just an operator's license. However, it 
is also probable that the high accident drivers in this study are not average drivers. It is certainly possible that many of these high accident drivers also travelled many more miles in 1967 and the years following than the average driver with an operator's license.

The summary statistics of this study, as shown in Table 3 , indicate that as the number of accidents in which a driver is involved goes up, the probability that he is a holder of either a chauffeur or public passenger chauffeur's license also goes up.

While only 7.7 percent of the control group were drivers with chauffeur's 1 icenses, 23.6 percent of the drivers with eight or more accidents during the five year study period were drivers with chauffeur's licenses. The accident involvement of drivers holding the public passenger chauffeur's license is even more stunning. While they consitute only 1.8 percent of the control group, 18.1 percent of the drivers in the eight or more accident group were public passenger chauffeur's license holders.

This evidence that a high percentage of the drivers who had a high number of accidents during the five year study period hold chauffeur's or public passenger chauffeur's licenses probably provides some explanation of some of the other characteristics of this group. The finding that a high number of the drivers of this group resided in large urban areas and had accidents there is undoubtedly highly correlated with the license type. Similarly the finding that as the 
number of accidents increased the seriousness of the accidents decreased probably results from the fact that many of these accidents are in urban areas where speeds are low and congestion great and that those possessing chauffeur's or public passenger chauffeur's licenses are likely driving during these congested conditions.

The question now arises, is it realistic to expect that a person who makes his living by driving will be involved in more accidents because he travels more miles and thus has a greater number of opportunities to become involved in an accident? Or should we expect the person who makes his living by driving to be such a better driver that he will be involved in fewer accidents? Unfortunately, an answer to these questions is not yet available.

\section{The Driving Record}

The 1967 driving record of drivers with three or more accidents during the year 1967 and a total of five or more accidents during the entire five year study period appears to be of little use in predicting those drivers that will continue to have accidents. Drivers who had no violation citations in 1967 constituted 54.3 percent of the drivers who had eight or more accidents during the five year study period and 57.9 percent of the drivers who had five accidents during the same period (See Table 9). Those drivers who had two or more violation citations during the year 1967 constituted 13.9 percent of the drivers who had five total 


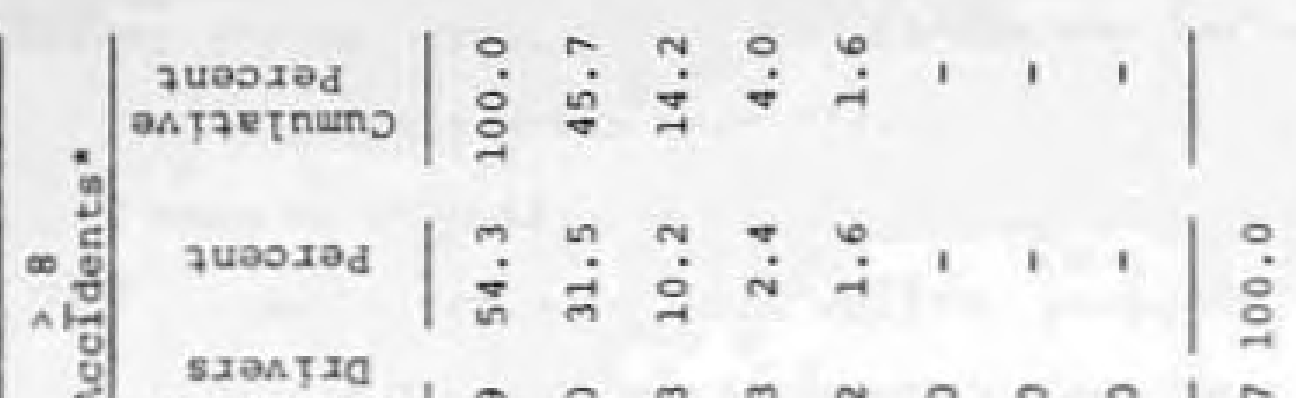

if

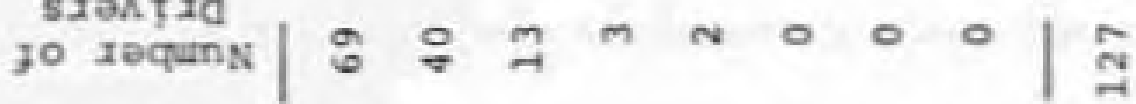

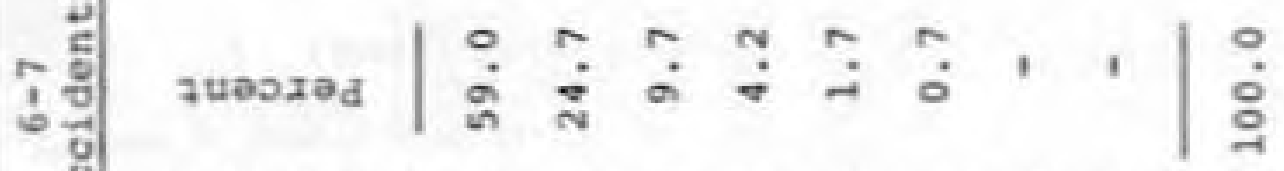

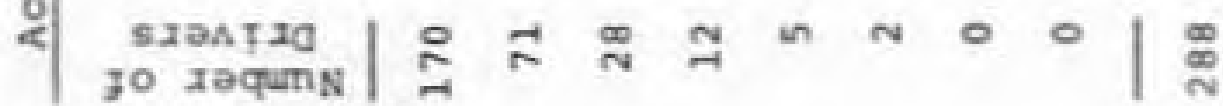

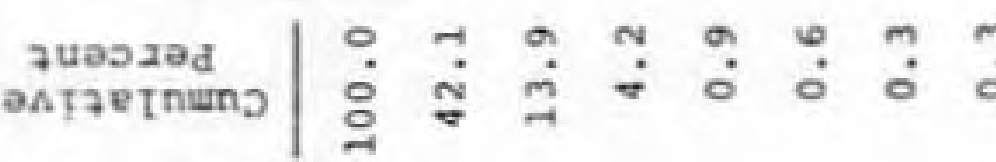

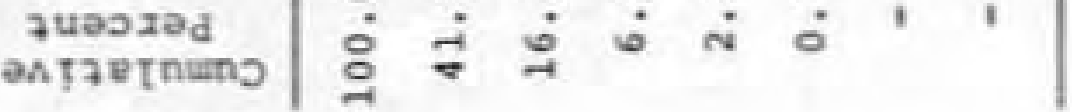

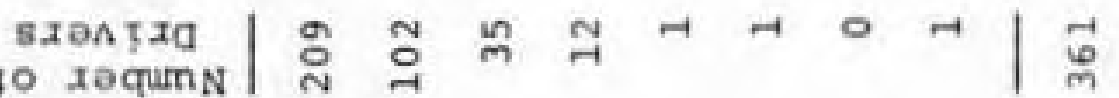

告

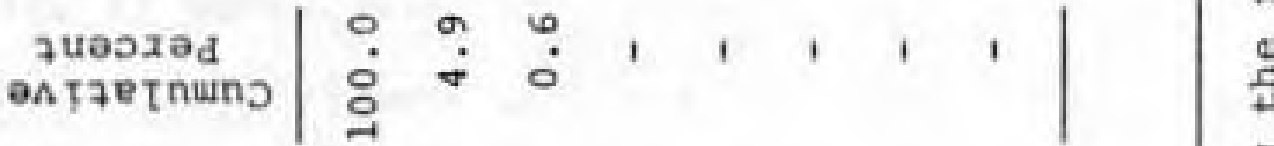

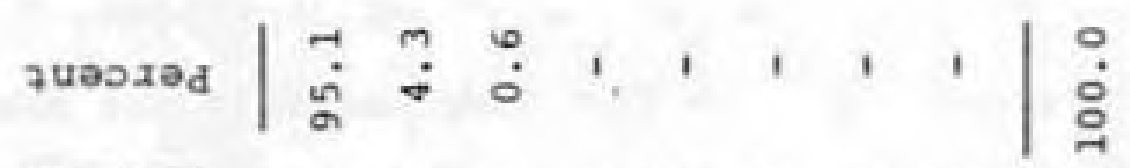

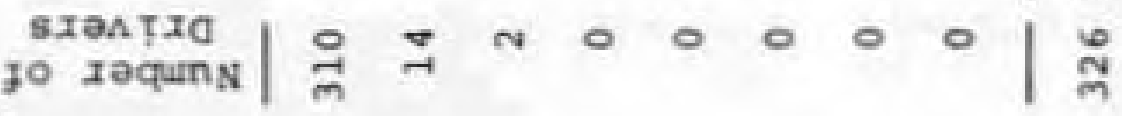

물 
accidents and 14.2 percent of the drivers who had eight or more total accidents. The percentage of drivers having various numbers of citations from each of the high accident groups is roughly the same, thus making violation citations of little use as a predictor to determine whether a driver who has a number of accidents during a particular year will continue to have accidents during the following years.

As can be seen in Table 10 , the same situation seems to be true of serious violations. The fact that a driver had one or more serious violations during the year 1967 did not have any significant relationship to the number of accidents in which the driver was involved during the following years.

Tables 11 and 12 report the relationship of 1967 license suspensions (Table 11) and 1967 license suspensions for driving while intoxicated (Table 12) with 1967 and future accident record. The numbers of such suspensions are so small as to make findings impossible.

While in many cases the violation record of a driver may be highly correlated to his accident record $(2,3,5,10$, $12,15)$, it appears to be of little use for predicting whether drivers who are high accident drivers during one period will continue to be high accident drivers in the following period.

\section{The Combined Characteristics as Accident Predictors}

As it has already been noted, the variables so far examined in this study do not clearly indicate which drivers with high accident records during a particular year will 


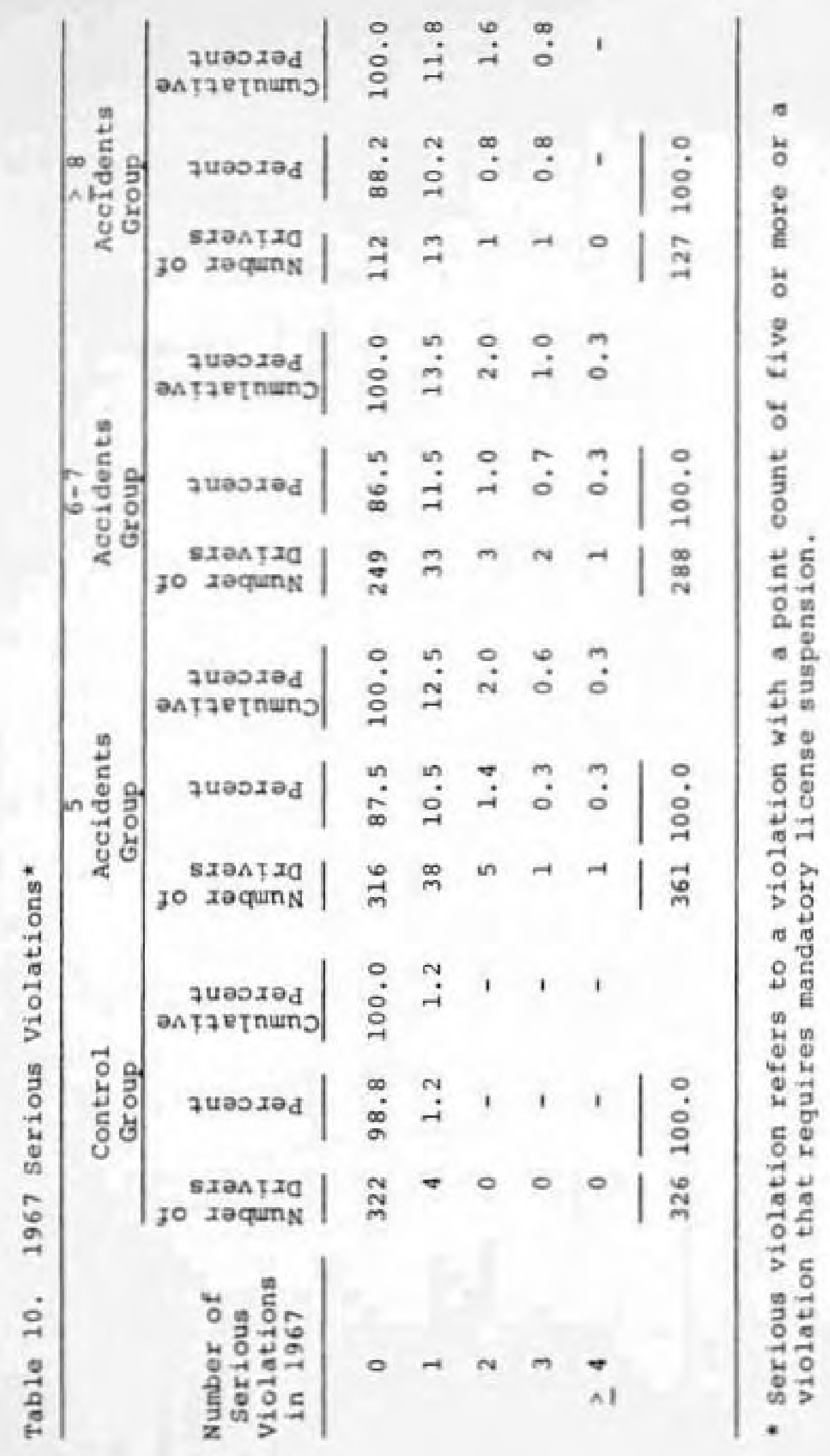




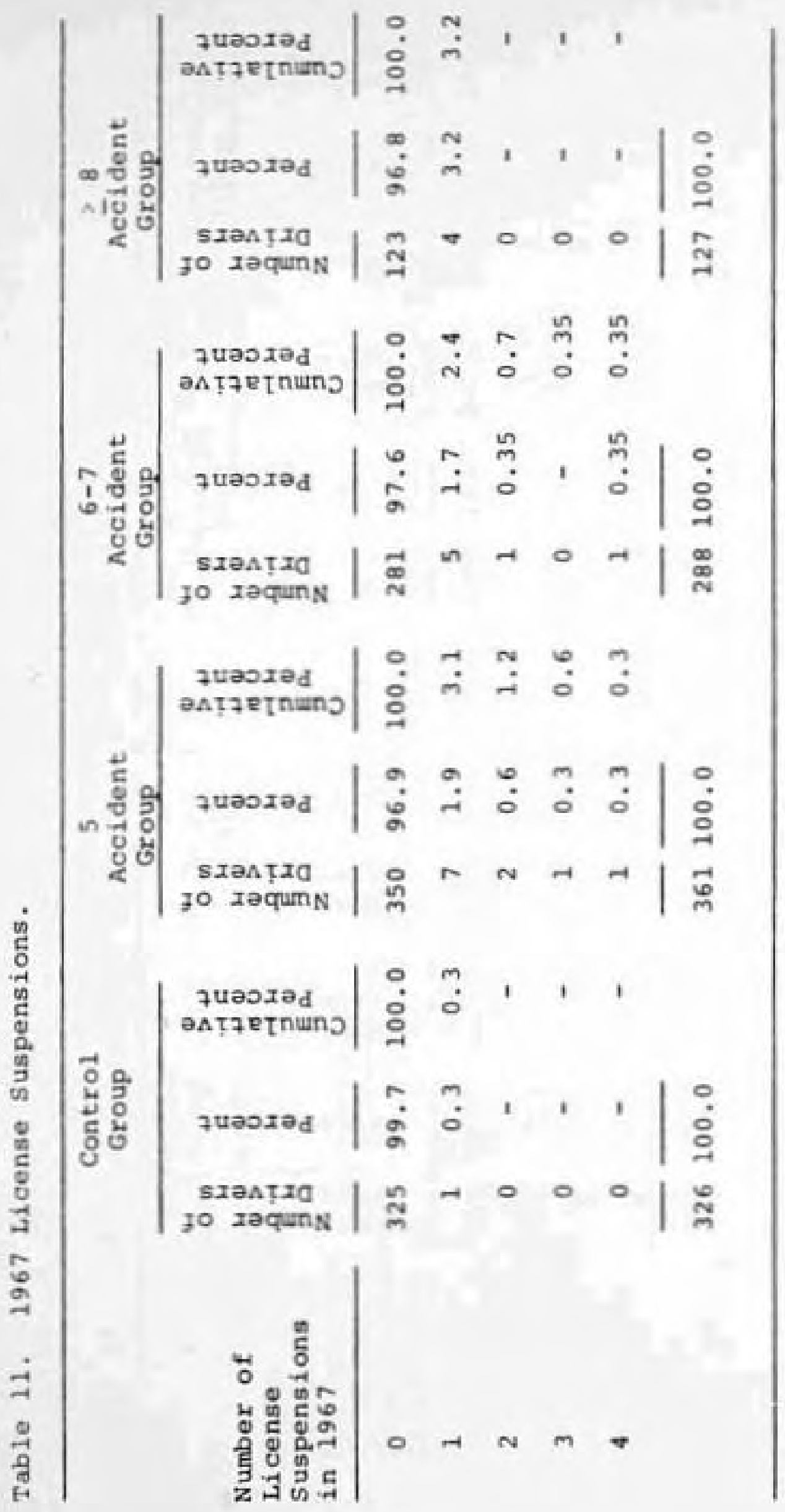




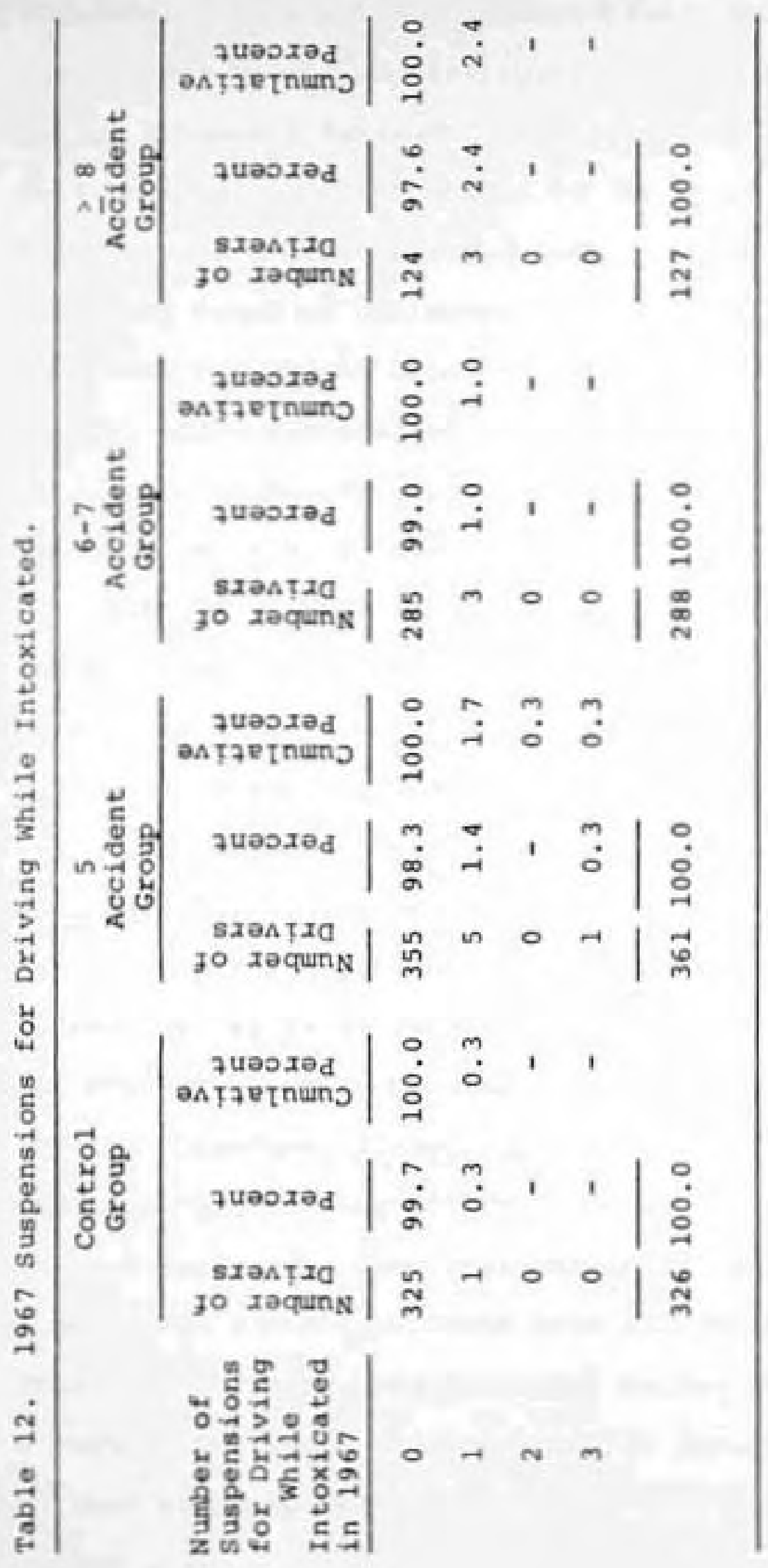


continue to have a high accident rate. In order to evaluate the effects of all the variables combined, a technique called Automatic Interaction Detector, or AID, was utilized. This program, supplied by the Purdue University Computer Center, uses a least squared technique to determine that dichotomy based on any predictor that has the largest correlation with the dependent variable. Having made the initial split the program continues the splitting process in a stepwise manner using predictors in order of their relative importance (17).

The 776 drivers who had five or more accidents during the five year study period were tested using this program in an attempt to determine characteristics known in 1967 that would allow prediction of their future accident involvement. The dependent variable used was the total accidents during the years 1968 through 1971. If a driver had two reported accidents or less during this four year period, he was coded with a "zero". If the driver was involved in three or more accidents he was coded with a "one". Therefore, a subgroup with a mean of zero would indicate that all the drivers in that group had two accidents or less during the four year period following the year 1967 . A mean of 1.0 would indicate that all drivers in that subgroup had three or more accidents during the same period. A mean of 0.4 would indicate that 40 percent of the drivers in that subgroup had three or more accidents. Of the 
original group of 776 drivers, 342 drivers or 44.1 percent of the group were drivers who had three or more accidents during the period following the year 1967.

The following driver characteristics were used as predictors in the AID program:

1. Sex,

2. Age,

3. License type,

4. License suspensions in 1967,

5. Driving while intoxicated suspensions in 1967 ,

6. Serious violations in 1967 ,

7. Total accidents in 1967, and

8. Total violations in 1967 .

The results of the program are shown in Figure 4. As can be seen, there are only four subgroups in which more than sixty-five percent of the drivers were ones who had three or more accidents during the four year period following 1967.

Looking at Subgroup 3, forty drivers out of fifty-nine or 67.8 percent of the 1967 high accident drivers who held public passenger chauffeur's licenses had three or more accidents during the four year period following the year 1967. As shown in Subgroup 25, twenty-six out of thirtyfour drivers or 76.5 percent of the drivers in this public passenger chauffeur group who were between the ages of 15 to 24 or $\mathbf{4 5}$ or older, had three or more accidents during the four year period following the year 1967. 


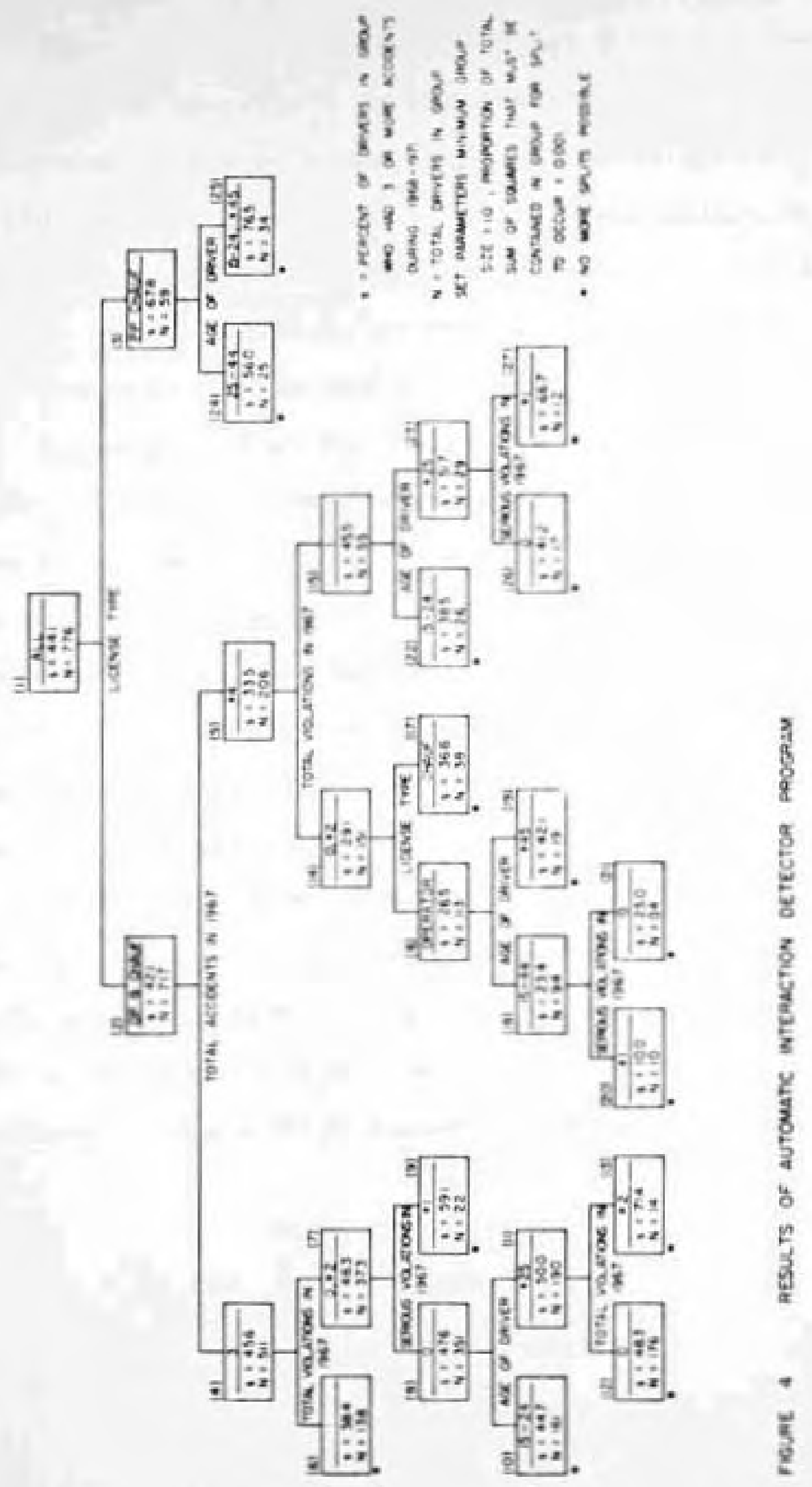


Subgroup 13 were drivere who had three accidents in 1967, had an operator's or chauffeur's license, were twentyfive years of age or older, and had two or more violations during the year 1967, none of which were defined as serious violations. Ten of the fourteen drivers, or 71.4 percent of this group, had three or more accidents during the four year period following the year 1967.

Subgroup 27 included those drivers who were twenty-five years old or older, held an operator's or chauffeur's license and were involved in four or more accidents during the year 1967. These drivers also had one violation citation during the year 1967 which was defined as a serious violation. Eight of the twelve drivers in this group, or 66.7 percent, had three or more accidents during the following four year period.

It is clear that using only the characteristics available from the driver and accident records, it is extremely difficult to predict with much accuracy which drivers that have a high number of accidents during a particular year will continue to have a high number of accidents during following years. 
CONSEQUENCES OF LICENSE SUSPENSION OR REVOCATION

One of the purposes of this study was to evaluate controls that would best prevent drivers who have a number of accidents during one year from having additional accidents during future years. The only method that will absolutely assure that a driver does not have accidents is to prevent him from driving. In todays society where personal automobile transportation is a necessity in many areas, this form of restriction may have devastating effects on the mobility and economic status of a family or individual. The importance of the driving privilege might be noted by the fact that a large number of drivers in this study who had license suspensions also had citations for driving while their license was suspended.

If a persons driving privileges are to be suspended, perhaps there should be a reasonable indication that he has a high probability of becoming involved in further accidents.

\section{Drivers Having Three Accidents During the Year 1967}

If all of the 1763 drivers in this study who had three accidents during the year 1967 were prevented from driving during the following four year period, they as a group would not have become involved in the 2102 additional accidents that they had during this period as shown in Table 13. 
However, 728 drivers or 41.3 percent (See Table 13) of the group had no additional reported accidents during the following four year period and denying them the right to drive would have provided no recognizable benefits to society. An additional 481 drivers or 27.3 percent of the group had only one additional accident during the following four year period. It was determined that the mean number of accidents per driver over the five year period for the control group was 0.45 , as shown in Table 3 . This means that the average accident rate of the Indiana control group is about one accident per driver every eleven years. Perhaps one accident during a four year period is not too bad of a record. Even two accidents in four years might not be considered too unusual. Therefore, by denying licenses to al1 drivers who had a total of three accidents during the year 1967,728 individuals who had no additional accidents plus 481 who had only one additional accident during the following four year period would have suffered in order to prevent 554 persons from this group from having 1621 accidents.

If only those drivers who had three or more additional accidents during the following four year period were considered, then 1500 persons who had two accidents or less during this period would have lost their license in order to prevent 263 drivers from having 1039 accidents. 


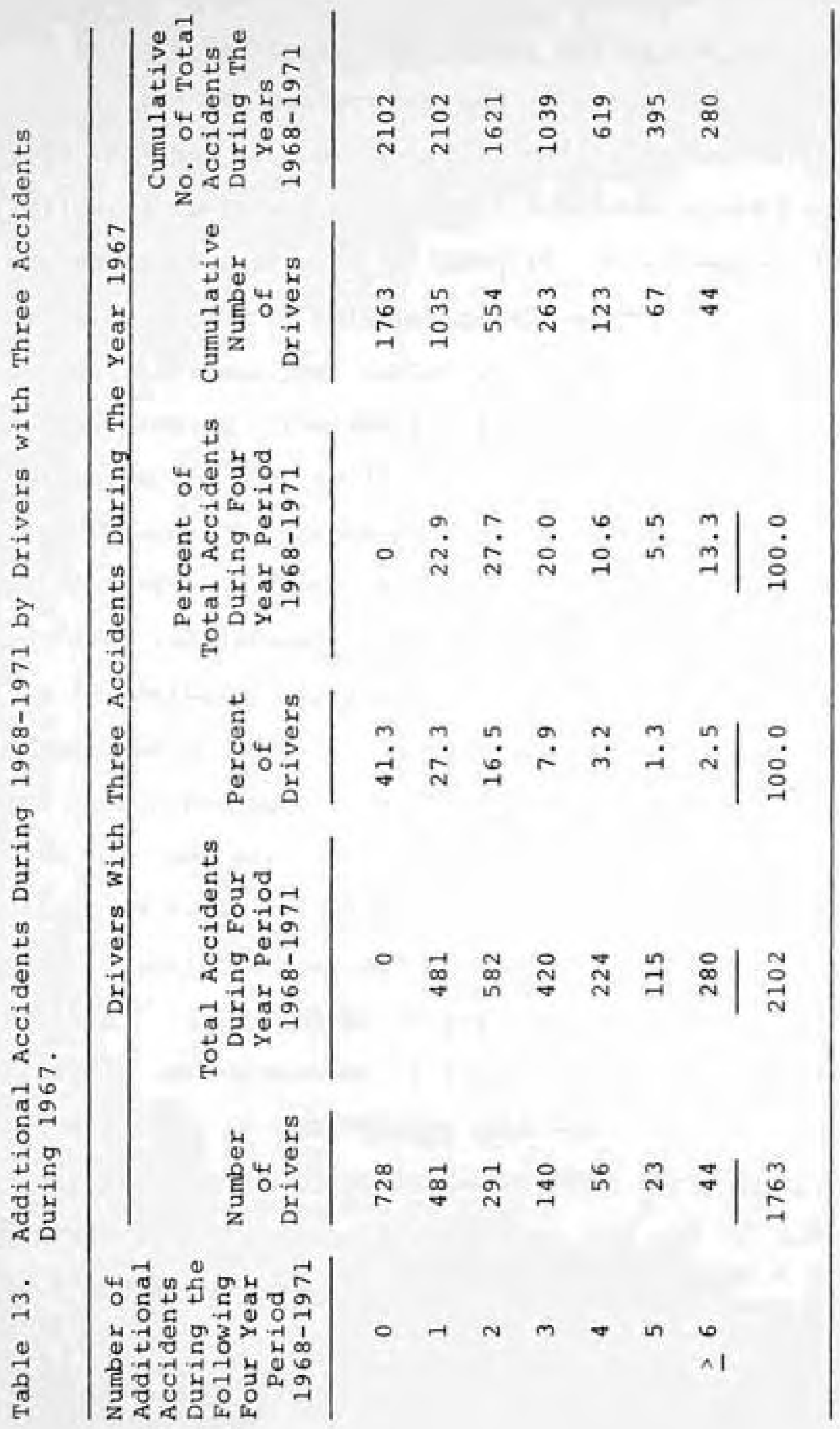


Drivers Having Four Accidents During The Year 1967

If the 241 drivers who had four accidents during the year 1967 had been prevented from driving during the following four year period, 393 accidents would have been prevented as indicated in Table 14. Seventy-nine drivers or 32.8 percent of this group had no additional accidents during this four year period and sixty-two drivers or 25.7 percent had only one additional accident. Thus by denying driving privileges to the entire group of drivers who had four reported accidents during the year 1967,141 or 58.5 percent of the group who had either no further additional accident involvement or only one additional accident during the following four year period would also have lost their driving privileges. Only 100 drivers, or 41.5 percent of the group, had more than two accidents in the following four year period. These 100 drivers, however, had 331 accidents, 84.2 percent of the total for this group.

If only the drivers who had three or more additional accidents during the following four year period were considered, 186 drivers or $\mathbf{7 7 . 2}$ percent of the drivers who had two accidents or less during this period would have lost their licenses in order to renove from the highways 55 drivers, 22.8 percent of the group, who had 241 accidents, 61.3 percent of the accidents. 


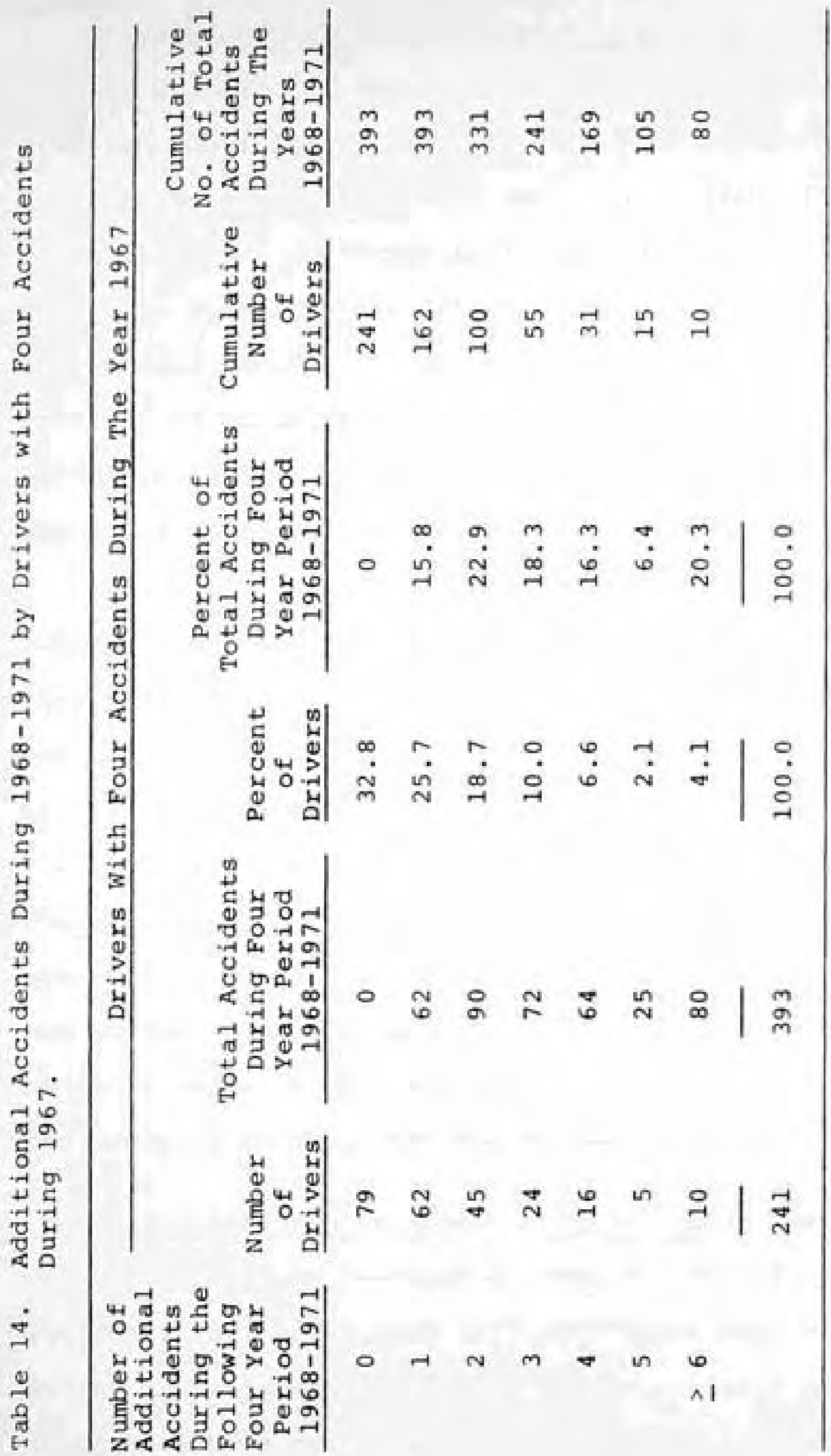




\section{Drivers Having Five Accidents During the Year 1967}

If all of the forty-six drivers who were involved in five accidents during the year 1967 were prevented from driving during the following four year period, 116 accidents would have been prevented as indicated in Table 15. During this same period, eight drivers or 17.4 percent of the group had no additional accidents and ten drivers or 21.7 percent of the group had only one additional accident. Thus by denying driving privileges to the entire group of drivers who had five accidents during the year 1967, 18 drivers or 39.1 percent of the group who had either an accident free record or only one additional accident during the following four years would be denied the privilege of driving. On the other hand, 28 drivers, 60.9 percent of this group, who had 106 accidents would have been taken off the road.

If only those drivers who had three or more accidents during the four year period following the year 1967 were considered, 30 drivers or 65.2 percent of the group who had two accidents or less during this same period would be suspended in order to prevent the 16 drivers, 34.8 percent of the group, that accounted for 82 accidents from driving.

\section{Drivers Having Six or More Accidents During the Year 1967}

If all of the fourteen drivers who had six or more accidents during the year 1967 were prevented from driving during the following four year period, seventy accidents would have been prevented as indicated in Table 1. All of 


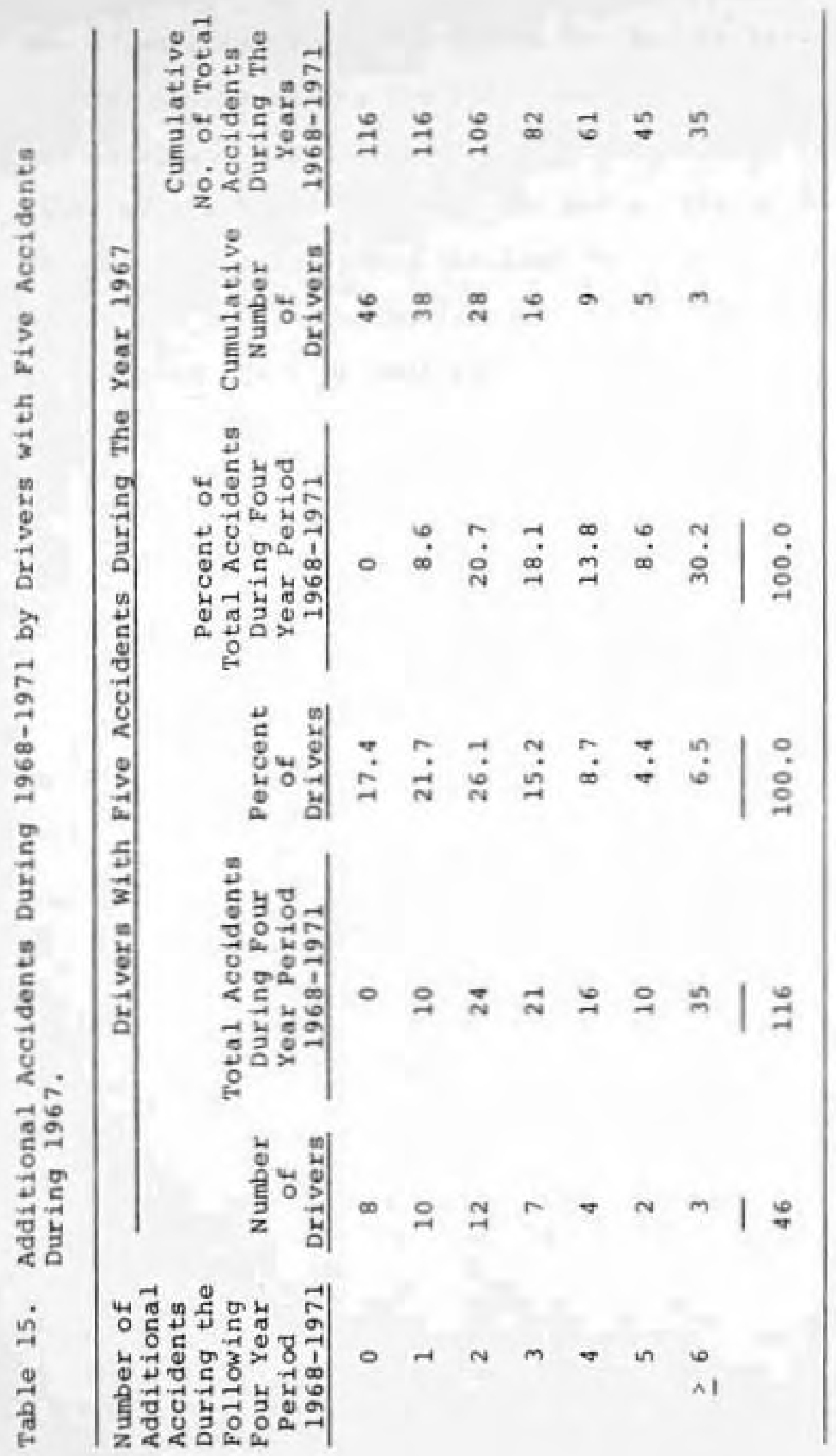


the drivers in this group except one had at least two or more accidents during the following four year period. The one exception had a single accident during the same period. Eight of the drivers or 57.1 percent of the group had three or more accidents during the four year period. The group as a whole had an average of 1.25 accidents per driver per year during the four year period following the year 1967 . 


\section{CASE HISTORIES OF SELECTED \\ HIGH ACCIDENT DRIVERS}

In order to paint a more vivid picture of the characteristics of the high accident driver, case histories of several selected drivers are presented here. Entries on their driving records and accident records have been combined and chronologically ordered so that the sequence of events in their driving history over the five year study period may be noted.

\section{Clear Driving Record}

The first three individuals presented are drivers with clear driving records; that is, with no citations for violations .

DRIVER:

RESIDENCE :

LICENSE:

AGE :

SEX:

RESTRICTIONS :
2174

Crown Point

Chauffeur

38

Male

Glasses or contact lenses, outside review mirror

VIOLATION

DATE

$1 / 31 / 67$

ACTION

POINTS

Property damage accident

$2 / 18 / 67$

$6 / 05 / 67$

Injury Accident

Property damage accident 


$\begin{aligned} 4 / 24 / 68 & \text { Property damage accident } \\ 1 / 31 / 69 & \text { Injury accident } \\ 9 / 24 / 70 & \text { Chauffeur license issued } \\ 11 / 23 / 70 & \text { Property damage accident } \\ 1 / 12 / 71 & \text { Property damage accident } \\ 3 / 12 / 71 & \text { Property damage accident } \\ 6 / 7 / 71 & \text { Property damage accident } \\ 10 / 15 / 71 & \text { Chauffeur 1icense issued } \\ 2 / 10 / 72 & \text { Current status-clear }\end{aligned}$

Five year summary: Total accidents 9

Total violations 0

Total violation points 0

Total suspensions 0

\begin{tabular}{ll} 
DRIVER: & 3077 \\
RESIDENCE: & Indianapolis \\
LICENSE: & Operator \\
AGE: & 41 \\
SEX: & Male \\
RESTRICTIONS: & None \\
& \\
DATE & ACTION \\
\hline $3 / 10 / 67$ & Property damage accident \\
$5 / 30 / 67$ & Injury accident \\
$7 / 29 / 67$ & Property damage accident \\
$8 / 14 / 67$ & Property damage accident \\
$3 / 02 / 68$ & Property damage accident \\
$4 / 17 / 68$ & Operator license issued \\
$1 / 17 / 69$ & Property damage accident \\
$3 / 03 / 69$ & Injury accident \\
$5 / 21 / 70$ & Operator license issued \\
$7 / 31 / 70$ & Injury accident \\
$2 / 10 / 72$ & Current status-clear
\end{tabular}


$\begin{array}{lll}\text { Five year summary: } & \text { Total accidents } & 8 \\ & \text { Total violations } & 0 \\ & \text { Total violation points } & 0 \\ & \text { Total suspensions } & 0\end{array}$

\begin{tabular}{|c|c|}
\hline DRIVER: & 1996 \\
\hline RESIDENCE : & Indianapolis \\
\hline LICENSE: & Operator \\
\hline GE : & 24 \\
\hline EX: & Male \\
\hline RESTRICTIONS: & None \\
\hline DATE & ACTrON \\
\hline $0 / 08 / 67$ & Property damage accident \\
\hline $12 / 23 / 67$ & Injury accident \\
\hline $12 / 25 / 67$ & Property damage accident \\
\hline $5 / 03 / 68$ & Operator license issued \\
\hline $2 / 19 / 69$ & Property damage accident \\
\hline $5 / 07 / 70$ & Operator 1 icense issued \\
\hline $11 / 19 / 71$ & Property danage accident \\
\hline $4 / 20 / 72$ & Current status-clear \\
\hline
\end{tabular}

Five year sumary: Total accidents 5

Total violations 0

Total violation points 0

Total suspensions 0

Drivers with Improved Accident

Records After 1967

Two individuals are presented next who displayed a much improved accident record during the four year period following the year 1967 . The first driver had five reported accidents during the year 1967 and none during the following four year period. The second driver had six accidents 
during the year 1967 and only one additional accident during the first quarter of the year 1968. No further accidents were noted.

DRIVER :

RESIDENCE:

LICENSE:

AGE:

SEX:

RESTRICTIONS:
1269

Kokomo

Operator

49

Female

Glasses or contact lenses, outside rearview mirror

This driver had two previous violation citations during the year 1964 .

DATE

ACTION

VIOLATION

POINTS

$1 / 23 / 67$

Property damage accident

$2 / 03 / 67$

Sign violation

$3 / 02 / 67$

Property damage accident

$5 / 29 / 67$

Injury accident

$5 / 30 / 67$

Injury accident

$6 / 16 / 67$

Injury accident

$8 / 09 / 68$

Operator license issued

$8 / 12 / 70$

Operator license issued

$2 / 15 / 72$

Current status-clear

Five year summary: Total accidents 5

Total violations 1

Total violation points 4

Total suspensions 0

DRIVER:

2625

REST DENCE:

Elkhart

LICENSE :

Chauffeur

AGE: 


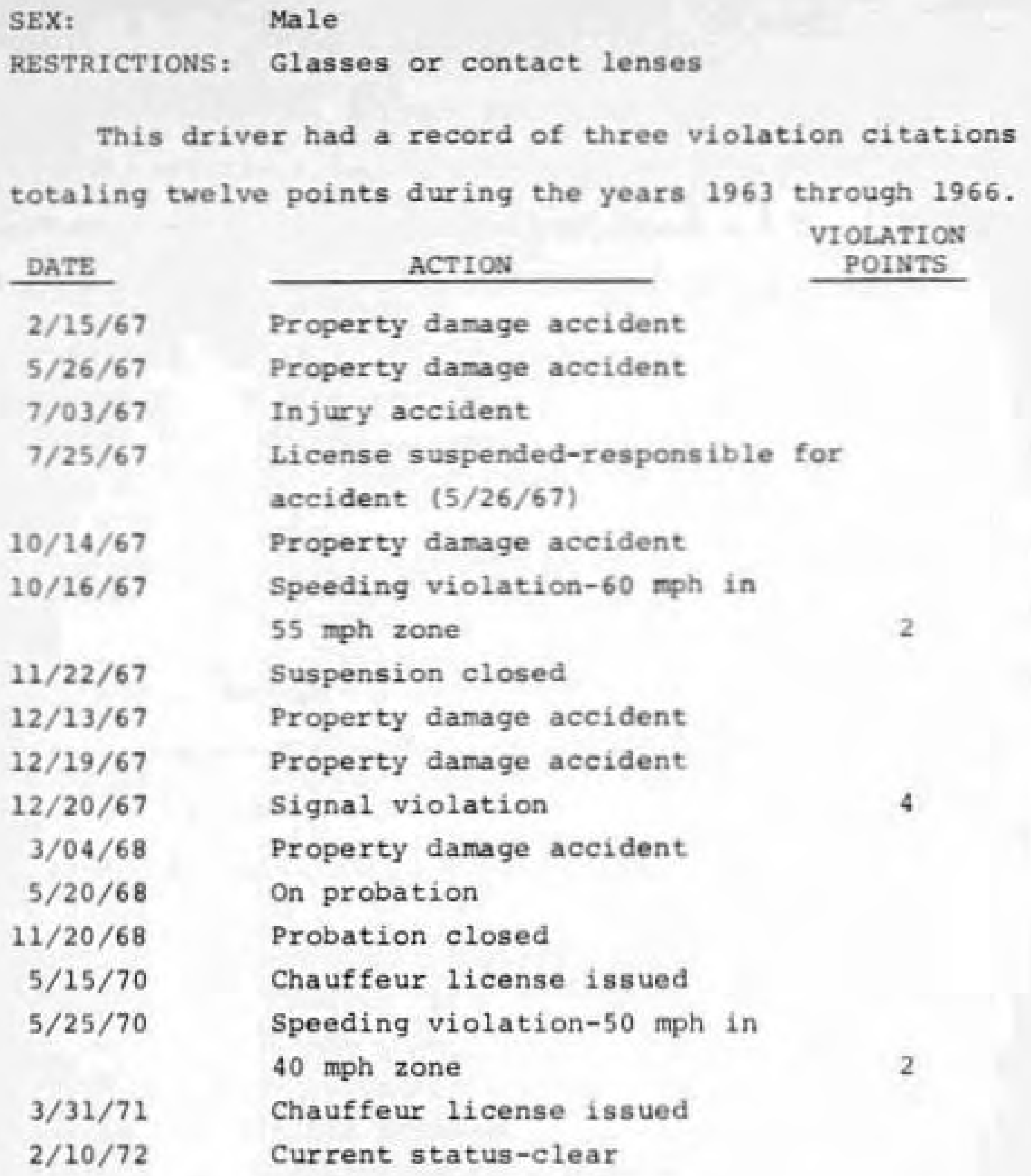

Five year summary: Total accidents 7

Total violations 3

Total violation points 8

Total suspensions 1 
Three Accidents in 1967 and Continued High Accident Rate Afterward

The next three drivers presented all had only three reported accidents during the year 1967. They all continued, however, to have three or more additional accidents during the four year period following the year 1967 .

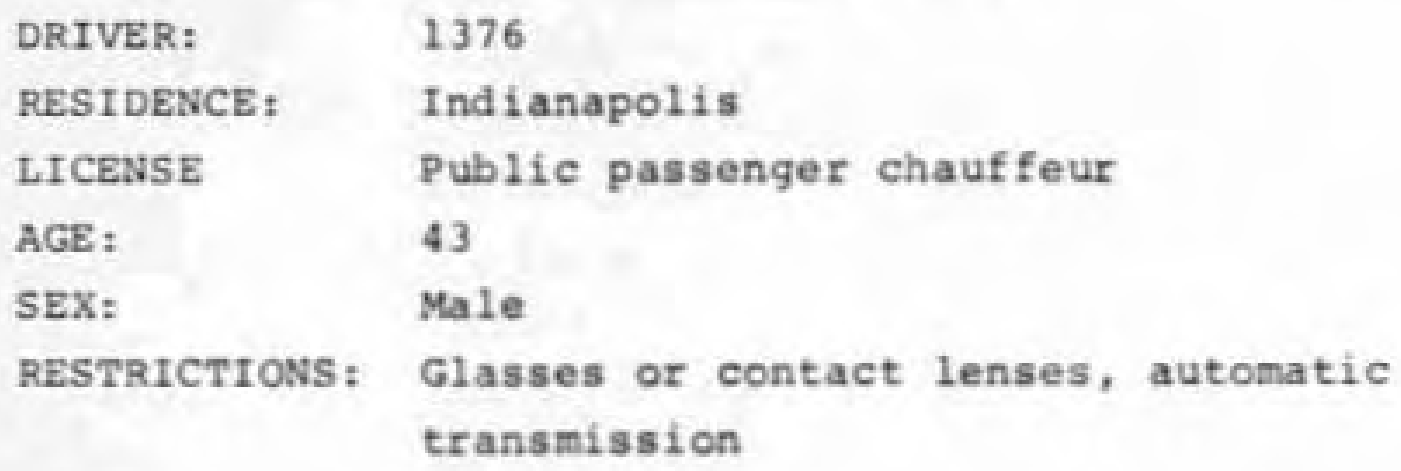

During the years 1962 through 1966, this driver accumulated fifteen violation citations with a total point value of 50 points. He was placed on probation in 1963 and again in 1964,1965 and 1966.

DATE

$4 / 29 / 67$

$8 / 08 / 67$

$9 / 15 / 67$

$10 / 16 / 67$

$11 / 11 / 67$

$1 / 25 / 68$

$2 / 08 / 68$

$12 / 13 / 68$

$2 / 28 / 69$

$6 / 11 / 69$

$1 / 16 / 70$
ACTION

VIOLATION

POINTS

Speeding violation-85 mph in

70 mph zone

On probation

(1)

Injury accident

Property danage accident

Property damage accident

Turning violation

Probation (1) closed

Speeding violation-67 mph in

50 mph zone

Signal violation

Property damage accident

Turning violation 


\begin{tabular}{|c|c|}
\hline $1 / 17 / 70$ & Signal violation-1ocal ordinance \\
\hline $1 / 22 / 70$ & Signal violation-local ordinance \\
\hline $1 / 22 / 70$ & Signal violation-local ordinance \\
\hline $7 / 13 / 70$ & On probation (2) \\
\hline $7 / 28 / 70$ & Property damage accident \\
\hline $9 / 18 / 70$ & $\begin{array}{l}\text { Public passenger chauffeur license } \\
\text { issued }\end{array}$ \\
\hline $1 / 13 / 71$ & Probation (2) closed \\
\hline $2 / 03 / 71$ & Property damage accident \\
\hline $2 / 23 / 71$ & Turning violation \\
\hline $9 / 20 / 71$ & $\begin{array}{l}\text { Speeding violation- } 42 \mathrm{mph} \text { in } \\
30 \mathrm{mph} \text { zone }\end{array}$ \\
\hline $9 / 28 / 71$ & $\begin{array}{l}\text { Public passenger chauffeur license } \\
\text { issued }\end{array}$ \\
\hline$(1 / 10 / 72$ & Signal violation-local ordinance \\
\hline$(2 / 03 / 72$ & Turning violation \\
\hline $2 / 15 / 72$ & $\begin{array}{l}\text { Current status- } 8 \text { active violation } \\
\text { points }\end{array}$ \\
\hline
\end{tabular}

Five year summary: Total accidents 6

Total violations $\quad 10$

Total violation points 23

Total suspensions 0

DRIVER: 2753

RESIDENCE: Valparaiso

LICENSE: Operator

AGE : $\quad 22$

SEX: Male

RESTRICTIONS: None

This driver had two speeding violation citations during the year 1966 .

DATE

$3 / 13 / 67$

$9 / 28 / 67$
ACTION

VIOLATION

POINTS

\section{Property damage accident}

Property damage accident 


$\begin{aligned} 11 / 04 / 67 & \text { Signal violation } \\ 12 / 05 / 67 & \text { Injury accident } \\ 2 / 28 / 68 & \text { Injury accident } \\ 6 / 18 / 68 & \text { Operator license issued } \\ 10 / 12 / 68 & \text { Speeding violation-60 mph in } \\ & 45 \text { mph zone } \\ 12 / 06 / 68 & \text { Speeding violation-57 mph in } \\ & 45 \text { mph zone } \\ 2 / 05 / 69 & \text { Property danage accident } \\ 2 / 10 / 69 & \text { Speeding violation-50 mph in } \\ 3 / 05 / 69 & \text { Po mph zone } \\ 5 / 01 / 69 & \text { Property danage accident } \\ 6 / 08 / 69 & \text { Injury accident } \\ 8 / 16 / 69 & \text { Injury accident } \\ 9 / 04 / 69 & \text { On probation } \\ 12 / 22 / 69 & \text { Injury accident } \\ 3 / 24 / 70 & \text { Injury accident } \\ 5 / 16 / 70 & \text { License suspended-responsible for } \\ 6 / 25 / 70 & \text { accident (12/22/69) } \\ 9 / 04 / 70 & \text { Injury accident } \\ 10 / 15 / 70 & \text { Probation closed } \\ 1 / 03 / 71 & \text { Suspension closed } \\ 1 / 20 / 71 & \text { Injury accident } \\ 5 / 29 / 71 & \text { Operator 1icense issued } \\ 2 / 10 / 72 & \text { Injury accident } \\ & \text { Current status-clear } \\ & \\ & \\ & \end{aligned}$

Five year summary: Total accidents 14

Total violations 4

Total violation points 11

Total suspensions 1

DRIVER: $\quad 1032$

RESIDENCE: Indianapolis

LICENSE: $\quad$ Public passenger chauffeur 
AGE :

65

SEX:

Male

RESTRICTIONS: Glasses or contact lenses

During the years 1960 through 1966, this driver had a record of two license suspensions and eleven violation citations totaling 39 points.

DATE

$1 / 04 / 67$

$1 / 05 / 67$

$1 / 30 / 67$

$9 / 20 / 67$

$1 / 19 / 68$

$4 / 11 / 68$

$6 / 21 / 68$

$9 / 24 / 6 B$

$11 / 29 / 68$

$3 / 25 / 69$

$8 / 16 / 69$

$8 / 20 / 69$

$9 / 02 / 69$

9/09/69

9/29/69

$9 / 29 / 69$

$1 / 23 / 70$

2/15/70

2/12/70

2/16/70

$2 / 16 / 70$

$3 / 24 / 70$

$10 / 05 / 70$
ACTION

VIOLATION

POINTS

Property damage accident

Injury accident

Property damage accident

Turning violation

Property damage accident

Turning violation

Property damage accident

Injury accident

Sign violation

Signal violation

4

Injury accident

Speeding violation-47 mph in

$30 \mathrm{mph}$ zone

License suspended(1)-failure to

appear for driver instruction

Signal violation

On probation (1)

Suspension(1) closed

Public passenger chauffeur license

issued

Injury accident

Turning violation

Probation(1) closed

On probation (2)

Turning violation

On probation ( 3 ) 


$\begin{aligned} 10 / 05 / 70 & \text { Probation(2) closed } \\ 1 / 04 / 71 & \text { Public passenger chauffeur license } \\ & \text { issued } \\ 3 / 24 / 71 & \text { Property damage accident } \\ 6 / 07 / 71 & \text { License suspended(2)-responsible for } \\ & \text { accident }(3 / 24 / 71) \\ 10 / 05 / 71 & \text { Probation (3) closed } \\ 2 / 10 / 72 & \text { Current status-suspended }\end{aligned}$

It is difficult to understand why a driver with this record should be issued a public passenger chauffeur's license less than four months after his suspension was closed and while he was still on probation.

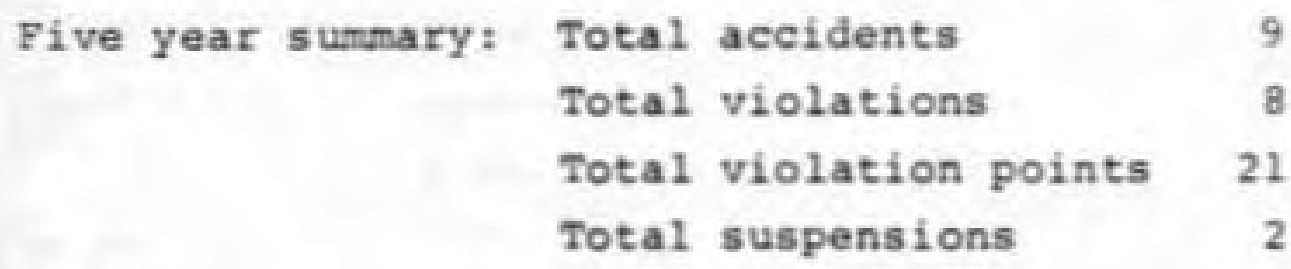

\section{Drivers With Multiple Suspensions}

The following three drivers are presented as examples of individuals with multiple license suspensions. All had three or more suspensions during the five year study period. The last driver's license was suspended during the entire study period.

DRIVER:

RESIDENCE:

LICENSE:

AGE:

SEX:

RESTRICTIONS: None
2683

South Bend

Operator

37

Male 
This driver had a history of ten licenses suspensions during the years 1954 through 1966. Three of those suspensions were for being responsible for accidents.

DATE

$3 / 25 / 67$

$5 / 24 / 67$

$6 / 03 / 67$

$8 / 02 / 67$

$9 / 16 / 67$

$10 / 14 / 67$

$10 / 25 / 67$

$11 / 15 / 67$

$12 / 13 / 67$

$6 / 03 / 68$

$6 / 30 / 68$

$6 / 30 / 68$

$10 / 14 / 68$

$4 / 30 / 69$

$5 / 18 / 69$

$7 / 03 / 69$

$9 / 13 / 69$

$5 / 18 / 70$

$3 / 11 / 71$

$3 / 23 / 71$

$9 / 16 / 71$

$9 / 28 / 71$
ACTION

VIOLATIOA

POINTS

Property danage accident

License suspended(1)-responsible

for accident $(3 / 25 / 67)$

Property damage accident

License suspended (2)-responsible

for accident $(6 / 03 / 67)$

Speeding violation- $80 \mathrm{mph}$ in

$65 \mathrm{mph}$ zone

Injury accident

License suspended(3)-failure to

appear for driver instruction

Suspension(1) closed

License suspended(4)-responsible

for accident $(10 / 14 / 67)$

Suspension(2) closed

Driving while suspended violation

License suspended(5)-driving while suspended

Suspension(4) closed

Suspension(5) closed

Property damage accident

Speeding violation-45 mph in

$30 \mathrm{mph}$ zone

License suspended(6)-responsible

for accident (5/18/69)

Suspension(6) closed

Suspension(3) closed

Operator license issued

Property damage accident

Operator license issued 
11/25/71 License suspended (7)-responsible for accident $(9 / 16 / 71)$

4/21/72 Current status-suspended

Five year summary: Total accidents 5

Total violations 3

Total violation points 4

Total suspensions 7

$\begin{array}{ll}\text { DRIVER: } & 2018 \\ \text { RESIDENCE: } & \text { Fort wayne } \\ \text { LICENSE : } & \text { Operator } \\ \text { AGE: } & 22 \\ \text { SEX: } & \text { Male } \\ \text { RESTRICTIONS: } & \text { None }\end{array}$

During the years 1962 through 1966, this driver received eight violation citations. Four of these were serious violations, three of which required mandatory license suspension. His license was suspended one additional time during this period for failure to appear for driver instruction.

DATE

$2 / 09 / 67$

$2 / 23 / 67$

$4 / 10 / 67$

$7 / 14 / 67$

$9 / 13 / 67$

$9 / 19 / 67$

$11 / 18 / 67$

$12 / 03 / 67$
ACTION

VIOLATION

POINTS

Property damage accident

Reckless driving violation

6

License suspended(1)-responsible

for accident (2/09/67)

Suspension(1) closed

Reckless driving violation

6

Property damage accident

License suspended(2)-responsible

for accident $(9 / 19 / 67)$

Injury accident 


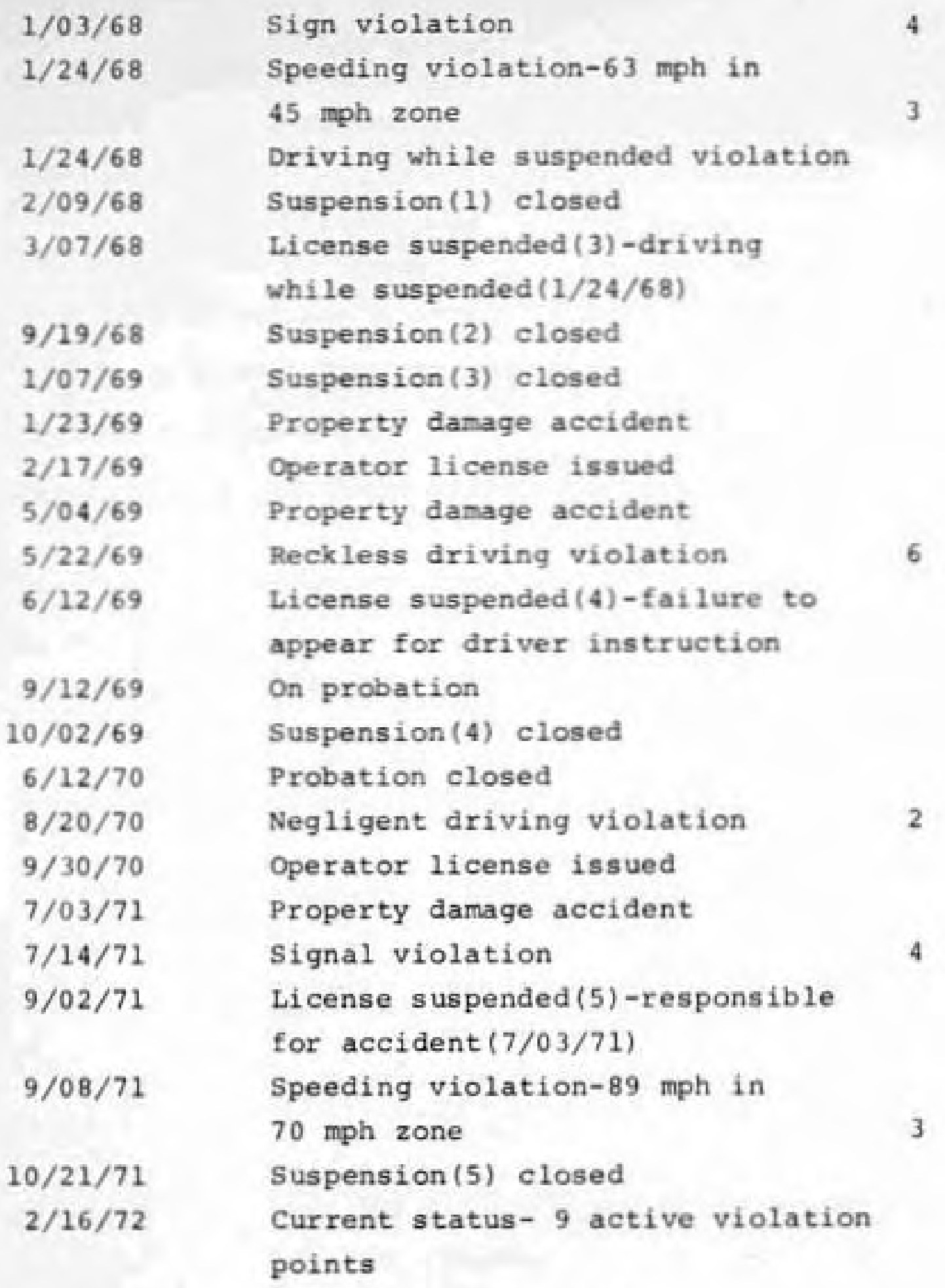

Five year summary: Total accidents 6

Total violations 9

Total violation points 34

Total suspensions 5 


$\begin{array}{ll}\text { DRIVER: } & 1590 \\ \text { RESIDENCE: } & \text { St. Anthony } \\ \text { LICENSE: } & \text { Operator } \\ \text { AGE : } & 45 \\ \text { SEX : } & \text { Male } \\ \text { RESTRICTIONS : None }\end{array}$

This driver had a record of four license suspensions, two of which were for driving while intoxicated, during the years 1960 through 1966. His last suspension was still in effect during the first part of the year 1967.

\section{DATE}

$5 / 29 / 67$

$6 / 10 / 67$

$6 / 10 / 67$

$6 / 10 / 67$

$7 / 01 / 67$

$7 / 10 / 67$

$7 / 10 / 67$

$9 / 02 / 67$

$10 / 09 / 67$

$10 / 09 / 67$

$10 / 09 / 67$

$12 / 10 / 67$

$6 / 10 / 68$

$6 / 10 / 68$

$10 / 21 / 68$

$10 / 21 / 68$
ACTION

VIOLATION

POINTS

Property damage accident

Reckless driving violation

6

Leaving the scene of an

accident violation

License suspended(1)-leaving

the scene of an accident $(6 / 10 / 67)$

Property damage accident

Failed to report accident violation 7

Driving while suspended violation

Injury accident

Reckless speed violation

Driving while intoxicated

violation

Driving while suspended violation

License suspended(2)-driving while

suspended $(7 / 10 / 67)$

Suspension(2) closed

License suspended(3)-driving while

suspended $(10 / 09 / 67)$

Driving while intoxicated violation

Driving while suspended violation 


$\begin{array}{ll}12 / 10 / 68 & \text { License suspended(4)-driving while } \\ & \text { intoxicated(10/09/67) } \\ 11 / 01 / 69 & \text { Property damage accident } \\ 11 / 01 / 69 & \text { Property damage accident } \\ 11 / 03 / 69 & \text { Reckless driving violation } \\ 11 / 03 / 69 & \text { Driving while suspended violation } \\ 12 / 10 / 69 & \text { License suspended(5)-driving while } \\ & \text { intoxicated(10/21/68) } \\ 3 / 15 / 70 & \text { Driving while intoxicated violation } \\ 3 / 15 / 70 & \text { Driving while suspended violation } \\ 3 / 22 / 70 & \text { License suspended(6)-responsible for } \\ 5 / 21 / 70 & \text { accident(11/01/69) } \\ 12 / 10 / 70 & \text { Suspension(6) closed } \\ & \text { License suspended(7)-driving while } \\ 12 / 10 / 71 & \text { suspended(10/21/68) } \\ & \text { License suspended(8)-driving while } \\ \text { suspended(11/03/69) } & \text { Suspension(7) closed } \\ 12 / 14 / 71 & \text { License suspended(9)-driving while } \\ 12 / 10 / 72 * & \text { intoxicated(3/15/70) } \\ 12 / 10 / 73 * & \text { License suspended(10)-driving while } \\ 2 / 15 / 72 & \text { suspended(3/15/70) } \\ \text { Current status-suspended until } 6 / 08 / 74\end{array}$

*These are dates that the suspensions will automatically go into effect for the past violations listed.

The fact that this driver's 1 icense was suspended during the entire five year study period gives emphasis to the need for better controls to prevent unlicensed individuals from driving.

$\begin{array}{llr}\text { Five year sunmary: } & \text { Total accidents } & 5 \\ & \text { Total violations } & 13 \\ & \text { Total violation points } & 25 \\ & \text { Total suspensions } & 10\end{array}$




\section{Pifteen or More Accidents During \\ the Five Year Study Period}

This last group of drivers are presented because they are certainly high accident drivers. All of them had fifteen or more accidents during the five year period. The last driver presented had a high of twenty-nine accidents.

DRIVER :

RESIDENCE:

LICENSE:

AGE :

SEX:

\section{Bloomington}

Public passenger chauffeur

40

Male

RESTRICTIONS: Glasses or contact lenses

This driver had a single speeding violation in 1965 and had his license suspended in 1966 for being responsible for an accident.

DATE

$1 / 24 / 67$

$2 / 03 / 67$

$5 / 05 / 67$

$9 / 01 / 67$

$10 / 31 / 67$

$11 / 07 / 67$

$3 / 11 / 68$

$3 / 30 / 68$

$5 / 20 / 68$

$6 / 15 / 68$

$10 / 29 / 68$

\section{ACTION}

VIOLATION

POINTS

Property damage accident

Property damage accident

Property damage accident

Property damage accident

License suspended-responsible for

accident $(9 / 01 / 67)$

Property damage accident

Suspension closed

Speeding violation-56 mph in

$45 \mathrm{mph}$ zone

Public passenger chauffeur license

issued

Speeding violation-65 mph in

$55 \mathrm{nph}$ zone

Injury accident 


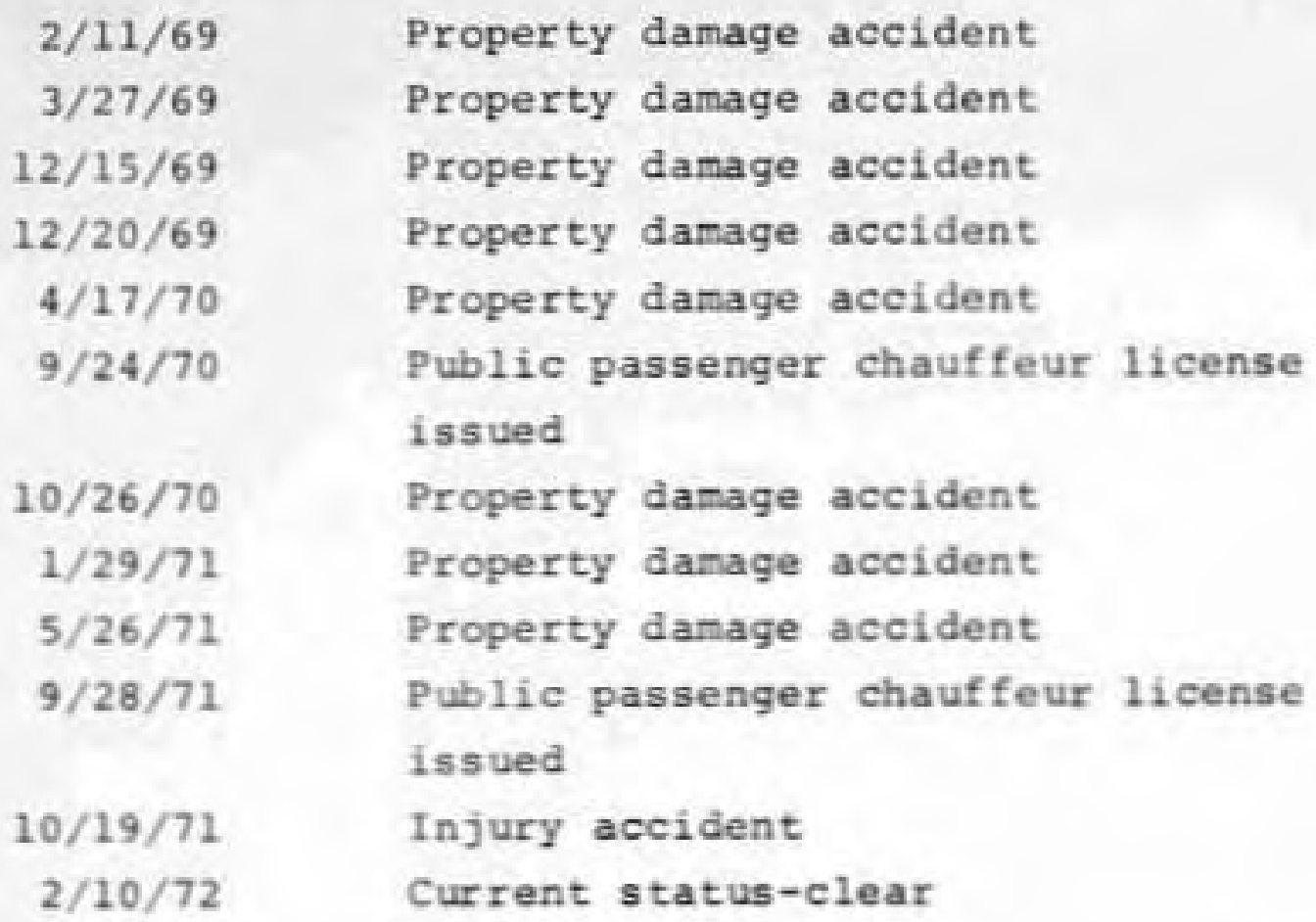

This driver had two previous license suspensions, one in 1963 and one in 1964. He also had four violation citations, three of which were in 1963 and one in 1964. A public passenger chauffeur's license was issued to him in January 1965, and his violation record has been clear since that date. 
DATE

$1 / 13 / 67$

$3 / 14 / 67$

$3 / 27 / 67$

$6 / 12 / 67$

$8 / 21 / 67$

$10 / 11 / 67$

$10 / 23 / 67$

$11 / 29 / 67$

$2 / 13 / 68$

$5 / 20 / 68$

$7 / 23 / 68$

$9 / 24 / 68$

$5 / 13 / 69$

$9 / 18 / 69$

$10 / 08 / 69$

$11 / 26 / 69$

$1 / 18 / 70$

$11 / 13 / 70$

$12 / 17 / 70$

$7 / 22 / 71$

$10 / 22 / 71$

$12 / 30 / 71$

$2 / 10 / 72$
ACTION

VIOLATION

POINTS

Property damage accident

License suspended-responsible

for accident (1/13/67)

Property damage accident

Property damage accident

Property damage accident

Property damage accident

Suspension closed

Property damage accident

Public passenger chauf feur license

issued

Property damage accident

Property damage accident

Property damage accident

Property damage accident

Property damage accident

Property damage accident

Injury accident

Injury accident

Injury accident

Public passenger chauffeur license

issued

Property damage accident

Injury accident

Public passenger chauffeur license

issued

Current status-clear

Five year summary: Total accidents

Total violations 0

Total violation points 0

Total suspensions 1 


$\begin{array}{ll}\text { DRIVER: } & 1396 \\ \text { RESIDENCE: } & \text { Indianapolis } \\ \text { LICENSE: } & \text { Public passenger chauffeur } \\ \text { AGE: } & 33 \\ \text { SEX: } & \text { Male } \\ \text { RESTRICTIONS: } & \text { Glasses or contact lenses, outside rearview } \\ & \text { mirror }\end{array}$

This driver had eight violation citations on his record during the years 1955 and 1962. He also had three suspensions during this same period for failure to appear for driver instruction.

DATE

$1 / 21 / 67$

$3 / 19 / 67$

$5 / 10 / 67$

$5 / 11 / 67$

$11 / 07 / 67$

$1 / 18 / 68$

$1 / 19 / 68$

$3 / 18 / 68$

$7 / 13 / 68$

$8 / 05 / 68$

$3 / 09 / 69$

$9 / 04 / 69$

$10 / 01 / 69$

$10 / 15 / 69$

$11 / 10 / 69$

$1 / 06 / 70$

$1 / 30 / 70$

2/06/70

$4 / 05 / 70$
ACTION

VIOLATION

POINTS
Property damage accident

Property damage accident

Injury accident

Property damage accident

Property damage accident

Property damage accident

Property damage accident

Speeding violation-50 mph in

$30 \mathrm{mph}$ zone

Injury accident

Injury accident

Property damage accident

Property damage accident

Property damage accident

Property damage accident

Property damage accident

Property damage accident

Turning violation

2

Property danage accident 


$\begin{aligned} 4 / 10 / 70 & \text { Property damage accident } \\ 5 / 15 / 70 & \text { Public passenger chauffeur license } \\ & \text { issued } \\ 6 / 22 / 70 & \text { Property damage accident } \\ 6 / 23 / 70 & \text { Injury accident } \\ 7 / 06 / 70 & \text { License suspended(1)-responsible } \\ & \text { for accident }(2 / 06 / 70) \\ 9 / 10 / 70 & \text { Suspension(1) closed } \\ 10 / 18 / 70 & \text { Property damage accident } \\ 10 / 30 / 70 & \text { Property damage accident } \\ 2 / 05 / 71 & \text { Property damage accident } \\ 2 / 22 / 71 & \text { Signal violation } \\ 5 / 24 / 71 & \text { Public passenger chauffeur 1icense } \\ & \text { issued } \\ 10 / 29 / 71 & \text { License suspended(2)-judgement } \\ 12 / 07 / 71 & \text { Suspension(2) closed } \\ 2 / 10 / 72 & \text { Current status- } 2 \text { active violation } \\ & \text { points }\end{aligned}$

Five year summary: Total accidents

Total violations

Total violation points

Total suspensions

DRIVER :

2745

RESIDENCE :

Indianapolis

LICENSE:

Public passenger chauffeur

AGE :

29

SEX :

Male

RESTRICTIONS: None

This driver had one violation for speeding for which his license was suspended for one month in 1960 . 
DATE

1/20/67

$6 / 22 / 67$

$9 / 05 / 67$

$10 / 26 / 67$

$10 / 29 / 67$

$11 / 11 / 67$

$3 / 29 / 68$

$7 / 06 / 68$

$8 / 29 / 68$

$11 / 06 / 68$

1/11/69

$5 / 30 / 69$

$6 / 05 / 69$

$6 / 17 / 69$

$7 / 11 / 69$

$10 / 25 / 69$

$12 / 24 / 69$

$12 / 30 / 69$

$1 / 02 / 70$

1/07/70

1/12/70

1/16/70

$4 / 14 / 70$

$5 / 04 / 70$

$5 / 18 / 70$

$6 / 12 / 70$

8/15/70

$9 / 03 / 70$

$9 / 18 / 70$

11/08/70

2/12/71

2/18/71

$5 / 10 / 71$
ACTION

VIOLATION

POINTS

Property damage accident

Property damage accident

Property damage accident

Injury accident

Property damage accident

Property damage accident

Chauffeur license issued

Property damage accident

Injury accident

Property danage accident

Injury accident

Injury accident

Property damage accident

Property damage accident

Speeding violation-44 mph in

$30 \mathrm{mph}$ zone

Property damage accident

Property damage accident

Property damage accident

Injury accident

Property damage accident

Signal violation

Injury accident

Injury accident

Property damage accident

Signal violation-local ordinance 2

Property damage accident

Injury accident

Injury accident

Property damage accident

Property damage accident

Property damage accident

Injury accident

Operator license issued 


\begin{tabular}{|c|c|}
\hline $5 / 11 / 71$ & Property damage accident \\
\hline $6 / 24 / 71$ & Signal violation-local ordinance \\
\hline $6 / 24 / 71$ & Signal violation-local ordinance \\
\hline $7 / 09 / 71$ & $\begin{array}{l}\text { Public passenger chauffeur license } \\
\text { issued }\end{array}$ \\
\hline$/ 10 / 72$ & $\begin{array}{l}\text { Current status- } 6 \text { active violation } \\
\text { points }\end{array}$ \\
\hline
\end{tabular}

The longest period that this driver was able to go during the five year study period without having an accident was less than six months. During the same period he averaged approximately one accident every two months.

$\begin{array}{llr}\text { Five year summary: } & \text { Total accidents } & 29 \\ & \text { Total violations } & 5 \\ & \text { Total violation points } & 10 \\ & \text { Total suspensions } & 0\end{array}$

\section{Summary Comments}

The 15 case studies of high accident drivers in 1967 which have been presented indicate the dissimilar characteristics which are available from the driver's and accident records. Three cases are presented of high accident drivers who had no driving violations on their Indiana record. Two drivers are discussed who had some violations but who have had a much improved accident record after a bad 1967. Three case studies are presented of drivers who following a high accident record in 1967 continued to have a large number of accidents during the next four years. Violations, both predating and in the study period, are rather numerous for these three. Three drivers with more than one suspension of 
their license, at least one of which was for driving while suspended, are also presented. These drivers, however, had only 5,6 and 5 accidents during the five year period of which three or more were in 1967. Their accident record since 1967 has not been exceptionally excessive.

Finally, the only four drivers who had 15 or more accidents during the five years are reviewed. All of them have a history of violations and at least one suspension. The violations, however, in some of the cases were very few in the five year study period.

There is some indication that a study of the history of a few driver's driver and accident records over a period of several years would permit a reasonably accurate prediction of their future accident involvement. The evidence, however, must be so great that only an extremely small number of drivers could be so rated. Unfortunately, it appears this can be predicted only after they have had numerous accidents and violations. Even if these drivers were removed from the road - which driver license suspension does not do - only an extremely small reduction in the accidents in any one year would result.

It should also be noted that a study of drivers and their accident records is not now easily done in Indiana. Accident records and driver records are maintained separately and accident records are not maintained on a driver basis. The result is that a driver's records do not show his accident history. 


\section{CONCLUSIONS}

The following conclusions concerning high accident drivers summarize the findings of this research.

1. As a group, the accident record of drivers who are involved in three or more accidents during a particular year tends to show much improvement during following years.

2. A large proportion of those drivers who are involved in three or more accidents during a particular year remain accident free during the following four years.

3. Nearly all high accident drivers are male.

4. Drivers with chauffeur's licenses and particularly public passenger chauffeur's licenses account for a large proportion of the individuals who are high accident drivers during one year and continue to be high accident drivers during the following years.

5. High accident drivers are $1 i k e l y$ to be residents of large urban areas.

6. The violation record of a driver who has a high accident involvement during a particular year has little relationship to his accident record in the following years. 
7. The following are applicable to the average driver in a high accident group:

a. The more accidents in which a driver is involved during a particular year increases the probability that he will be involved in additional accidents during the following years.

b. As the number of accidents that a driver has increases, the seriousness of these accidents in terms of injury and fatality accidents tends to decrease.

8. In general, the accident record of a driver during one year, even when combined with information available in the Indiana drivers records, does not enable a reasonable prediction of the drivers accident record for future years. In a very few cases, where a history of numerous violations and accidents are recorded, a reasonable prediction of continued high accident involvement can possibly be made. 


\section{RECOMMENDATIONS}

It would be very informative to be able to obtain additional information about high accident drivers that is not available from Indiana driver or accident records. Much more knowledge could be realized about high accident drivers if qualified researchers were allowed to conduct thorough investigations and interviews of selected drivers.

The accident record file is maintained on a yearly basis and in order to determine an individuals accident history it is necessary to search the records for each year that the history is desired. It is recommended that the accident record file be coded by driver license numbers and that an accident record file be maintained for each driver involved in one or more accidents.

At the present time it is very time consuming to correlate an individuals accident record with his driver record. The accident record file is maintained by the State Police while the driver record file is maintained by the Bureau of Motor Vehicles and both files are completely separate. It is recommended that these files be linked together. A properly designed system would make it simple for personnel from either the State Police or the Bureau of Motor Vehicles to obtain a record of an individual's complete driver and 
accident history. This would greatly facilitate identification of problem drivers.

Additional study is needed on that class of drivers who hold chauffeur's and public passenger chauffeur's 1icenses. It appears that their involvement in the high accident groups is excessive to the proportion to their numbers in the driving population. This may be due to their increased exposure rate. Nevertheless, it appears that more stringent licensing controls would be in order for these drivers, particularly those in the public passenger chauffeur class. 
LIST OF REFERENCES 


\section{LIST OF REPERENCES}

1. Campbell, B. J., "Who Really Causes the Accidents?", Signal 99, North Carolina Governor's Highway Safety Program, Vol. 1, No. 2, Spring 1971.

2. Carlson, w. L., "Identifying the Problem Driver from State Driver Records", Research, Michigan University, Ann Arbor, May 1968, pp. 1-7.

3. Coppin, R, S., Peck, R. C., The 1964 California Driver Record Study, Part 8, The Prediction of Accident Involvement Using Concurrent Driver Record Data, Report No. 20, Research and Statistics Section, California Department of Motor Vehicles, Sacramento, January 1967.

4. Crancer, Alfred, Jr., "Involvement of the Problem Driver in Fatal Motor Vehicle Accidents", Traffic Quarterly, October 1967, pp. 601-610.

5. Crancer, Alfred, Jr., Accident and Violation Rates for Washington Drivers, washington Department of Motor Vehicles, Olympia, Report No. 003, May 1967.

6. Crancer, Alfred, Jr., McMurray, Lucille, Credit Ratings as a Predictor of Driving Behavior and Improvement, washington Department of Motor Vehicles, Olynpia, Report No. 010, May 1968.

7. Goldstein, Leon G., "Psychological Aspects of Traffic Accidents", Traffic Digest and Reviek, Vo1. 12, No. 6 , July 1964, pp. $10-12,23$.

8. Homburger, Wolfgang S., "On the Analysis of Accident Trends", Accident Analysis and Prevention, Vol. 1, 1969, pp. 101-104.

9. Johnson, H. M., "The Detection and Treatment of Accident Prone Drivers", Psychological Bulletin, No. 43, 1946, pp. 489-533.

10. Kaestner, Noel F., "The Similarity of Traffic Involvement Records of Young Drivers and Drivers in Fatal Traffic Accidents", Traffic Safety Research Review, Vo1. 8, No. 2, 1964, pp. 34-40. 
11. McFarland, Ross, "Psychological and Behavioral Aspects of Automobile Accidents", Traffic Safety Research Review, Vol. 12, No. 3, September 1968, pp. 71-80.

12. O'Neal1, P. A., Relationship of Accident Involvement and Number of Citations: 1966 Data, Washington Department of Motor Vehicles, Olympia, Report No. 006, 1967.

13. Penn, H. S., Causes and Characteristics of Single Car Accidents, Parts $3 \& 4$, California Highway Patrol, Sacramento, January 1965.

14. Schuster, D. H., Guilford, J. P., An Analys is of Accident Repeater and Chronic Violater Drivers, Traffic Project Report No. 1, U.S. Public Health Grant M-2353, Los Angeles, California, 1956.

15. Schuster, D. H., "Prediction of Follow-up Driving Accidents and Violations", Research Review, March 1968, pp. 17-21.

16. Shaw, L., Sichel, H. S., "The reduction of Accidents in a Transport Company by the Determination of the Accident Liability of Individual Drivers", Research Review, December 1961.

17. Sonquist, J. A., Morgan, J. N., The Detection of Interaction Effects, 5th ed., Cushing-Malloy, Inc., 1969.

18. Waller, Julian A., "Traffic Accidents, A Medical Viewpoint, Part 1," Automotive Industries, Vol. 136, No. 8, April 15, 1967, pp. 87-90.

19. Waller, Julian A., "Traffic Accidents, A Medical ViewPoint, Part 2," Automotive Industries, Vol. 136, No. 10, May 15, 1967, pp. 92-94.

20. Zylman, Richard, "Comparing Collision Drivers with the Driving Population-at-Risk: A Challenge to Conventional Methods," Behavioral Research in Highway Safety, Vol. 1, Summer $197 \overline{0,}$, $78-86$.

\section{General References}

Adams, James R., "Personality Variables Associated With Traffic Accidents," Behavioral Research in Highway Safety, Vol. 1, No. 1, January 1970, pp. 3-18.

Baker, Susan P., Characteristics of Fatally Injured Drivers - Final Report, School of Hygiene and Public Health, John Hopkins University, Baltimore, Maryland, February, 1970. 
Berkey, Ben, "The Average Man - and the Non-average Driver," California Highway Patrolman, Vol. 32, No. 11, January 1969 , pp. $7,16,32,36$.

Brenner, R., Mosher, W. W. The Use of Mass, Nonspecific Accident Data in Research, Institute of Transportation and Traffic Engineering, University of California at Los Angeles, 1965.

Burg, Albert, "The stability of Driving Record Over Time", Accident Analysis and Prevention, Vol. 2, No. 1, May 1970 , pp. 57-65.

Coppin, R. S., Samuels, I., Control of the Negilgent Driver, Part I, Characteristics of Negligent Drivers, C.E.S.T.I. PB 177647 , 1961 .

Coppin, R. S., Van Oldenbeek, G., Control of the Negligent Driver, Part II, Driving Performance of Negligent Drivers, C.F.S.T.I. PB $177648,1962$.

Coppin, R. S., et al., The Patal Accident Reexamination Progran in California, California Department of Motor Vehicles, Sacramento, January 1966.

Crancer, Alfred, Jr., Quiring, D. L., Driving Records of Persons Arrested for Illegal Drug Use, Washington Department of Motor Vehicles, Olympia, Report No. 011, May 1968.

Garrett, J. W., Tharp, J. B., Development of Improved Methods for Reduction of Traffic Accidents, National Cooperative Highway Research Progran, Report 79.

Greenshields, B. D., Driving Behavior and Traffic Accidents, Transportation Institute, University of Michigan, Ann Arbor, November 1, 1962.

Greenshields, B. D., Platt, F. N., "Development of a Nethod of Predicting High Accident and High Violation Drivers", Journal of Applied Psychology, Vol. 51, No. 3. $1967, \mathrm{pp} .205-210$.

Harrington, David M., "Factor Analysis of Driver Record", Traffic Safety and Research Review, Vol. 12, No. 3, September 1968, pp. B1-87.

Kraus, A. S., et al., "Pre-driving Identification of Young Drivers with a High Risk of Accidents". Journal of Safety, Research, Vo1. 2, No. 2, June 1970, pp. $55-66$. 
Levonian, E., Prediction of Negligent Operators, Institute of Transportation and Traffic Engineering, University of California at Los Angeles, December 1963.

Levonian, E., "Prediction of Accidents and Violations Using Non-driving Predictors", American Association of Motor Vehicle Administrators-Summary of Proceedings: Research Conference and Workshop, Apri1 4-7, 1966, pp. $6-8$.

McFarland, Ross, "Measurement of Human Factors in Accident Research", Traffic Digest and Review, Vol. 14 No. 6 , June $1966, \mathrm{pp}, 4-11,19,20$.

Rice, R. A., Tindal1, J. T., "Police Use of Accident and Violation Records in Queensland for Accident Reduction and Driver Improvement Purposes," Australian Road Research, Proceeds of Third Conference, Vol. 3, Pt. 1, 1966, pp. 604-627.

Schuster, D. H., Guilford, J. P., The Psychometric Prediction of Problem Drivers, University of Southern California, Los Angeles, Decenber 1961.

Shaw, L., Sichel, H. S., Accident Proneness, Perganon Press, New York, 1971.

Stoner, J. E., et al., Highway Traffic Accident Records, Their Analysis, Use, and Improvement, Indiana University, 1966.

Waller, Julian A., "The High Traffic Accident Rate Among the Middle-aged, A problem and Its Solution, Part II", Traffic Digest and Review, Vol. 15, No. 9, September 1967, pp. 13-18. 


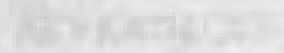

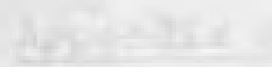

APPENDICES 


\section{APPENDICES}

\section{Appendix A}

State Record Summaries

The tables in this Appendix provide accident record sumaries as compiled by the Indiana State Police and number of licensed drivers as compiled by the Indiana Bureau of Motor Vehicles. 


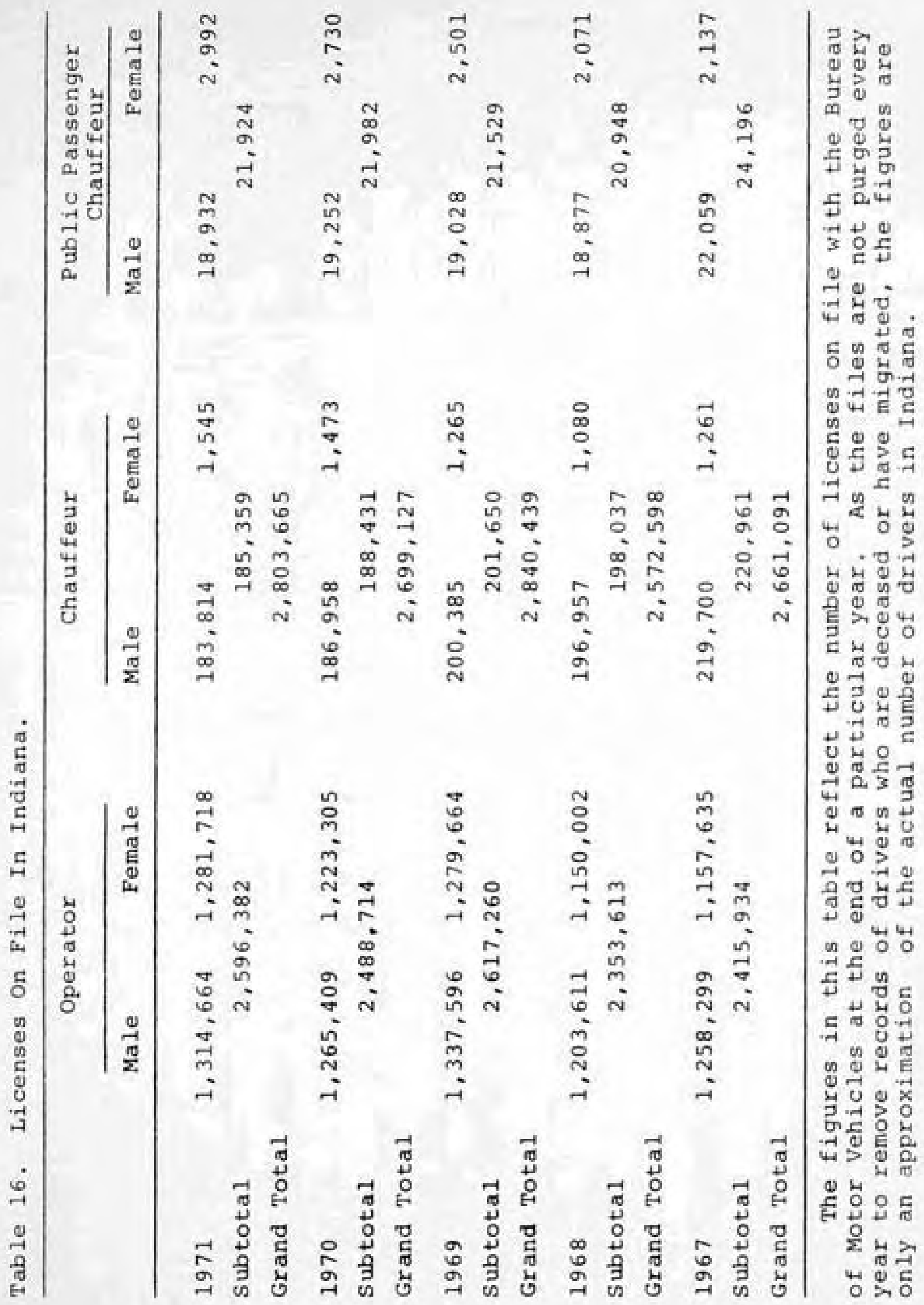


Table 17. Standard Sumary of Motor Vehicle Traffic Accidents

\section{STANDARD SUMMARY OF MOTOR VEHICLE TRAFFIC ACCIDENTS}

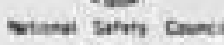
Chens: in TIDTANA

$-10$

$326-3457-10986-179$

$10 \quad 372 \quad 337 \quad \frac{1}{2}$

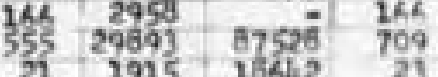

21251542

$90-1233$

$1112 \quad 3 k 00$

$160-1057$

1057

25013

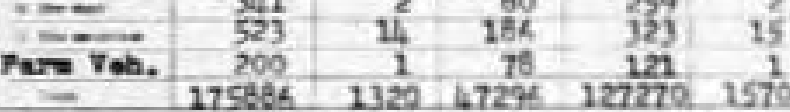

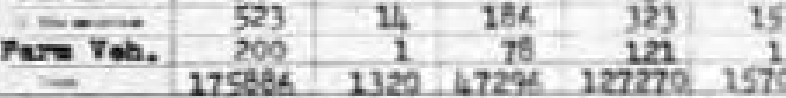

9157 Lis. 29501753

216 189 109

$1330613052226 \%$

$1079711 \quad 518$

L40 570 283

$x^{72}+76$ is 55

(5) 33 26

112. वर 28

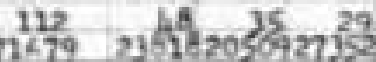

믄

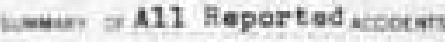
$1=-7$

tx ……

Mareh 1, 1948

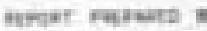

TNDTAKa sTaTE POLTCE 100 5. Sonats Nronia

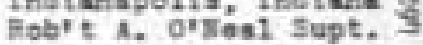
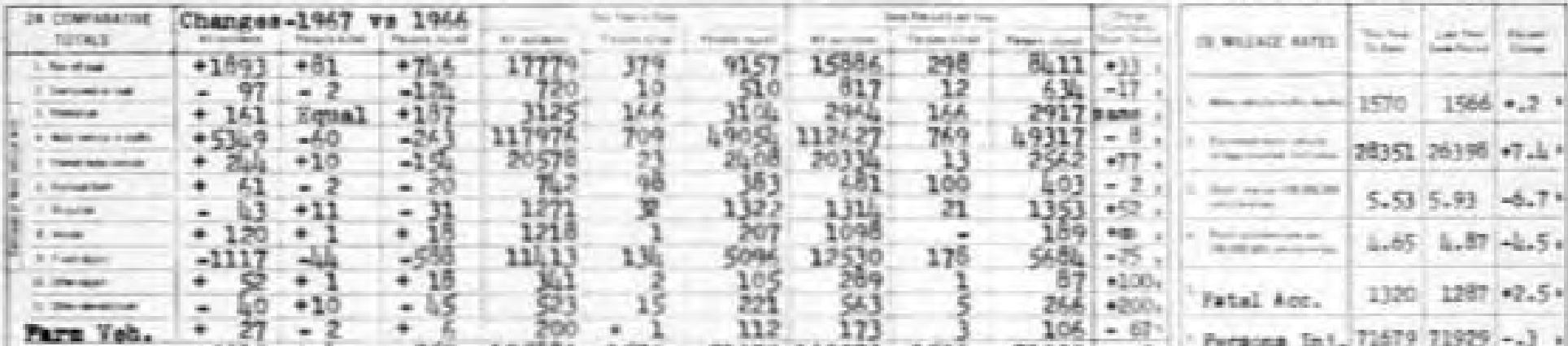

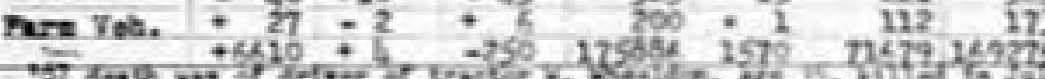

\begin{tabular}{|c|c|c|c|c|c|c|c|c|c|c|c|c|c|}
\hline \multirow{3}{*}{\multicolumn{2}{|c|}{ neoves }} & \multicolumn{6}{|c|}{$x-1=-1=$} & \multicolumn{6}{|c|}{ 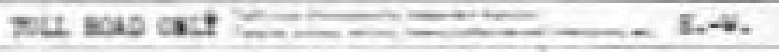 } \\
\hline & & \multirow{2}{*}{\multicolumn{4}{|c|}{ 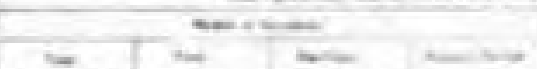 }} & \multicolumn{2}{|c|}{$-\pi$} & \multirow{2}{*}{\multicolumn{4}{|c|}{$-1+3$}} & \\
\hline & & & & & & - & - & & & & & - & - \\
\hline iti & $x=-1$ & 14355 & 59 & 328 & 111日e? & S9. & 919 & & & & & & \\
\hline 谇 & $\cos$ & 1487 & 15 & 4005 & ix. & 90 & sta22 & & & & $=$ & & \\
\hline & ineser & 1007 & है & 396 & यूक & 23 & 802 & & & & & & \\
\hline$f$ & insonom & 33902 & 90 & 7909 & $2 \cos \alpha$ & 10 & 1217 & & & & & & \\
\hline $\mathrm{h}_{1}$ & . nen & 2597 & 25 & 287 & 19212 & $70^{\circ}$ & 5315 & & & & & & \\
\hline & Coster 1000 & $\frac{218}{102}$ & 20 & 472 & 142 & 26. & 293 & & & & & & \\
\hline 神 & $=000-2500$ & $2 x<152$ & 357 & $205 \%$ & 2635 & $3 \%$ & $\frac{1132}{2216}$ & & & & & & \\
\hline & $\cdots$ & & & & 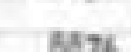 & & & 407 & 15 & ase & 450 & 15 & 47 \\
\hline & 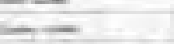 & $\frac{4}{22} 569$ & 251 & 743 & 19155 & วน & $112 \%$ & & & & & & \\
\hline $1=$ & I3 now? & 12096 & $3 \alpha$ & 435 & 730 & 35. & 789 & & & & & & \\
\hline & strespar & sots? & 82 & 27300 & 32329 & 1133 & 2425 & & & & & & \\
\hline
\end{tabular}

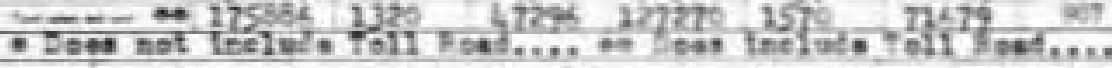

\begin{tabular}{|c|c|c|c|}
\hline \multirow{2}{*}{\multicolumn{2}{|c|}{$2 \pi$}} & \multicolumn{2}{|c|}{-} \\
\hline & & $=$ & \\
\hline & $\because$ & 286 & \\
\hline & $*$ & 364 & \\
\hline & $\because$ & 3524 & \\
\hline & 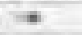 & 2153 & \\
\hline & $\cdots$ & 133 & \\
\hline. & $=$ & 1390 & \\
\hline & $\omega$ & $3 n$ & \\
\hline & 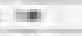 & 7906 & 26 \\
\hline & $\infty$ & 6775 & \\
\hline & $\cdots$ & 575 & \\
\hline & $m$ & 6452 & \\
\hline & $\cdots$ & 9091 & \\
\hline & - & 502 & \\
\hline & 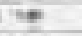 & 585 & \\
\hline - & 10 & $96 \%$ & \\
\hline$=$ & $*$ & 26075 & \\
\hline$=$ & $\ldots$ & 16127 & \\
\hline & $\cdots$ & 13752 & \\
\hline * & $\ldots$ & 958 & \\
\hline & $=$ & 172 & \\
\hline & $\omega$ & 7231 & \\
\hline & $\cdots$ & 670 & \\
\hline & $=0$ & 6331 & \\
\hline n & $\cdots$ & 5706 & \\
\hline & $-\infty$ & & \\
\hline & " & 9836 & \\
\hline
\end{tabular}

\begin{tabular}{|c|c|c|}
\hline \multicolumn{3}{|c|}{$* \quad-$} \\
\hline 16 & $\mathrm{a}$ & 14 \\
\hline ar & z & \\
\hline ins & 2 & 27 \\
\hline 167 & 1 & $2 \mathrm{~B}$ \\
\hline 100 & 2 & 165 \\
\hline at & 2 & 26 \\
\hline 636 & 6 & 6) \\
\hline 160 & 6 & $2 y=$ \\
\hline 215 & $E$ & 1130 \\
\hline 59 & 6 & 77. \\
\hline 93 & 2 & b) \\
\hline 1206 & 3 & $\mathrm{~min}$ \\
\hline 212 & 5 & 26 \\
\hline 201 & 7 & zont \\
\hline 2362 & 7 & $2 \pi$ \\
\hline 23 & 7 & 13 \\
\hline 245 & 9 & 272 \\
\hline 2522 & in & $28 x$ \\
\hline $11 \% 6$ & 21 & 200 \\
\hline 201 & 12 & $m$ \\
\hline 661 & 9 & 7 \\
\hline 52 & 7 & 7 \\
\hline 650 & 6 & 6 \\
\hline 573 & 21 & 5 \\
\hline & & \\
\hline
\end{tabular}
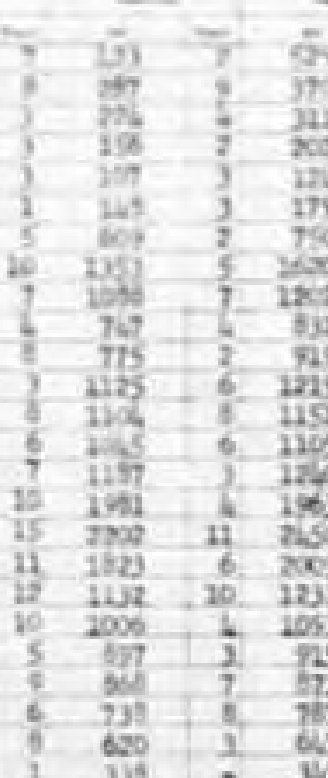

$\frac{5}{37}$

\section{(2)}

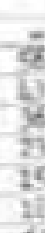

घं

200

175

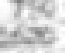

182

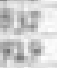

124

$\frac{119}{1205}$

120

(b)

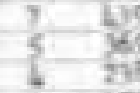

$\begin{array}{ll}3 & 10 \\ 3 & 68\end{array}$

$\frac{125}{106}$

$\begin{array}{ll}7 & 76 \\ 7 & 206\end{array}$

2139

2. 100

? 159

$\begin{array}{ll}9 & 250 \\ 9 & 3129\end{array}$

23. त्र

b. 29.4
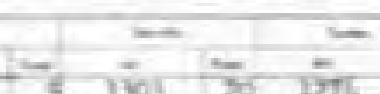

$=-1$ 


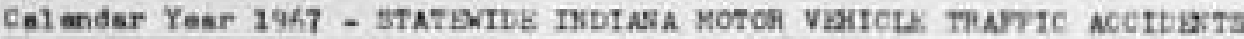

\begin{tabular}{|c|c|c|c|c|c|c|c|c|c|c|c|c|c|c|c|c|c|}
\hline \multirow{2}{*}{ 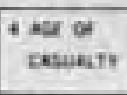 } & \multicolumn{9}{|c|}{ Conetery } & \multicolumn{8}{|c|}{ 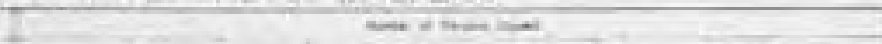 } \\
\hline & & $-\infty$ & & & $=$ & $G$ & & $\therefore$ & & 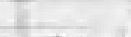 & $-\cdots$ & & + & & & $\cdots$ & \\
\hline$\ldots$ & इक & & 22 & 22 & 15 & 7 & & & - & $2525^{\circ}$ & 1370 & hes & 263 & 156 & & & \\
\hline$\ldots$ & 60 & 39 & 32 & $2 k$ & 20 & 2 & 10 & 8 & 4 & 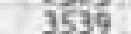 & 19 & 2681 & 719 & और & & $3 \hat{k}=$ & 80 \\
\hline$\infty \cdots$ & 4 & 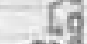 & 24. & 14 & 5 & 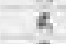 & If & 13 & 1 & 3243 & 1739 isol & the? & 265 & 106 & 572 & 482 & 20 \\
\hline$\because *$ & $\times 92$ & 213 & 73. & 11 & 8 & 3 & 3 & 5 & - & 1462 & 55905072 & 262 & 256 & 226 & 125 & 111 & 17. \\
\hline 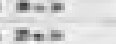 & $\frac{21}{209}$ & $\frac{163}{163}$ & 48 & 10 & 8 & i & 3 & $?$ & $=$ & $\frac{1}{204} 58$ & 5101479 & 102 & 140 & $\frac{38}{53}$ & $1 E$ & $\frac{15}{2}$ & 3 \\
\hline n... & 17 & 126 & కె. & 11 & है & 9 & - & 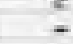 & $=$ & $6 \times 53$ & 4854109 & il & 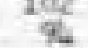 & 47 & $20^{\circ}$ & & \\
\hline$\cdots$ & 124 & 117 & 47 & 1) & 6 & 5 & - & - & $=$ & 7137 & 36253512 & 150 & 90 & 59 & & 2 & \\
\hline w... & 127. & 96 & 31 & 12 & 12 & 3 & - & - & - & 4725 & 23602315 & 150 & 86 & 12 & E & 5 & \\
\hline 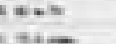 & 117 & 72 & 45 & कै & $\frac{1 .}{3}$ & 7 & $=$ & $=$ & $=$ & 2,93 & 12112257 & 125 & $y$ & 5 & $=$ & $z$ & \\
\hline$=$ & $i$ & 7 & & & 21 & 7 & 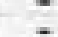 & & . & $2 \times 23$ & 1117.43 & 101 & $\frac{77}{27}$ & $\frac{14}{32}$ & & 5 & \\
\hline$\sim$ & $1570^{\circ}$ & 117 & Bis & 27 & 123 & 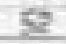 & 32 & 27 & 2 & nofe. & 39 'ilison. & tho: & 2069 & 1262 & $128 \frac{13}{3}$ & 070 & 2313 \\
\hline
\end{tabular}

t J

\begin{tabular}{|c|c|c|c|c|}
\hline 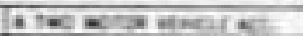 & 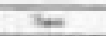 & 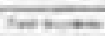 & $=-$ & E- \\
\hline 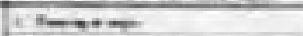 & 31 & 180 & & 21400 \\
\hline 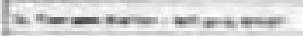 & 2505 & $\mathrm{E}$ & 475 & 2320 \\
\hline un & 7004 & 7 & 1361 & 5635 \\
\hline$-\infty$ & 22785 & E & 4270 & $12 x-92$ \\
\hline$\cdots-\cdots$ & 89 & . & 55 & 3 \\
\hline 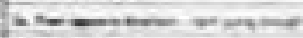 & (17) & 14. & 23 & \\
\hline$-1-\ldots$ & sais & 33 & 1793 & 3757 \\
\hline$\cdots \cdots$ & 667 & is & 57 & 395 \\
\hline$\cdots$ & & 28 & 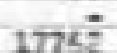 & 787 \\
\hline
\end{tabular}

\begin{tabular}{|c|c|c|c|c|c|c|}
\hline \multirow{2}{*}{2 resivos } & \multirow{2}{*}{$= \pm$} & \multicolumn{3}{|c|}{$6+2$} & \multicolumn{2}{|c|}{-1.} \\
\hline & & $\sqrt{12}$ & 19 & 212 & 150075 & ने \\
\hline 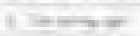 & -5 & 1 & 2 & - & 73 & 11 \\
\hline$+\infty$ & 261 & $i$ & $i$ & 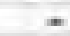 & 260237 & 2 \\
\hline . & 42 & - & - & - & 31 & 5. \\
\hline 1. & 13 & - & - & $=$ & 13 & 1 \\
\hline$\cdots$ & $31 x^{\circ}$ & $x \vec{B}$ & 20 & 25 & 3 & \\
\hline
\end{tabular}

\begin{tabular}{|c|c|c|c|c|}
\hline$x+0=0$ & E & ma & $\ldots+$ & = \\
\hline ratas & 75 & 220 & $22 n$ & 50 \\
\hline $10-1+1$. & $117 C 2$ & 48 & 2679 & \\
\hline$\infty-$ & 20229 & 21 & 192 & 158 \\
\hline$+\infty$ & 23667 & 15 & 6732 & 9572 \\
\hline 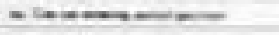 & 357 & $=$ & 20 & 33 \\
\hline 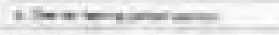 & & 1 & 235 & 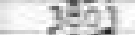 \\
\hline 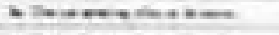 & & 10 & 2,05 & 53 \\
\hline$x \rightarrow+\infty$ & 32 & 1. & 1233 & 725 \\
\hline$\cdots$ & 760 & 2 & 124 & \\
\hline 3 & 78171 & $37 \bar{I}$ & $1: 1=4$ & 70 \\
\hline
\end{tabular}

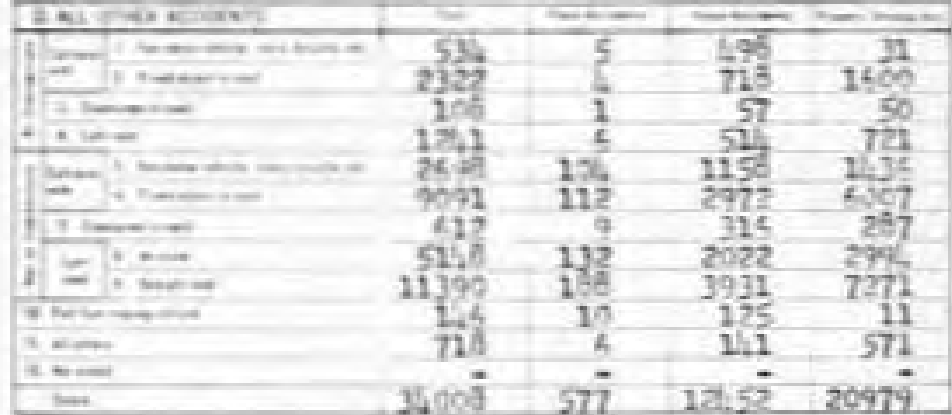

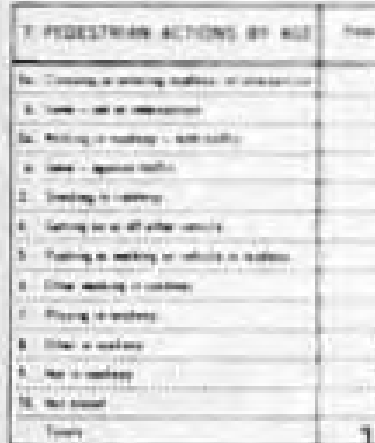

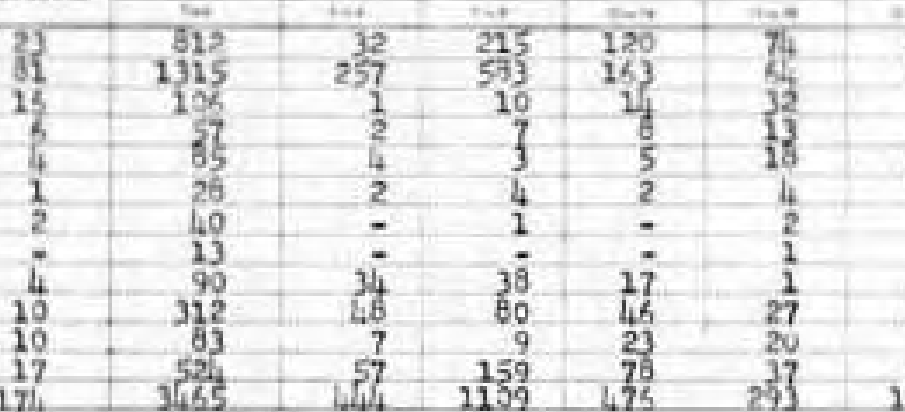

\begin{tabular}{|c|c|c|c|c|}
\hline & & & & \\
\hline 27 & $d_{4}$ & 125 & 125 & 10 \\
\hline 6 & 75 & की & 53 & 17 \\
\hline 8) & i? & 15 & 10 & 4 \\
\hline & a & 9 & 7 & 2 \\
\hline 8 & 25 & 11 & 7 & 2 \\
\hline 5 & 7 & 3 & 1 & - \\
\hline & 24 & 7 & - & $=$ \\
\hline & 8 & 4 & - & - \\
\hline & : & $=$ & $=$ & $=$ \\
\hline & 43 & 32 & 13 & 6 \\
\hline & 10 & 6 & 2 & 2 \\
\hline & 30 & 35 & $\frac{32}{260}$ & 66 \\
\hline
\end{tabular}
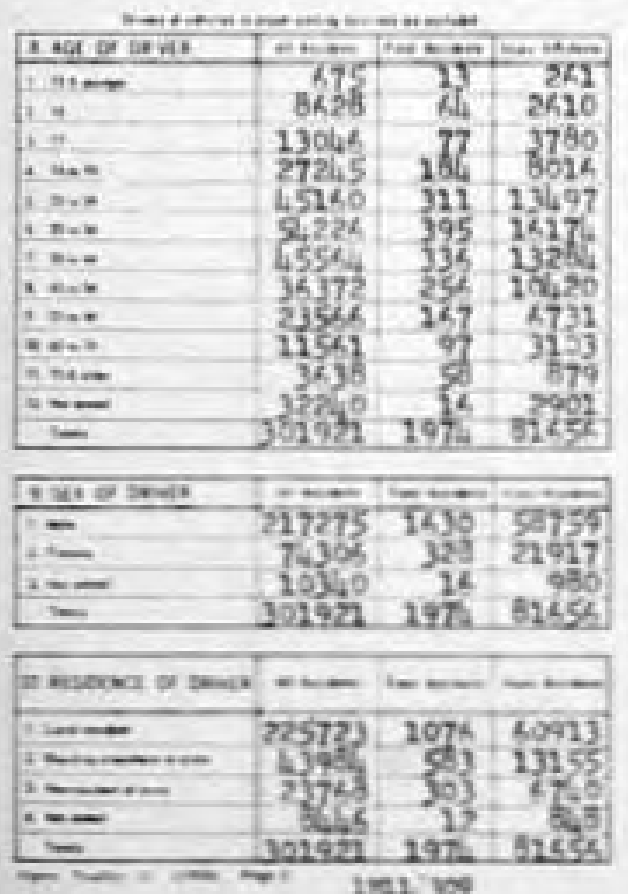
Table 17. (Continued)

\section{STANDARD SUMMARY OF MOTOR VEHICLE TRAFFIC ACCIDENTS}

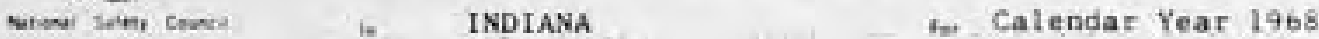

\begin{tabular}{|c|c|c|c|c|c|c|c|c|c|c|}
\hline \multirow{2}{*}{$\begin{array}{l}\text { 1. Trm os } \\
\text { accosent }\end{array}$} & \multicolumn{5}{|c|}{ 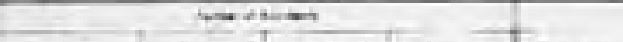 } & \multicolumn{4}{|c|}{ monim } & \multirow{3}{*}{ 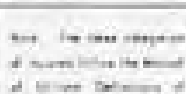 } \\
\hline & $=$ & $=$ & $\ldots$ & $-\infty$ & $t=0$ & & - & & & \\
\hline$\ldots+$ & & & & & & सrol. & & & & \\
\hline 1000 & $1900 ?$ & 325 & 6951 & 11756 & 360 & 9694 & 4622 & 3017 & 2055 & $-2+2$ \\
\hline 1000 & 7212 & If & 380 & 327 & 6 & 191 & 283 & 201 & 107 & 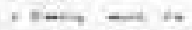 \\
\hline $1=$ & 2943 & 163 & 2760 & - & 186 & 2911 & 1029 & 1258 & 724 & Het. \\
\hline 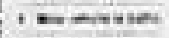 & 120473 & 511 & 30491 & 89471 & 665 & 49726 & 12678 & 13017 & 23931 & $=-\cdots$ \\
\hline $1 \times-2$ & 21705 & 2] & 2012 & 19670 & 25 & 2494 & 1066 & 764 & 652 & $\Rightarrow$ \\
\hline 1.tenest & 722 & $5 h$ & 266 & 108 & 70 & 389 & 205 & 99 & 05 & 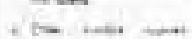 \\
\hline 10 & 1206 & 16 & 1179 & ii & 16 & $12 / 5$ & 392 & 593 & 260 & $-\ldots+\ldots$ \\
\hline$\cdots$ & 3486 & 3 & 155 & 1326 & 3 & 105 & 61 & 69 & 56 & monstens \\
\hline+10 & 22596 & 139. & 1250 & 8607 & 154 & 5799 & 2940 & 1650 & 1179 & $-n-4=$ \\
\hline a 110. & 380 & 1 & $7 \mathrm{~b}$ & 305 & 1. & 102 & 38 & $4 I$ & 23 & 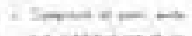 \\
\hline it $m-m$ & 512 & 11 & 180 & 351 & 11 & 220 & 92 & 74 & 47 & $4+1,20=$ \\
\hline Farm Veh, & 102366 & $12 \frac{13}{30}$ & 1.8717 & $\begin{array}{r}164 \\
132392\end{array}$ & $\begin{array}{r}14 \\
1519\end{array}$ & $\begin{array}{r}139 \\
73355\end{array}$ & 23561 & $\begin{array}{r}62 \\
20774\end{array}$ & 29050 & An... \\
\hline
\end{tabular}

nuvas: All Reported sceocm

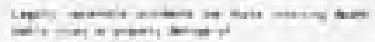

50,00

X $x+\cdots$

Narch 12, 1969

arper movate in

Indiana State Police

100 N. Serlate Ave.

Ind iarapolis, Ind lanab620l. Robert K. Konkle, Supt.

\begin{tabular}{|c|c|c|c|c|c|c|c|c|c|c|}
\hline \multirow{2}{*}{ 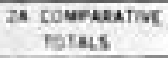 } & \multicolumn{3}{|c|}{$10-1=$} & \multicolumn{3}{|c|}{ 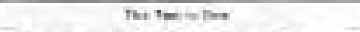 } & \multicolumn{3}{|c|}{$10+10+10+1$} & \multirow{2}{*}{25} \\
\hline & nac- & nembers & nementer & $\ldots$ & newise & romener & $x=-$ & thesilnt & nemend & \\
\hline 1600 & & & & 19062 & 369 & $96 \%$ & 17779 & 379 & 9157 & $\$ 29$. \\
\hline 1000 & & & & 711 & 6. & 491 & 720 & 10 & 510 & -40 \\
\hline 10 & & & & 2843 & 186 & 2911 & 3125 & 166 & $310 \mathrm{~L}$ & +12 \\
\hline$\therefore$ - nona & & & & 120473 & 65 & W9726 & 117976 & 709 & 49054 & -62 \\
\hline$x=-\infty$ & & & & 21705 & 25 & 21,85 & 20578 & 23) & 2405 & +9. \\
\hline and & & & & 722 & 70 & 389 & 742 & 90 & 383 & -29. \\
\hline $100=$ & & & & 120 & 16 & 121.5 & 1271 & 32 & 1322 & -50 \\
\hline 10 & & & & 11,86 & 3 & 135 & 1218 & 1 & 207 & -200 \\
\hline$x=-$ & & & & 12686 & 154 & 5799 & 11413 & 132. & 5086 & -15, \\
\hline$=\infty$ & & & & 360 & 1 & 102 & $2 \mathrm{LI}$ & 2 & 105 & -50 \\
\hline 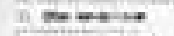 & & & & 562 & 11 & 220 & 523 & 15 & 221 & -27. \\
\hline Fara Veh & & & & $\begin{array}{r}266 \\
16239\end{array}$ & 1519 & 739 & $\begin{array}{r}200 \\
175866\end{array}$ & $\frac{1}{1570}$ & $\frac{112}{1679}$ & $\frac{-1300}{-32}$ \\
\hline
\end{tabular}

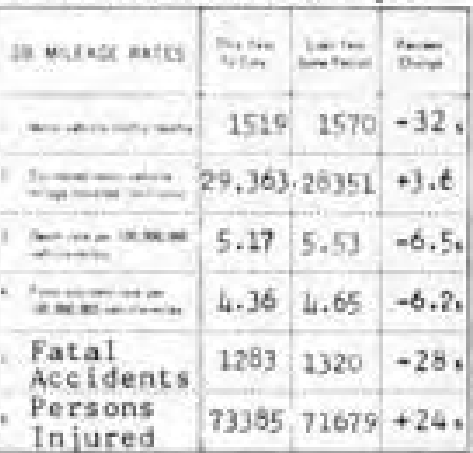

\begin{tabular}{|c|c|c|c|c|c|c|c|c|c|c|c|c|c|}
\hline \multirow{3}{*}{\multicolumn{2}{|c|}{ 3 tocator }} & \multicolumn{6}{|c|}{ 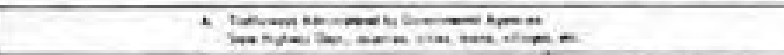 } & \multicolumn{6}{|c|}{ 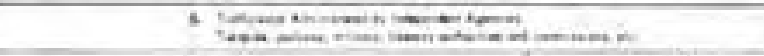 } \\
\hline & & \multicolumn{4}{|c|}{ notsens } & \multicolumn{2}{|c|}{ Southen } & \multicolumn{4}{|c|}{$\rightarrow \infty$} & \multicolumn{2}{|c|}{ - $-1+0}$. \\
\hline & & - & 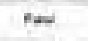 & $\cdots$ & $n-\infty$ & $\omega$ & - & - & w- & $=$ & 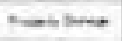 & $\infty$ & - \\
\hline \multirow{9}{*}{ 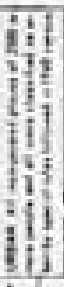 } & $x=0=$ & 24859 & 46 & 3229 & 21614 & 50 & 4655 & & & & & & \\
\hline & $f=00-\pi=$ & 17245 & 50 & 4,254 & 12641 & 60 & $617 \mathrm{~L}$ & & & & & & \\
\hline & $1 \times 0=0$ & 17002 & 40 & 3794 & 13168 & 43 & 5320 & & & & & & \\
\hline & 1 $2=-1=0$ & 11364 & 25 & 2545 & e824. & 25 & 3649 & & & & & 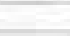 & \\
\hline & $\therefore=-m-n=$ & 35094 & 101 & 8216 & 36677 & 217 & 11610 & & & & & & \\
\hline & $+\operatorname{mon}=-$ & 26.897 & 76 & 6040 & 18371 & 86 & 9186 & & & & & & \\
\hline & Under $1000^{\circ}$ & 2092 & 19 & 46 & 1637 & 21 & 623 & & & & & & \\
\hline & $1000-2500$ & 612 & 24 & 870 & 321,6 & 27 & 1257 & & & & & 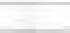 & \\
\hline & {$[\ldots$} & 126746 & 383 & 29692 & 96670 & 1627 & 424.82 & \multirow[b]{2}{*}{1196} & \multirow{3}{*}{16} & & & & \\
\hline$i$ & con-mint & & & & & & & & & \multirow[t]{2}{*}{317.} & 865 & \multirow[t]{2}{*}{22} & 593 \\
\hline ti & $m$ & 2471.7 & 301 & 5257 & 9189 & 356 & 8716 & & & & & & \\
\hline$H^{2}$ & $\infty=$ & 25149 & 24 & 0125 & 16780 & 261 & 12297 & & & & & & \\
\hline 0 & .S. Roads & 12100 & 293 & 4560 & 7569 & 369 & 8005 & & & & & & \\
\hline i) $\mathrm{I}$ & nteratate & 2151 & 46 & 766 & 1319 & 64 & 1792 & & & & & & \\
\hline ti & $\tan -\pi$ & shilikg & 884 & 18706 & 31857 & 1070 & 30310 & & & & & & \\
\hline & 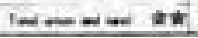 & 182322 & 1283 & 46727 & 132392 & 1519 & 73385 & & & & & & \\
\hline
\end{tabular}

\begin{tabular}{|c|c|c|c|c|c|c|c|c|c|c|c|c|c|c|c|c|c|c|c|}
\hline \multirow{2}{*}{\multicolumn{2}{|c|}{$\operatorname{lin}_{-\infty}$}} & \multicolumn{2}{|l|}{ In } & \multicolumn{2}{|l|}{$\Leftrightarrow$} & \multicolumn{2}{|c|}{10} & \multicolumn{2}{|c|}{ 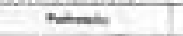 } & \multicolumn{2}{|c|}{ Nens } & \multicolumn{2}{|c|}{$\cdots$} & \multicolumn{2}{|c|}{$=$} & \multicolumn{2}{|l|}{ 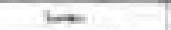 } & \multicolumn{2}{|c|}{$\omega$} \\
\hline & & $=$ & $\therefore$ & H & $\therefore$ & $*$ & $\Leftrightarrow$ & 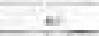 & $+\infty$ & $=$ & $t=$ & * & 10 & + & $=$ & $\approx$ & 10 & $*$ & tor \\
\hline & 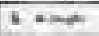 & 2917 & 64 & 289 & 5 & 454 & 9. & Who & 4 & 557 & a & 565 & 7. & $2290^{\circ}$ & 20 & 1314 & 17 & & \\
\hline & A. & 5135 & 60 & 275 & 3 & 376 & 5 & 335 & 7 & 136 & 5 & Whi & 9 & 1250 & 10 & 1164 & 13 & & \\
\hline & 210 & 3703 & 65 & 157 & - & 291 & 5 & 272 & 2 & 365 & 6 & 420 & 7 & 1109 & 25 & 1169 & 20 & & \\
\hline & 330 & 2160 & 16 & 127 & - & 180 & 4 & 163 & 2 & 209 & 7 & 231 & 7 & 61,0 & if & 618 & 12 & & \\
\hline & $\ldots$ & 1511 & 31. & 105 & 3 & 124 & 1 & 138 & 5 & 155 & 4 & 179 & 5 & 390 & 6 & 130 & 7 & & \\
\hline & wis & 1369 & 26 & 125 & 1 & 157 & 2 & 157. & 1 & 165 & 16 & 176 & 5 & 324 & 7 & 275 & 3 & & \\
\hline & $\cdots$ & 3870 & 35. & 529 & 4 & 674 & 6 & 692 & 7 & 592 & 7 & 683 & 2 & 640 & 5 & 262 & is & & \\
\hline & i. 10 & $800 ?$ & 47 & 1257 & 10 & 2612 & 6 & 1594 & 7 & 2362 & 10 & 1375 & 7 & 507 & $L$ & 236 & 3 & & \\
\hline & $\theta *$ & 7135 & 36 & 2074 & 6 & 1326 & 5 & 1268 & 6 & 1092 & 6 & 1210 & 1 & 804 & 6 & 361 & 6 & & \\
\hline & $\cdots$ & 6211 & 31 & 915 & 4 & 970. & 4 & 867 & 3. & 833. & 6 & 894 & 2 & 1094 & 6 & 649 & 6 & & \\
\hline & $=0$ & 7328 & $4 ?$ & 1005 & 3 & 1074 & 5 & 937 & 10 & 912 & 1 & 979 & 8 & 1602 & 7. & BL & 8 & & \\
\hline & ii $\mathrm{ne}$ & 6933 & 36 & 1226 & 5 & 1225 & 3 & 1151 & 4 & $1 L_{4} 2$ & 4 & 1221 & 5 & 1966 & 10 & 1003 & 5 & & \\
\hline & 10 & 9805 & 50 & 1297 & 3 & 1372 & 10 & 1360 & 6 & 1242 & 7. & 1499 & 3 & 1819 & 12 & 1216 & 11. & & \\
\hline & 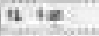 & $90 \%$ & 37 & 1235 & 4 & 1210 & 2 & 1164 & 3. & 1192 & 9 & 1304 & 9 & 1770 & 5. & 1219 & 5 & & \\
\hline & 410 & 20061 & 51. & 1367 & 10 & 1393 & 4 & 1763 & B & 1241 & 5 & 1560 & 6 & 1911 & 13 & 1366 & 5 & & \\
\hline & in 10 & 1455 ? & 72 & 2064 & 9 & 2194 & 11 . & 2131 & 13 & 2109 & 10 & 2682 & 7 & 2133 & 10 & 1639. & 12. & & \\
\hline & $4+5$ & 16265 & 76 & 2676 & 7 & 2,15 & 8 & 2365 & 15 & 238 & 10 & 3024 & 17 & 2116 & 6 & 1509 & 13 & & \\
\hline & it $1=$ & 14284 & 75 & 2073 & 20 & 2051 & 5. & 2019 & 11 & $210 y$ & 7 & 2691 & 9 & 1905 & 13 & 1436 & 7 & & \\
\hline 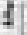 & is. . & 9092 & 69 & 2243 & 8 & 1207 & 6 & 1270 & 10 & 1332 & 6 & 1873 & 21 & 1708 & 12 & 2759 & 6 & & \\
\hline & $n=$ & 8967 & 83. & 1048 & 13. & 1058 & 10 & 1075 & 6 & 1259 & 12 & 1823 & 19 & 1691 & 13 & 1013 & 10 & & \\
\hline & $=$. & 7392 & 59. & 825 & 5 & 865 & 6 & 802 & 12 & $\mathrm{niv}_{3}$ & s & $146 ?$ & 9 & 1420 & 23 & 77 & 9. & & \\
\hline & $n \cdot m$ & 7160 & 49 & 8i. & 7 & 926 & 3 & 850 & 5 & 1070 & है & 1400 & 11 & 1376 & 12 & 708 & j! & & \\
\hline & $n=100$ & 6709 & 6). & 725 & 10. & 759 & 6 & 780 & 7 & 892 & 6 & 1530 & 27 & 1460 & 24. & 564 & 3 & & \\
\hline & and & 6041 & 77 & 589 & 9 & 595 & 4 & 709 & 116. & 716 & 8 & 1475 & 18 & 1535 & 22 & 422 & 2. & & \\
\hline & $=-\ldots$ & 2784 & 2 & 399 & & 396 & & 330 & & 161 & & 479 & & 496 & & 332 & & & \\
\hline & 100 & 182352 & 120.1 & 2) 206 & 1169 & 216576 & 23 & 24302 & 166 & 21,810 & 167 & 30359 & $210^{\circ}$ & 32705 & $276^{\circ}$ & 23554 & 184 & & \\
\hline
\end{tabular}


Calendar Year - 1968 Statenide All Reported Accidents

\begin{tabular}{|c|c|c|c|c|c|c|c|c|c|c|c|c|c|c|c|c|c|c|}
\hline \multirow{2}{*}{$\begin{array}{l}\text { Pate of } \\
\text { caspatt }\end{array}$} & \multicolumn{9}{|c|}{ - } & \multicolumn{9}{|c|}{$-x+m-$} \\
\hline & & lention & & & 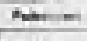 & & & $\Leftrightarrow$ & & & $m-$ & & & & & & & \\
\hline$\ldots t$ & 58 & 32 & 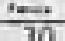 & 30 & 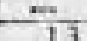 & ii & $t=$ &. & $=$ & $2466^{4}$ & and & 30 et & 353 & 231 & 123 & 10 & 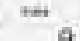 & f \\
\hline$\ldots$ & $65^{\circ}$ & 34 & 31 & 38 & 19 & 19 & 3 & 1 & 2 & 3509 & 2026 & 1483 & 1081 & 684 & 397 & 408 & $334^{\prime}$ & 74 \\
\hline$* \ldots$ & 42. & 29 & 13 & 9 & 6 & 8 & 5 & 3 & 2 & 3166 & 1689 & 1478 & 423 & 239 & 184 & 582 & 496 & 86 \\
\hline$\pi$ & 236. & 172 & 62 & ? & 2 & $i$ & 4 & 2 & 2 & 4367 & 8499 & & $25 ?$ & 161 & 96 & 126 & 112 & 14 \\
\hline$n=1$. & 211 & 167 & & 7 & 6 & 8 & 1 & & - & 1209 & 6519 & $4690^{\circ}$ & 145 & 90 & 55 & 12 & & 3 \\
\hline$m=\infty$ & 231 & 181 & so & 14 & 6 & $?$ & $=$ & : & $=$ & 1550 & 6700 & 4850 & ty & 94 & 45 & 0 & 3 & 3 \\
\hline 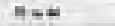 & 170 & 126 & 4.4 & 11 & 9 & 2 & 1 & 1 & 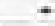 & 8845 & 4691 & 4152 & 142 & 82 & 60 & $?$ & & 3 \\
\hline 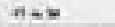 & 155 & 115 & 40 & 14 & 11 & 3 & 1 & 1 & - & 7346 & 3718 & 3628 & 167 & 93 & 54 & 4 & & \\
\hline$n=$ & 137 & 99 & 38 & 16 & 12 & 4 & & - & - & 472 & 2371 & 2350 & 12 & 68 & 52 & 5 & & 1 \\
\hline 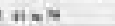 & 109 & 64 & 45 & 20 & 12 & 8 & 1 & 1 & - & 2552 & 1280 & 1272 & 115 & 73 & 42 & & & \\
\hline n..- & 101 & 70 & 31 & 32 & 20 & 12 & $=$ & & - & 1029 & 518 & S11 & 93 & & 35 & & & \\
\hline$\ldots$ & 18 & $20 e^{3}$ & $3^{3}$ & $10^{3}$ & $2^{2}$ & 1 & $\therefore$ & 10 & ? & 7645 & A151 & 1494 & 95 & 57 & 36 & 45 & 41 & 4 \\
\hline $1-$ & 1519 & 1088 & 431 & & 123 & 74 & 16 & 10 & & 73385 & 40464 & 32921 & 3110 & 1930 & 1150 & 1217 & & 196 \\
\hline
\end{tabular}

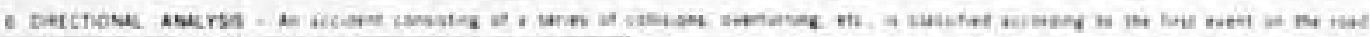

\begin{tabular}{|c|c|c|c|c|}
\hline A two voton wincil acs & 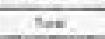 & Fention. & -2 & $n-1=0$ \\
\hline 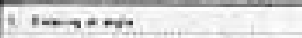 & 32685 & 150 & 9685 & 22852 \\
\hline 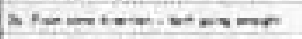 & 3123 & 3 & 563 & 2552 \\
\hline 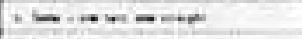 & 7310 & 18 & 1396 & 5696 \\
\hline$\therefore-\infty$ & 16504 & 1 & 4158 & 12345 \\
\hline$.-n=\ldots$ & 679 & - & 58 & 621 \\
\hline 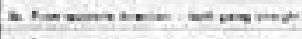 & 592 & 4 & 171 & 417 \\
\hline 1 - & 5726 & 35 & 1923 & 3768 \\
\hline 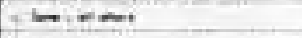 & 442 & - & 41. & 401 \\
\hline$x$ & 67061 & $21 i$ & $17998^{\circ}$ & $48852^{\circ}$ \\
\hline
\end{tabular}

\begin{tabular}{|c|c|c|c|c|c|}
\hline & I two wor vinetr ach. & 70 & 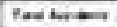 & -ardine & 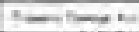 \\
\hline & 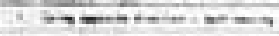 & 7625 & 213 & 2449 & 4963 \\
\hline & ason- -1 & 12679 & 60 & 2635 & 9786 \\
\hline & $t+\infty+\infty$ & 21813 & 23 & 2021 & 19769 \\
\hline & 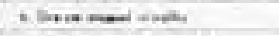 & 13899 & 8 & 4291 & 9600 \\
\hline & 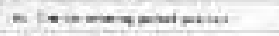 & 338 & - & $3 i$ & 30 \\
\hline & Hon- & 3971 & 2 & 206 & 3763 \\
\hline & 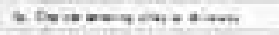 & 5715 & 8 & 1414 & 429 \\
\hline & 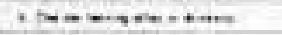 & 8653 & 10 & 1252 & 7391 \\
\hline & $\therefore-$ & 668 & 2 & 88 & 57 \\
\hline
\end{tabular}

\begin{tabular}{|c|c|c|c|c|c|c|}
\hline \multirow{2}{*}{ 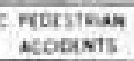 } & \multirow{2}{*}{+5} & \multicolumn{2}{|c|}{ tastate } & \multicolumn{3}{|c|}{ 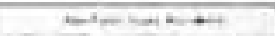 } \\
\hline & & $=$ & 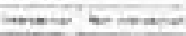 & Fore & $-\ldots$ & $-2+1+x+1$ \\
\hline 16000 & 2596 & 171 & 149 & 2625 & 599 & 1826 \\
\hline$x+a m$ & 79 & 3 & 2 & 76 & 70 & 6 \\
\hline $160+40$ & 208 & 8 & - & 200 & 188 & 12 \\
\hline$+50-19$ & 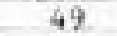 & 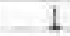 & 1 & 48 & 7 & 41 \\
\hline$\therefore=-$ & 11 & - & . & 11 & 2 & 9 \\
\hline$+\infty$ & 2943 & 183 & 151 & $2760^{\circ}$ & 866 & 1894 \\
\hline
\end{tabular}

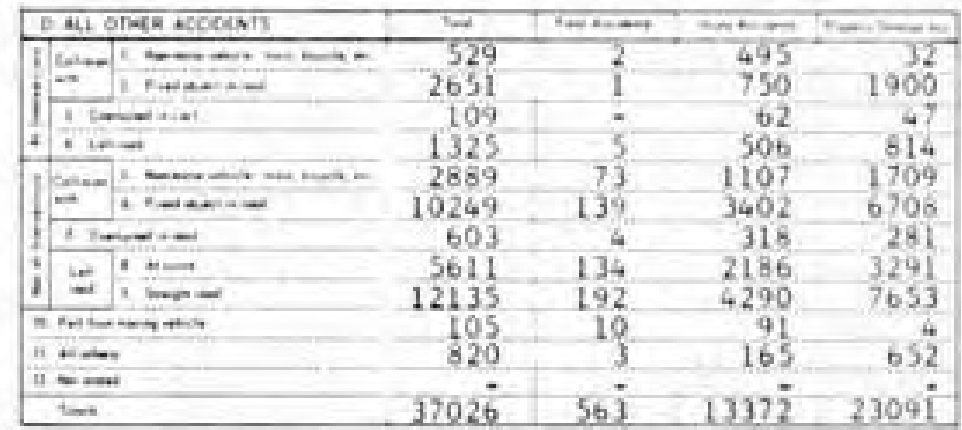

\begin{tabular}{|c|c|c|c|c|c|c|c|c|c|c|c|}
\hline 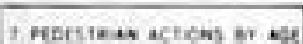 & tan-...... & & & & & 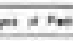 & $\rightarrow \infty$ & & & & \\
\hline & & $\infty$ & 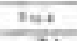 & $m$ & $7+4$ & itan -4 & $n+m$ & $\pi=\pi$ & $+\infty=$ & $4 !=$ & $-\infty$ \\
\hline 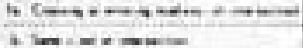 & 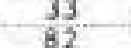 & $\begin{array}{l}724 \\
1286\end{array}$ & $\begin{array}{r}34 \\
209\end{array}$ & 606 & $\begin{array}{l}105 \\
150\end{array}$ & $\begin{array}{c}63 \\
59 \\
59\end{array}$ & 30 & $\begin{array}{l}75 \\
=1\end{array}$ & $9 ?$ & 105 & \\
\hline$x+x+\cdots$ & 23 & 100 & 1 & 6 & 21 & 25 & 4 & 14 & 15 & 11 & $\frac{14}{3}$ \\
\hline -Ln- & 5 & 66 & 5 & 9 & 9 & 15 & 9 & 4 & 7 & ? & $i$ \\
\hline 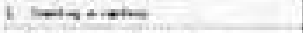 & 8 & 79 & 2 & 4 & 9 & 7 & 11 & 21 & 12 & 9 & 4 \\
\hline 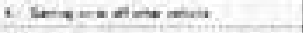 & 1 & 41 & 2 & 6 & 2 & 3 & 6 & 10 & 9 & 2 & \\
\hline 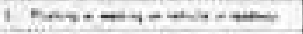 & t & 36 & . & i & 2 & 6 & 7 & 10 & 8 & 1 & $i$ \\
\hline cos.n.t. & & 13 & $\therefore$ & +6 & 2 & 3 & 2 & 3 & 4 & : & $i$ \\
\hline 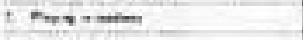 & 3 & 76 & 22 & 37 & 13 & 3 & $i$ & & - & - & \\
\hline 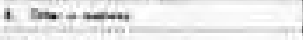 & 21 & 305 & 39 & 90 & 38 & 28 & 20 & 38 & 24 & 22 & \\
\hline$\therefore$ & 17 & 105 & $e^{3}$ & 10 & 20 & 18 & 9 & 19 & 1] & 9 & 2 \\
\hline 5 & $1 \frac{1}{97}$ & $\begin{array}{r}476 \\
3307\end{array}$ & 397 & $\begin{array}{l}148 \\
119\end{array}$ & $\begin{array}{r}63 \\
432\end{array}$ & 267 & ${ }_{137}^{13}$ & 306 & 293 & 258 & $\frac{61}{100}$ \\
\hline
\end{tabular}

\begin{tabular}{|c|c|c|c|}
\hline D Ast of exve & $=\ldots$ & $x=-\infty$. & $-m$ nint \\
\hline $8+100$ & 640 & 8 & 205 \\
\hline 19 & 9104 & 41 & 2595 \\
\hline 3.1 & 13536 & 61 & 3919 \\
\hline - $\|=\|$ & 27781 & 179 & 7991 \\
\hline 1. $n=n$ & 48882 & 319 & 14299 \\
\hline ( $n \rightarrow x$ & 57135 & 424 & 17041 \\
\hline P. Hax & 45024 & 299. & 13278 \\
\hline 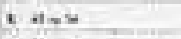 & 36950 & 266 & 10687 \\
\hline in $n=0$ & 24205 & 164 & 6775 \\
\hline$\ldots+\infty$ & 11667 & 97 & 3169 \\
\hline n me. & 3791 & 58 & 956 \\
\hline$u=\ldots$ & 32292 & 26 & \\
\hline 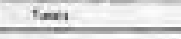 & & 942 & 3750 \\
\hline Y yx of donts & 20 & $1=-\infty$ & $-1+5$ \\
\hline$\cdots$ & 222555 & 1618 & 59852 \\
\hline $1 \cdots$ & 27416 & 301 & 22900 \\
\hline $1-\infty$ & 11038 & 23 & 998 \\
\hline
\end{tabular}

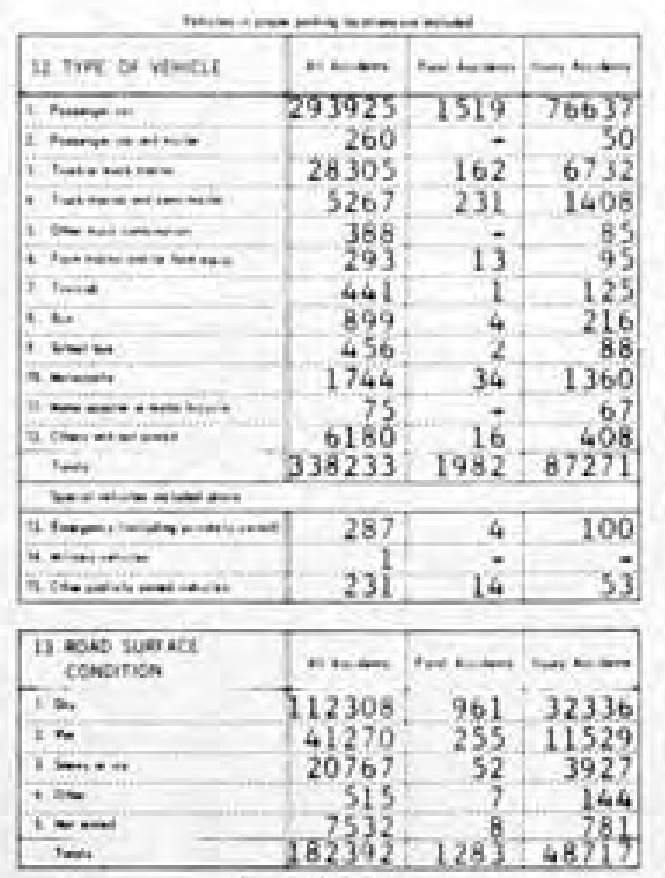

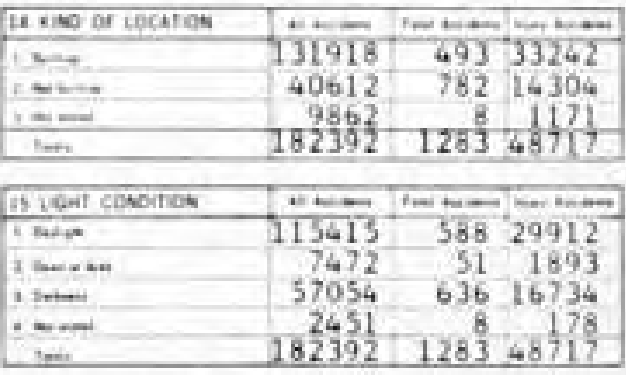

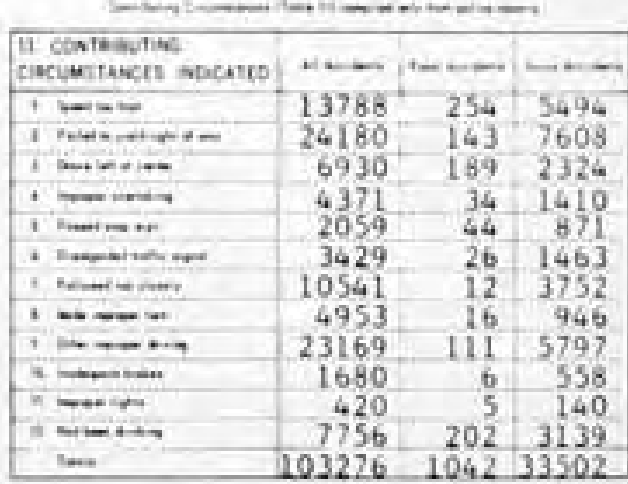


Does not include late reports.

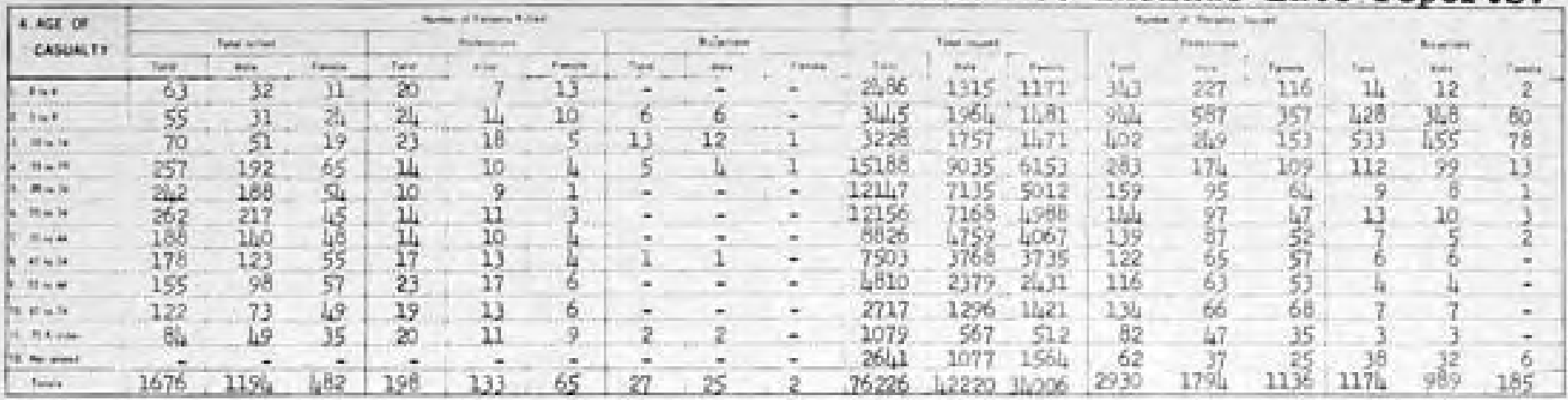

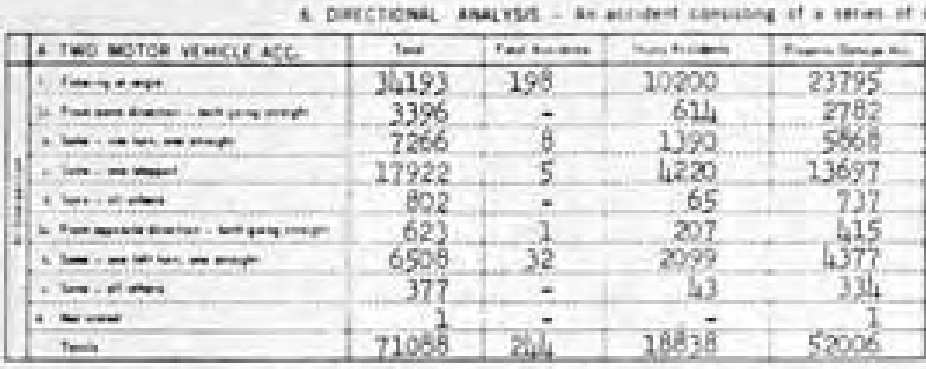

\begin{tabular}{|c|c|c|c|c|}
\hline 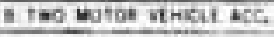 & $=$ & fortants & -2.2 & $N+4 \rightarrow n$ \\
\hline 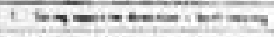 & 7692 & 202 & $2 h 03$ & \\
\hline $14-\infty \cdots$ & 13789 & 60 & 3161. & 10569 \\
\hline$x+\infty$ & 22709 & 28 & 2000 & 20611 \\
\hline$\therefore+\cdots$ & 14533 & 20 & 4154 & $10) 59$ \\
\hline 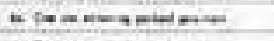 & 379 & & 20 & 359 \\
\hline$\therefore \Delta-1-9$ mating & 4297 & & 226 & 6081 \\
\hline 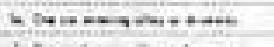 & 639 & 3 & 1554 & 4.930 \\
\hline $6 \infty-1,-10$. & 9537 & 7 & 1357 & 5173 \\
\hline$\therefore$ & 596 & 4 & 67 & 505 \\
\hline 10 & & 351 & $15022^{\circ}$ & $\frac{1}{6}$ \\
\hline
\end{tabular}

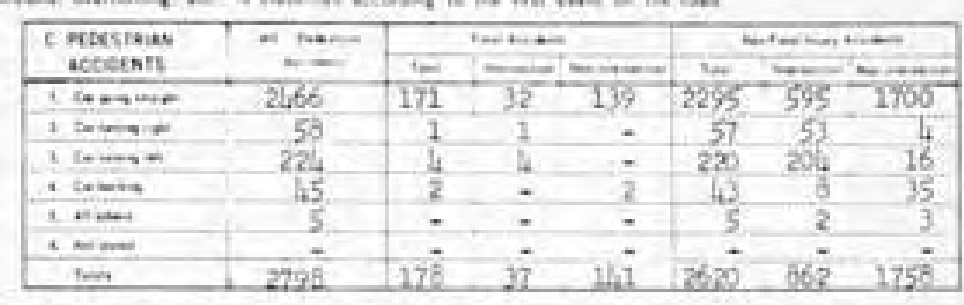

\begin{tabular}{|c|c|c|c|c|}
\hline 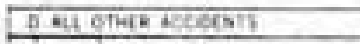 & $\Rightarrow$ & Bas & $x=$ & \\
\hline 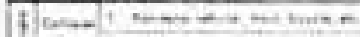 & 517 & 6 & 464 & \\
\hline$-1+6+\ldots-1+$ & 3001 & - & $657^{\circ}$ & \\
\hline 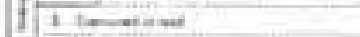 & 127 & ? & 66 & 57 \\
\hline a. & 1647 & 2 & 614 & \\
\hline$t=1 \rightarrow \cdots+\cdots$ & 2366 & 105 & 1127 & 113 \\
\hline $5 \ldots+\cdots$ & $1222 \mathrm{t}$ & 159 & 2997 & 8072 \\
\hline 1.120 & 84 & 7 & 270 & 268 \\
\hline$i=\cdots$ & 5722 & 152 & 203 & $336 ?$ \\
\hline$\frac{\partial-1 .+\infty}{2}$ & 12612 & 296 & 1.260 & \\
\hline 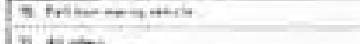 & 112 & 8 & 96 & 5 \\
\hline$n=-$ & 1561 & 2 & 285 & \\
\hline- & $544^{\circ}$ & $200^{\circ}$ & Whoi & $256: 13$ \\
\hline
\end{tabular}

\begin{tabular}{|c|c|c|c|c|c|c|c|c|c|c|c|}
\hline 7. metsthar actions at at & twa- & & & & & $=x+5$ & $\theta+4$ & & & & \\
\hline-2 & & ${ }^{200}$ & $\ldots$ & snt & 700 & ${ }_{63}$ & Fis & & $3 x$ & $=15$ & $=2$ \\
\hline 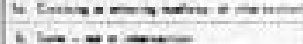 & 37 & 726 & 25 & 203 & 372 & 77 & 250 & 66 & 50 & 216 & \\
\hline$\therefore=1-$ & 77 & $\begin{array}{l}1105 \\
87\end{array}$ & 211 & +42 & 21 & 34 & 7 & 13 & $3 \%$ & $\frac{48}{5}$ & 3 \\
\hline C- - n. & $\frac{7}{6}$ & 50 & . & 7 & 7 & 12 & L & 5 & 6 & B. & 1 \\
\hline $1 \omega \cdots$ & 6 & 62 & 1 & 4 & 1 & a & 12 & 22 & 11 & 3 & - \\
\hline $15+. .00-4$ & 2 & 34 & 5 & 4 & 2 & 5 & 5 & 6 & 3 & 4 & $=$ \\
\hline $1 \sin x-10 \cos x$ & 5 & $y a$ & • & 1 & 2 & 3 & 7 & 8 & 7. & 2 & \\
\hline . osent. & - & 19 & a & - & - & 1 & 2 & 7 & 7 & - & 2 \\
\hline 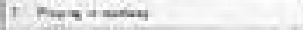 & 1 & 49 & 15 & 25 & 5 & 3 & - & 1 & 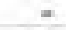 & & - \\
\hline $1 \infty \ldots$ & is & $0 ?$ & 33 & 100 & 39 & 26 & 17 & 42 & 30 & 16 & 4 \\
\hline$\cdots+$ & 13 & 70 & 2 & 11 & 14 & 9 & 11 & 12 & 10 & 8 & 1 \\
\hline$+\infty$ & $\frac{22}{199}$ & $\begin{aligned} 5 \mathrm{~B} 2 \\
3156 \\
315\end{aligned}$ & $\frac{70}{253}$ & $\frac{165}{665}$ & 66 & 62 & 135 & 54 & 48 & $\frac{45}{255}$ & 42 \\
\hline$=-\infty$ & 1959 & 3136 & 163 & 968 & 425. & 297 & 159 & 247 & 270 & & \\
\hline
\end{tabular}
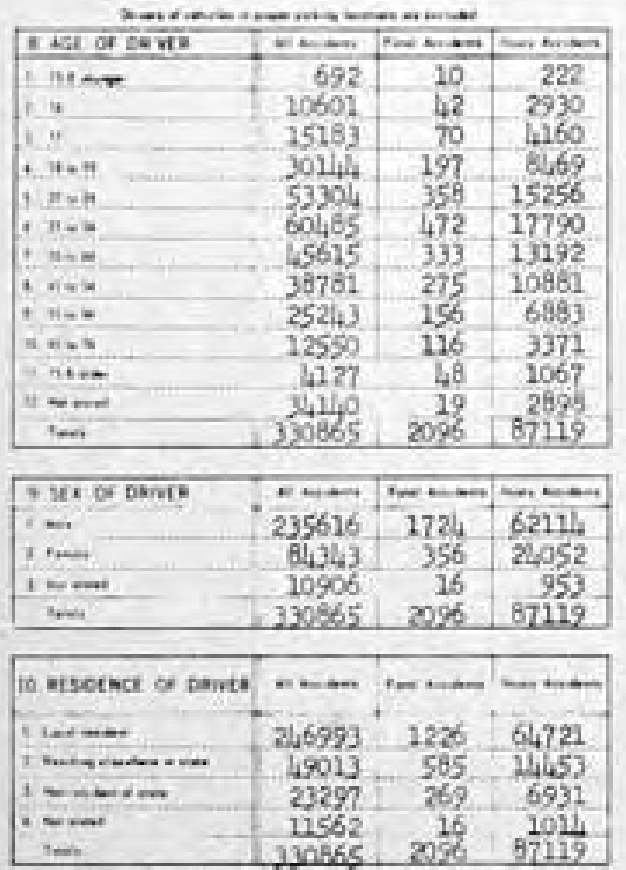
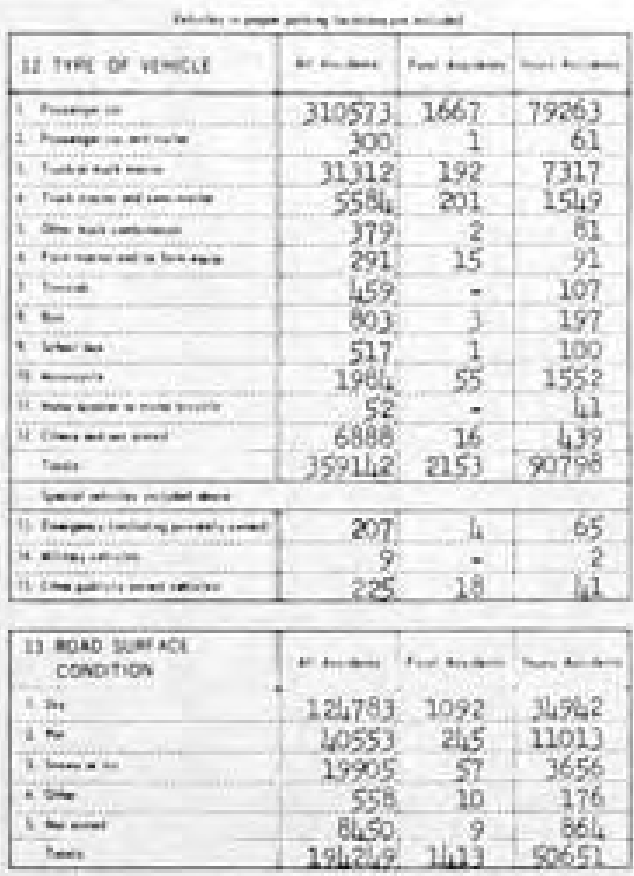
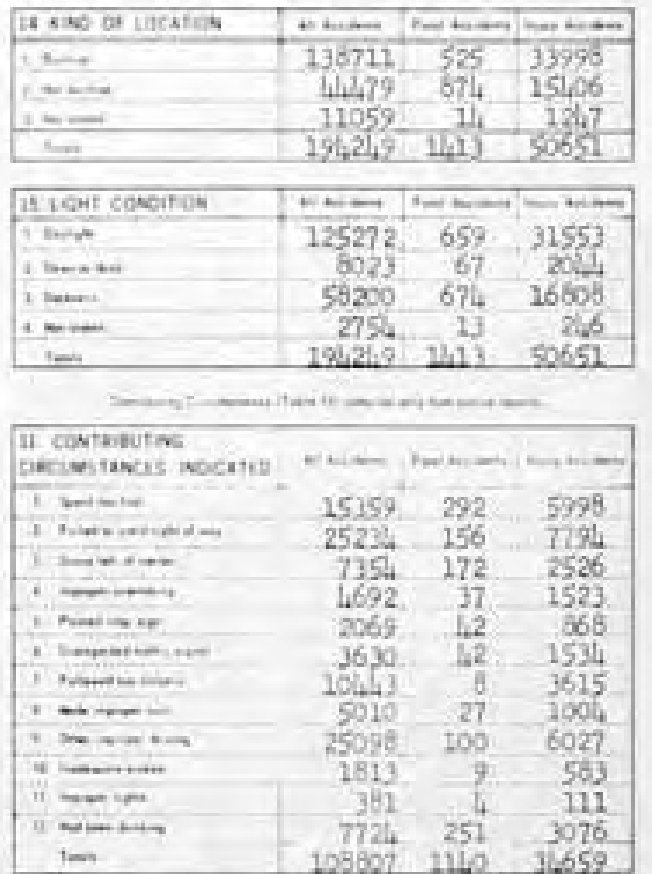
Table 17. (Continued)

\section{STANDARD SUMMARY OF MOTOR VEHICLE TRAFFIC ACCIDENTS}

tereen Saten Cenese Cheat:

INITIA

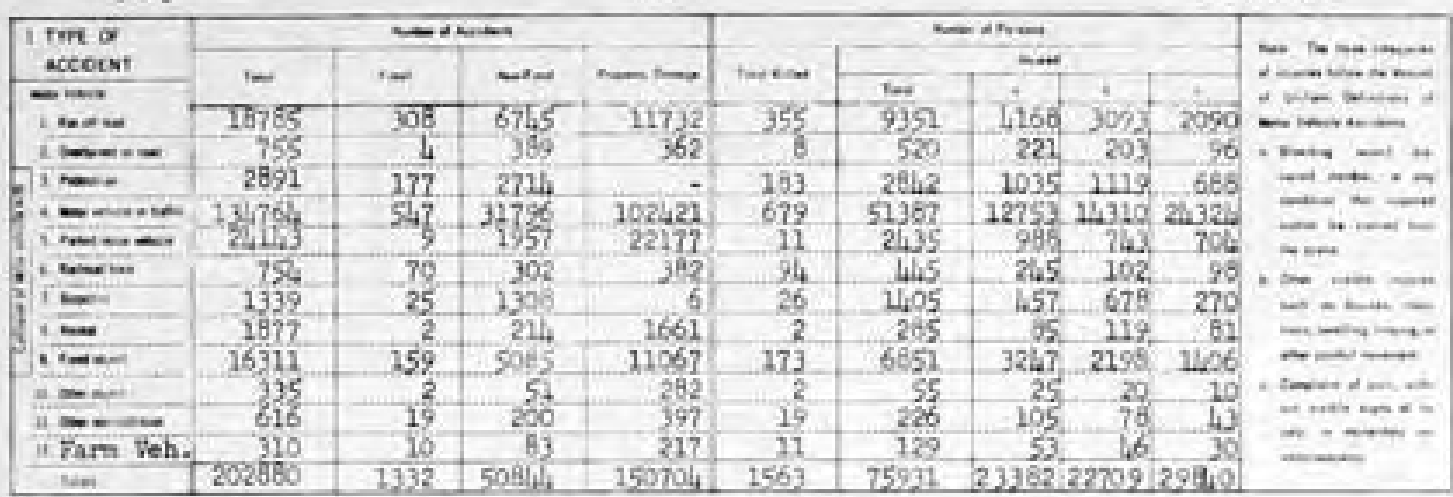

Calendar Year - 1970 Inelades a11 lates,
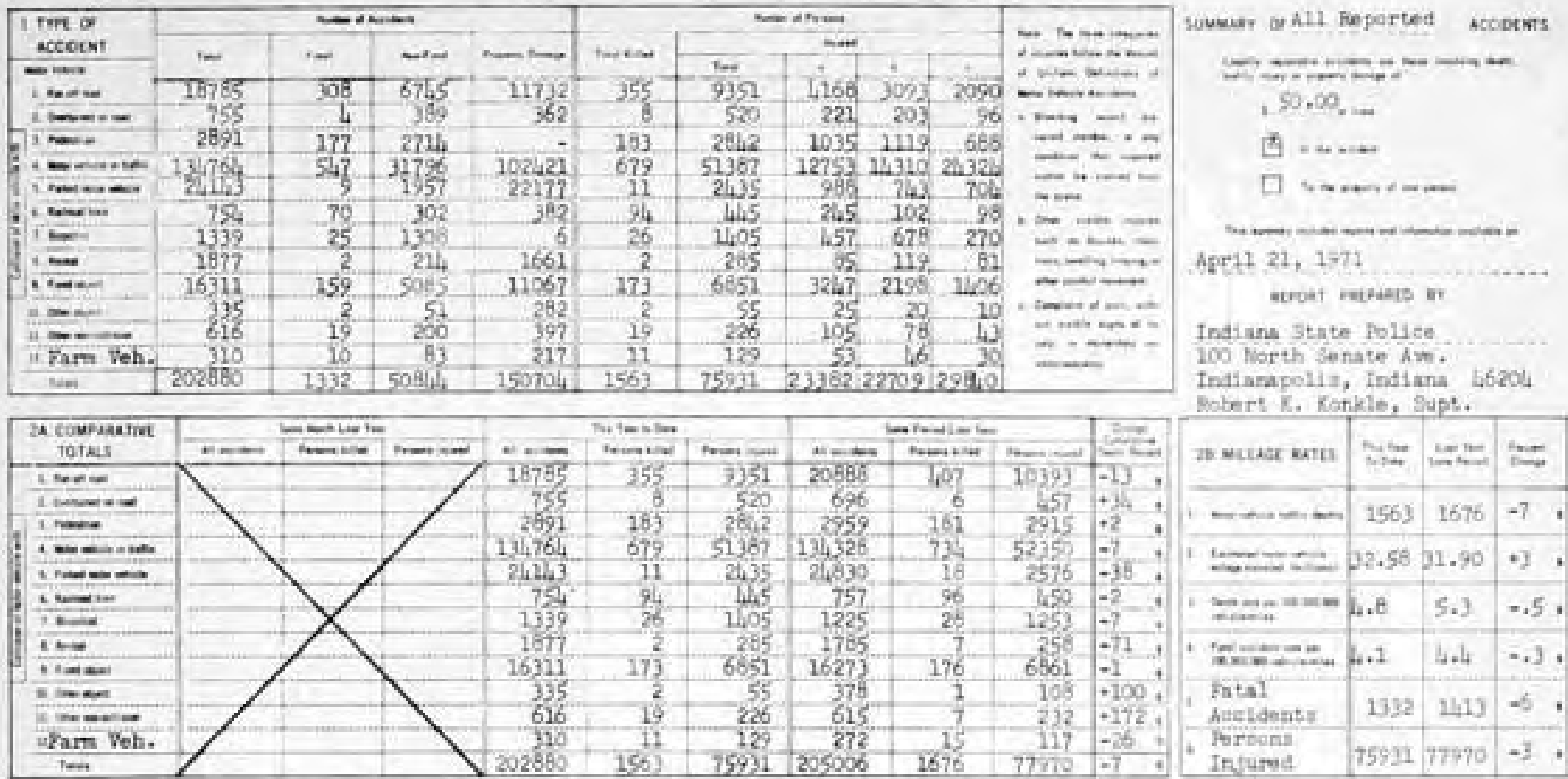

Inturve

\begin{tabular}{|c|c|c|c|c|c|c|c|c|c|c|c|c|c|}
\hline \multirow{3}{*}{\multicolumn{2}{|c|}{1 Loestes }} & \multicolumn{6}{|c|}{ 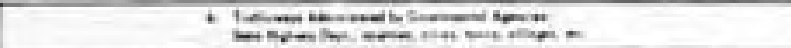 } & \multicolumn{6}{|c|}{ 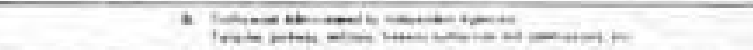 } \\
\hline & & \multicolumn{4}{|c|}{ wothe } & \multicolumn{2}{|c|}{ 2utrom } & \multicolumn{4}{|c|}{ ndmb } & \multicolumn{2}{|c|}{ 4iston } \\
\hline & & ton & Pan & $a=$ & Nonthen & 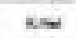 & $\omega$ & $1=$ & + & $\omega=$ & $n=-1=$ & sile & $\rightarrow$ \\
\hline \multirow{9}{*}{ 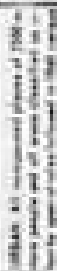 } & i 100000 & 17777 & 57 & 3645 & 14075 & 67 & 5105 & & & & & 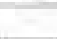 & \\
\hline & $i=0 . \mathrm{nm}$ & 19401 & 46 & 4232 & 15223 & 51. & 6045 & & & & & & \\
\hline & $i x n=n$ & $126 \%$ & 40 & 3970 & 14680 & 4 & 5575 & & & & & & \\
\hline & 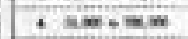 & 12745 & 30 & 2641 & 10074 & 32 & 3750 & & & & & & \\
\hline & $10 \mathrm{an}-\pi \mathrm{s}$ & 37333 & 214 & 8,210 & 29014 & 126 & 11058 & & & & & & \\
\hline & inn $n=$ & 27345 & 63 & 6520 & 20762 & 65 & 9022 & & & & & & \\
\hline & Inder 1000 & 2676 & 19 & $\$ 36$ & 2123 & 22 & B) & & & & & & \\
\hline & $1000-2900$ & 4685 & 36 & 917 & 3734 & 36 & 1329 & & & & & & \\
\hline & +2 & 1,0659 & 203 & 30671 & 109585 & 340 & 236.1 & & & & & & \\
\hline \multirow{7}{*}{ 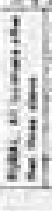 } & conmenter & & & & & & & 1276 & 9 & 323 & $99 \%$ & 11 & 610 \\
\hline & nom & 26306 & 311 & 5562 & $20 \times 33$ & 360 & 9231 & & & & & & \\
\hline & $c=$ & $206 x$ & 278 & 0735 & 19643 & 228 & 13055 & & & - & & & \\
\hline & U.S. Ploutes & $126 \%$ & 272 & $\sqrt{26}$ & 7932 & 346 & 7625 & & & & & & \\
\hline & Interatace & 3313 & 56 & 1722 & 3232 & 65 & 1779 & & & & & & \\
\hline & terse & 602,5 & 920 & 19545 & 40160 & 1112 & 31660 & & & & & & \\
\hline & letwenteds & 702850 & 1332 & 50064. & 150704 & 1563 & 75921 & & & & & & \\
\hline
\end{tabular}

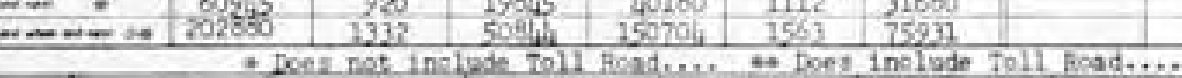

\begin{tabular}{|c|c|c|c|c|c|c|c|c|c|c|c|c|c|c|c|c|c|c|c|c|}
\hline \multirow{2}{*}{\multicolumn{3}{|c|}{$\begin{array}{l}3 \text { rat } \\
\end{array}$}} & \multicolumn{2}{|l|}{10} & \multicolumn{2}{|c|}{$\rightarrow$} & \multicolumn{2}{|c|}{$1-$} & \multicolumn{2}{|c|}{+} & \multicolumn{2}{|c|}{ Nouts } & \multicolumn{2}{|c|}{$\Leftrightarrow$} & \multicolumn{2}{|c|}{ innt } & \multicolumn{2}{|l|}{$\omega$} & \multicolumn{2}{|c|}{$n+\infty$} \\
\hline & & & 노 & $1=$ & $=$ & $t=$ & $=$ & $t=$ & *. & $\Leftrightarrow$ & $=$ & $\theta$ & $=$ & $\omega$ & $*$ & $t=$ & $=$ & $=$ & $*$ & $1=$ \\
\hline \multirow{12}{*}{ I } & 2 & 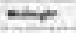 & 5286 & 59. & 329 & 3. & $49 \mathrm{~s}$ & L & 485 & 5 & 662 & 10 & $72 A$ & 6. & 1321 & 17 & 1274 & 14 & & \\
\hline & 4 & $1=$ & $4 \$ 02$ & 54 & 225 & 1. & 372 & 4 & $4 \mathrm{QD} 3$. & ]. & 539 & 9. & 511 & 6. & 1176 & 1日 & 1866 & 13 & & \\
\hline & 1. & $y$ & 3.67 & 72 & 177 & 3. & 313 & 5 & 318 & 7. & 423 & E) & h17. & 10 & 1135 & 16 & 1084 & 19 & & \\
\hline & 1 & in & 2709 & 54 & 123 & 2 & 214 & 5 & 209 & z & 292 & 5 & 302 & 7 & 750 & 18 & 811 & 14 & & \\
\hline &. & $\cdots$ & $1750^{\circ}$ & 37 & 89 & - & $150^{\circ}$ & 2 & $y_{11}$ & 2 & $19 \%$ & th. & 233 & 4. & $57 y$ & 10 & 272 & 10 & & \\
\hline & 1 & sa & 1540 & 21 & 194 & 1 & 161 & 4 & 157 & 1 & 202 & है. & 242 & 3 & 301 & 6 & 303 & 3 & & \\
\hline & - & $a x$ & 3597 & 35 & 680 & 3 & 688 & g & 539 & 5 & 673 & 6 & 670 & 4. & 306 & 6 & 263 & 3 & & \\
\hline & 2 & $r=$ & 2.76 & 36 & 1724 & 6 & 1606 & 6 & 1396 & 6 & 14,07 & 4. & 1552 & 4. & 535 & 4. & 296 & 4 & & \\
\hline & 4 & 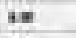 & 7720 & 32 & 1462 & 9 & 1426 & 7 & 1175 & 5 & 139) & 1 & 1276 & 6 & 703 & 4. & 375 & 4 & & \\
\hline & 1 & $*$ & 6568. & 38 & 1023 & 4. & 763 & 1 & d35 & 4 & 938 & 7 & 1068 & 7 & 1045 & 2) & 696 & 2 & & \\
\hline & $=7$ & $n x$ & 7200 & 31 & 1302 & 5. & 1067 & 4 & 929 & 7 & 1094 & 2 & 1224 & 3. & 1617 & 3 & 707 & 7 & & \\
\hline & in. & $11=$ & 10.18. & 28. & 1594. & 11 & 1352 & 2 & 2348 & ? & 1415 & 5 & 3657 & 11. & 2095 & 5 & 957. & 2 & & \\
\hline & us & - & 11296 & 64. & 1690 & 74 & 1480 & 6 & 1452 & 11. & 2459 & c. & 1915 & 11 & 2021 & 8 & 1168 & 6 & & \\
\hline & $\mathbf{n}$ & 30 & 10997 & 61. & 1699 & $i$ & 4428 & 5 & 1291 & 6. & 445 & 8 & 1792 & 13. & 2034 & 13 & 1271 & 9 & & \\
\hline & 4 & 30 & 11525. & 62. & 1735 & 7 & 1409 & 5. & 1416 & 8 & 1634 & 7 & 1673 & 11. & 2108 & 13 & 1349 & 10 & & \\
\hline & a & $t \approx$ & 16505 & 66. & 2690 & 15 & 2386 & 8. & 2369 & 6. & 2640 & 7 & 2952. & 13. & 2873 & 10 & 1461 & 7 & & \\
\hline 1 & 4 & $1=$ & 17658 & 70. & 2828 & 27 & 2527 & 22 & 2576 & L & 2701 & ?. & 3224 & 7. & 2231 & 16 & 1581 & 5 & & \\
\hline J & it: & 10 & 25269 & 72. & 2516 & 9 & 2055 & 13 & 2093. & 7. & 2292 & 15. & 2934 & 13. & 1945 & 7 & 1.74. & 5 & & \\
\hline \multirow{8}{*}{8} & $n$ & $\Leftrightarrow$ & 109hil. & 72 & 1484 & b. & 1310 & 12 & 1427 & 7 & 372 & 12. & 2000 & 16. & $186 \%$ & 7 & 1309 & 2 & & \\
\hline & 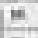 & $t=$ & 9950 & 78 & 1285 & 7 & 1140 & 11 & 1224 & 4. & 175 & 12 & 1979 & 22 & 1512 & 15 & 1153 & 7 & & \\
\hline & $n$ & is & 6190 & 86 & 1000 & 12 & 926 & 3 & 973 & 17 & 2143 & 13 & 1565 & 16 . & 1572 & 11 & 932 & 23 & & \\
\hline & n. & $n=$ & 7703 & 66 & 953 & 23 & $69 y$ & 6. & 967 & 2 & 1006 & It. & 1520 & 12 & 1,67 & 10 & 607. & 3 & & \\
\hline & $n$ & $6=$ & 7343 & 63 & 779 & d. & 8) & 5 & 991 & 4 & 1039 & $?$ & 1564 & 24 & 1560 & 9 & 679 & 4 & & \\
\hline & D: & $n=$ & 6972 & 67 & 302 & 17 & 689 & 5. & 251 & 4 & $90 \%$ & 8 & 769 & 13 & 1736 & 21. & 492 & 4 & & \\
\hline & 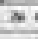 & $-\cdots$ & 3862 & 3 & 521 & $\ddot{2}$ & 85 & $\therefore$ & 453 & $\Rightarrow$ & 554 & $=$ & -735 & - & 651 & 2 & 4,0 & 3 & & \\
\hline & & tont: & 202880 & 335 & 23665 & 278 & 26.255 & 147 & 25046 & 131. & 28322 & 205 & 35686 & 1. & 24.667 & 265. & 20609 & Dits & & \\
\hline
\end{tabular}


Standard Swanary of Motor Vehicle Traffic dooidents - Calendar Year 1970 Inelubsa all late roports.

\begin{tabular}{|c|c|c|c|c|c|c|c|c|c|c|c|c|c|c|c|c|c|c|}
\hline \multirow{3}{*}{$\begin{array}{l}\text { act or } \\
\text { casuat th }\end{array}$} & \multicolumn{9}{|c|}{ 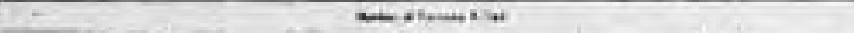 } & \multicolumn{9}{|c|}{ 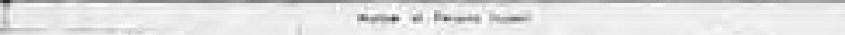 } \\
\hline & \multicolumn{3}{|c|}{$-\infty$} & \multicolumn{3}{|c|}{ nom $=$} & \multicolumn{3}{|c|}{ min- } & \multicolumn{3}{|c|}{$1=+$} & \multicolumn{3}{|c|}{ mons } & \multicolumn{3}{|c|}{ sivin } \\
\hline & 50 & - & . & to & - & $+\infty$ & tom & $\omega$ & $=$ & $m$ & $\infty$ & $\rightarrow$ & to & - & $\pi$ & tow & 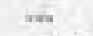 & - \\
\hline$\ldots$ & 47 & 26 & 21 & 20 & 14 & 6 & - & - & - & 2507 & 134.1 & 1166 & 350 & 227 & 131 & 15 & 12 & 3 \\
\hline$t a t$ & 61 & 37 & 24 & 33 & 19 & 14 & 7 & 5 & 2. & 3554 & 2010 & 15.4 & 933 & 584 & 349 & 645 & 360 & 06 \\
\hline tan & 56 & 35 & 21 & 11 & 9 & 2 & 12 & 7 & 5 & 3474 & 1906 & 1566 & 412 & $250^{\circ}$ & 152 & 626 & 496 & 130 \\
\hline$n \rightarrow$ & 277 & 209 & 68 & 16 & 11 & 5 & 6 & 6 & - & 14936 & 8622 & 63 & 360 & 201 & 139 & 143 & 218 & 25 \\
\hline$\Rightarrow \infty$ & 211 & 166 & 45 & 10 & 6 & 4 & - & - & - & 12352 & 7152 & 52. & 151 & 96 & 55 & 28 & 25 & 2 \\
\hline$n=0$ & 225 & 179 & $4 ?$ & 11 & 9 & 2 & - & - & - & 12011 & 6931 & 300 & 150 & 96 & 62 & ह8 & 7. & $i$ \\
\hline$n=\infty$ & 160 & III & 46 & 12 & 9 & 3 & - & - & - & Bl4.4 & 4543 & 3901 & 123 & 55 & 56 & 5 & 3 & 2 \\
\hline$n \infty$ & 150 & 95 & 52 & 12 & ge & 4 & 1 & 1 & - & 735 & 3700 & 36,8 & 149 & 95 & 54 & 8 & 7. & 2 \\
\hline$=0$ & 157 & 102 & 55 & 19 & 15 & 3 & - & - & - & 40,5 & 2640 & 24,68 & 114 & 82 & 52 & 5 & 5 & - \\
\hline$n n x v$ & 116 & 62 & 54. & 20 & 山 & 6 & - & - & - & 2612 & 1215 & 1397 & 112 & 59 & 53. & 6 & 6 & - \\
\hline now & 97 & 58 & 39. & 29 & 23 & 5 & - & - & - & 1122 & 576 & 5,6 & 73 & 42 & 32 & j & 3 & - \\
\hline$-\infty$ & & 3 & 3 & 1 & 1 & 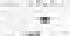 & $=$ & $=$ & $=$ & 2503 & 1112 & 1671 & Bs & 62 & & 53 & 50 & \\
\hline 6 & 1563 & 1068 & 475 & 193 & 139 & S4 & 26 & 19. & 7 & 75931 & $4159 \mathrm{E}$ & 34331 & 3029 & 1868 & 1161 & 1365 & 1092. & 255 \\
\hline
\end{tabular}

\begin{tabular}{|c|c|c|c|c|}
\hline A TwO Woton vtencLL ACE & $m$ & tont. & sintist & nesisis \\
\hline $10 \mathrm{sen}$ & 35135 & 193 & 10159 & 24253 \\
\hline 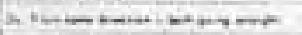 & 3519 & 3 & 54 & 72 \\
\hline 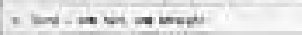 & 8110 & 16 & 1. & $6610^{\circ}$ \\
\hline $1 .-\infty$ & 19506 & 6 & 4195 & 15307 \\
\hline$x-\infty$ & 845 & - & 55 & 790 \\
\hline 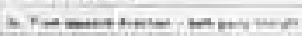 & 661 & 1 & 197 & 63 \\
\hline 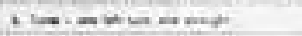 & 6552 & 10 & 2050 & 6,42 \\
\hline 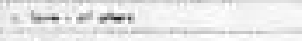 & 343 & - & 4 & 292 \\
\hline$\therefore-\infty$ & & 7 & & \\
\hline 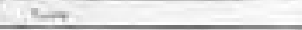 & $7 \mathrm{~h} .753$ & 24,9 & $1878 \mathrm{H}$ & 55716 \\
\hline
\end{tabular}

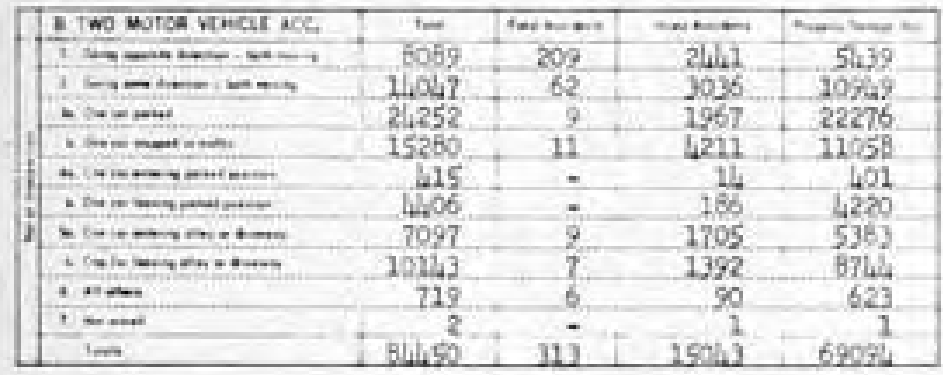

\begin{tabular}{|c|c|c|c|c|c|}
\hline \multirow{2}{*}{$\begin{array}{l}\text { C nidestants } \\
\text { acseonts }\end{array}$} & \multirow{2}{*}{$=$ nots } & \multicolumn{2}{|r|}{ 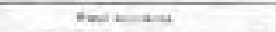 } & \multicolumn{2}{|c|}{ 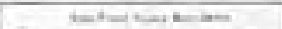 } \\
\hline & & $1=$ & 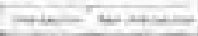 & tom & $4 m-n+0$ \\
\hline $1600=0$ & 2506 & 186 & 142 & 2,40 & 1750 \\
\hline $16+m$ & 92 & - & $=$ & 72 & 56 \\
\hline 3 conster & 220 & 10 & 1 & 210 & 192 \\
\hline+4010 & 61 & 1 & - & 60 & 52 \\
\hline$\therefore \neq$ & 11 & - & - & 11 & Io \\
\hline$\therefore \sim \ldots$ & $\frac{1}{2031}$ & $177^{\circ}$ & 3 & 1' & $\frac{1}{6}$ \\
\hline
\end{tabular}

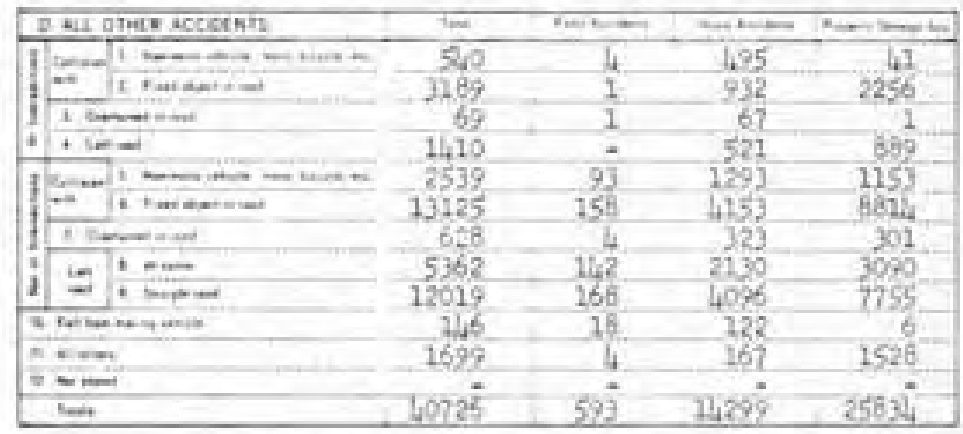

\begin{tabular}{|c|c|c|c|c|c|c|c|c|c|c|c|}
\hline \multirow{2}{*}{7 Hesstmas actions an sal } & \multirow{2}{*}{ nomintis } & \multicolumn{10}{|c|}{ 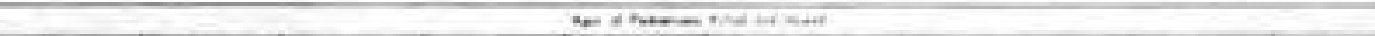 } \\
\hline & & $t=$ & $t=1$ & 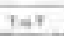 & $=06$ & $\pi=\pi$ & $\# \rightarrow$ & $H= \pm$ & fine & mene & that in t h h \\
\hline 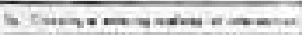 & 31 & 886 & 29 & 185 & 87 & 68 & 30 & 69 & 113 & 99 & 6 \\
\hline ibinom & 72 & 1089 & 212 & 454 & 151. & 78 & 26 & 53 & 60 & 47 & 9 \\
\hline 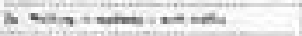 & 23 & $12 \%$ & i. & 2 & 13 & 52 & 12 & If & 24 & it & 1 \\
\hline$\therefore-\cdots$ & 11 & 49 & 1 & 4 & 7 & 13 & 1 & है & 5 & 10 & - \\
\hline 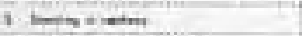 & 12 & 77 & 1 & 4 & 3 & gु & 16 & 19 & 16 & 6 & 3 \\
\hline 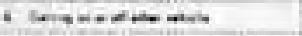 & - & 36 & - & 4 & 4 & 3. & 5 & 11 & 4 & 1 & 2 \\
\hline 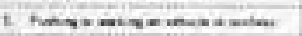 & 3 & 30 & - & $=$ & $i$ & 5 & tg & 12 & $\frac{1}{5}$ & 1 & 2 \\
\hline istant & - & 19 & - & - & - & 1 & 5 & 6 & 6 & 1 & - \\
\hline $1 \mathrm{Non+CO}$ & 2 & 67 & 12 & 35 & 15 & 5 & - & - & - & - & $=$ \\
\hline 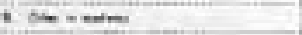 & 17 & 299 & 37 & 77 & 51 & 29 & 23 & 10 & 23 & 山 & 5 \\
\hline 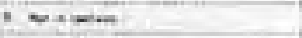 & 7 & 200 & 7 & 11 & 8 & 21 & 7 & 22 & 14 & 9 & 2 \\
\hline$=-$ & 15 & 639 & 79 & $10 ?$ & 78 & 72 & 32 & 5 & 26 & 37 & 58 \\
\hline $1-$ & 293 & $32 \pi 2$ & 378 & 966 & 423 & 356 & 262 & 30 & 324 & 233 & 87 \\
\hline
\end{tabular}

\begin{tabular}{|c|c|c|c|}
\hline I Bot or pents & 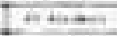 & for co & $-4=$ \\
\hline 1. $\mathrm{Htan}$ & 763 & 10. & 286 \\
\hline $3=4$ & $209 \omega 8$ & 57 & 2900 \\
\hline 1. $*$ & 25423. & 77 & .0056 \\
\hline 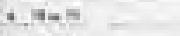 & $304: 4$ & 173 & 6375 \\
\hline yan & $\$ 215$ & 360 & 15711 \\
\hline - $-\mathrm{ntan}$ & 62801 & 417 & 17757 \\
\hline $1=\ldots$ & 66642 & 291 & 12626 \\
\hline 10.6 & 39621 & 268 & 10806 \\
\hline $4 \quad x=0$ & 26600 & 189 & 7019 \\
\hline$=0 \Rightarrow$ & 13160 & 10) & 3358 \\
\hline and... & 4632. & 50 & 2172 \\
\hline $7-2$ & 38754 & 23 & 2985 \\
\hline - & 14595 & 2002 & .87251 \\
\hline $13 x$ or osints & 20 & $x=4$ & 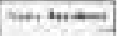 \\
\hline $1-$ & 202532 & 1641 & 61375 \\
\hline at... & 916.6 & 347 & 24837 \\
\hline$i=0$ & $2177 \mathrm{e}$ & 19 & 1039 \\
\hline $\mathrm{ser}$ & 345956 & 2007 & 67251 \\
\hline
\end{tabular}

\begin{tabular}{|c|c|c|c|}
\hline 10 ecsolnce of sen. & $=n$ & t. - & \\
\hline theten & 258728 & 117 & 64 \\
\hline $1+n+a-n$ & 51256 & 528 & 24508 \\
\hline 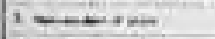 & 23109. & 235 & 6725. \\
\hline$\therefore-m$ & 12663 & 19 & 1229 \\
\hline
\end{tabular}

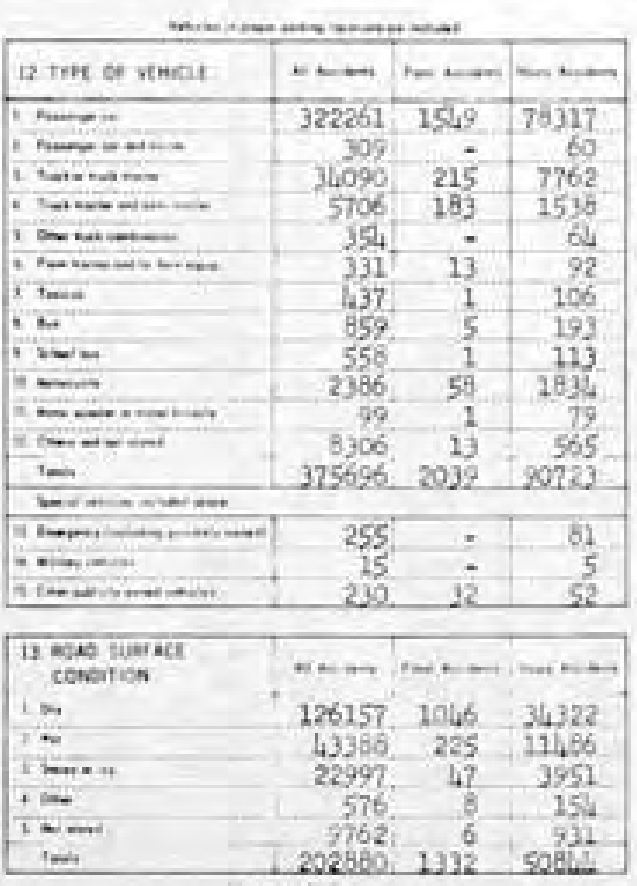

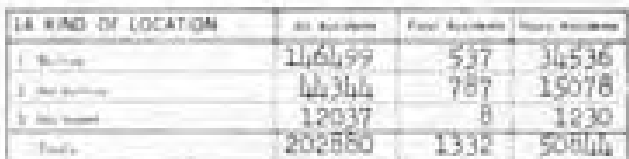

\begin{tabular}{|c|c|c|c|}
\hline II. uget conolnov & HE & $N=2$ & 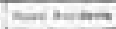 \\
\hline inow & 130628 & 635 & 31814 \\
\hline$i x \sin x$ & 7929 & 56 & 1974 \\
\hline is Hens & 5472 & $6 x_{4}$ & 16545 \\
\hline$\therefore-$ & 5572 & 7 & 51. \\
\hline 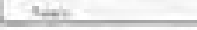 & 302652 & 1332 & Solt \\
\hline
\end{tabular}

\begin{tabular}{|c|c|c|c|c|}
\hline \multicolumn{2}{|r|}{ 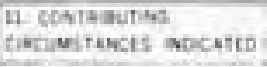 } & \multirow{2}{*}{ มไะ } & \multirow{2}{*}{253} & \multirow{2}{*}{5611} \\
\hline & $-\infty$ & & & \\
\hline & 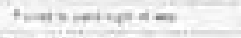 & 26027 & 174. & \\
\hline 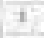 & $\ln x+100$ & & 175 & \\
\hline$\therefore$ & $-\cdots$ & 47 & 30 & 14. \\
\hline 2 & fautios of & & 31 & \\
\hline & $\sin -i-1+r$ & 28 & 33. & \\
\hline$x$ & notions & 106 & & \\
\hline . & 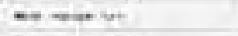 & 5069 & 24 & 10 \\
\hline 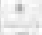 & $m$ & 27003 & 106 & 6525 \\
\hline s & $\operatorname{ling}$ & 1645 & 6 & 79 \\
\hline 3 & $-\infty+$ & 419 & 1 & 136 \\
\hline & Notuentits & 7801 & 226 & \\
\hline & … & 111327 & 1067 & $35 \%$ \\
\hline
\end{tabular}




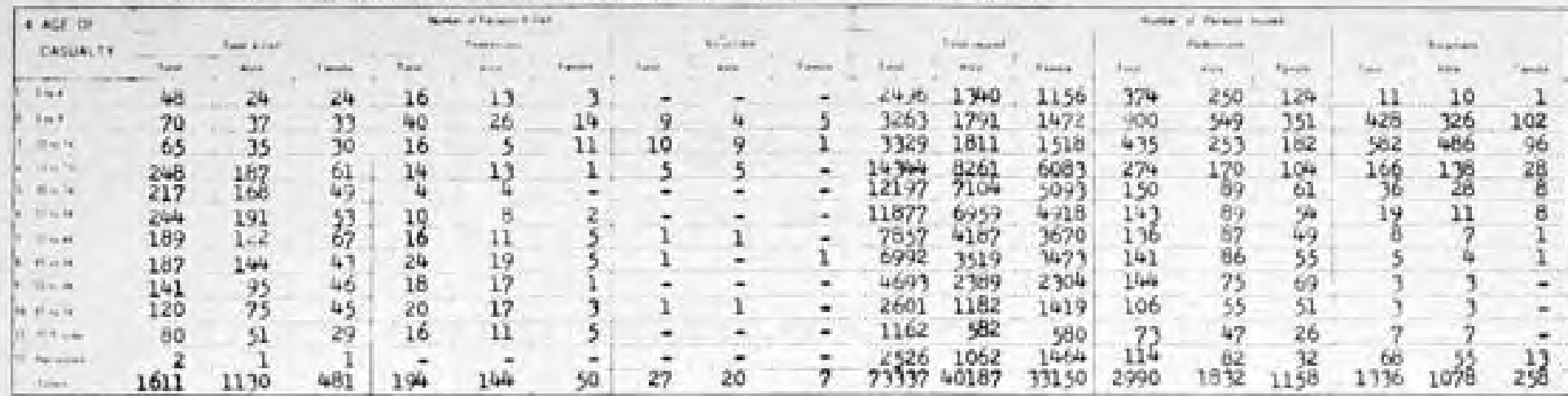

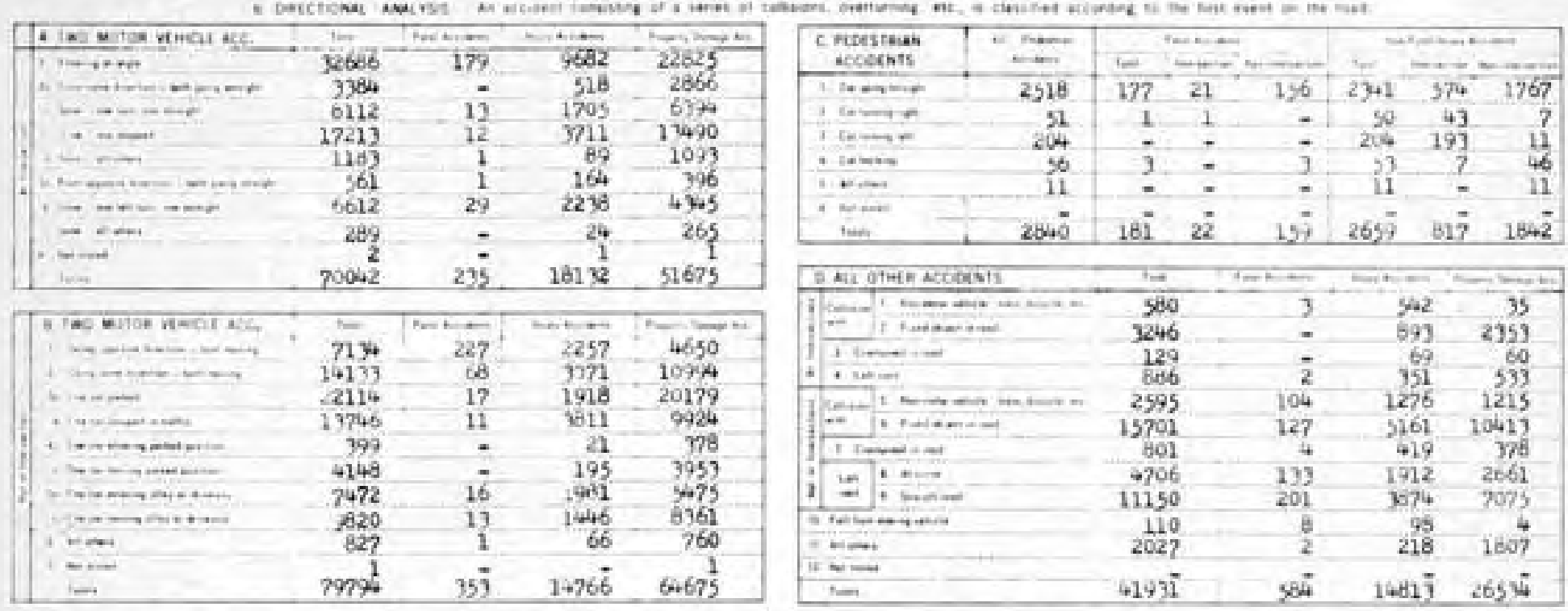

\begin{tabular}{|c|c|c|c|c|c|c|c|c|c|c|c|}
\hline \multirow{2}{*}{ intersmas actions or sa } & \multirow{2}{*}{ Nimin } & \multicolumn{10}{|c|}{ 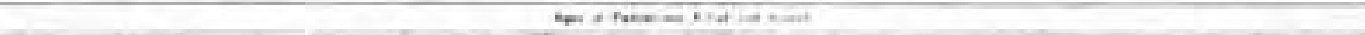 } \\
\hline & & $=$ & 604 & 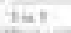 & ineit & $n=n$ & $m=n$ & $n=\infty$ & $n=2$ & stivo & $-\infty$ \\
\hline 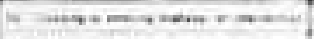 & 27 & 571 & 26 & 153 & 79 & I. & 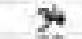 & \$8 & 100 & 75 & 12 \\
\hline 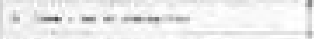 & 24 & 1059 & 208 & 438 & 150 & 96 & 22 & 36 & 74 & 45. & 9 \\
\hline 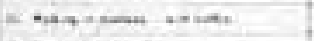 & 28 & 214 & 2 & 6 & 18 & 41 & 5 & 20 & 15 & 6 & 1 \\
\hline 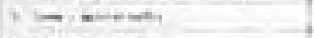 & 4 & 46 & 5 & 8 & $?$ & 8 & 4 & 2 & $?$ & 6 & - \\
\hline 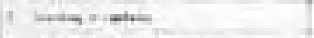 & 11 & 78 & 3 & 8 & 5 & 15 & 6 & 25 & 11 & 5 & - \\
\hline 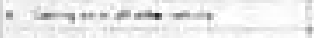 & 3 & 36 & 2 & 3 & 2 & 6 & 4 & 9 & 6 & 2 & - \\
\hline 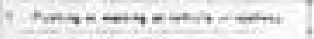 & - & 36 & - & 3 & $=$ & 7 & 8 & 13 & 5 & $=$ & - \\
\hline 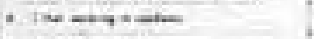 & 1 & 11 & - & $=$ & 1 & 2 & - & y & 4 & 1 & $=$ \\
\hline 1 navionen & a & 86 & 31 & 33 & 12 & 8 & 1 & $=$ & - & - & 1 \\
\hline . $\rightarrow \cdots$ & 20 & 937 & 34 & 101 & 62 & 25 & 21 & 36 & 22 & 23) & 11 \\
\hline$\therefore \sim$ & 4 & as & 3 & 8 & 17 & 15 & 6 & 15 & 14 & 5 & - \\
\hline$x-\infty$ & 14 & 725 & 77 & 176 & 96 & $7 i$ & 41 & 60 & 69 & 45 & 80 \\
\hline $\cos$ & $1 \%$. & 324 & $1 \%$ & 240 & 451 & 268 & 180 & 105 & $32 ?$ & 215 & 116 \\
\hline
\end{tabular}

\begin{tabular}{|c|c|c|c|}
\hline D. Act of canch & She & 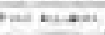 & C.t. \\
\hline 1 Inth & 767 & 6 & 305 \\
\hline 1.4 & $108 \%$ & 64 & 28.9 \\
\hline it & 14872 & 70 & 4024 \\
\hline 1. $4-4$ & 29170 & 171 & 8103 \\
\hline$\theta \mu=\omega$ & 94764 & 264 & 15774 \\
\hline C $\mathrm{Ban}$ & 60330 & 402 & $173<5$ \\
\hline $1 \mathrm{H} \rightarrow \mathrm{A}$ & 43129 & 329 & 12221 \\
\hline ans & 37070 & 260 & 10520 \\
\hline$+H=0$ & 25224 & 162 & $6 \pi / 40$ \\
\hline$=11=4$ & 12466 & 102 & 3379 \\
\hline n ne. & -633 & 57 & 1220 \\
\hline$y \rightarrow$ & 35440 & 26 & 2023 \\
\hline Nen & 369485 & 2052 & $0 \leq 472$ \\
\hline 9.40 or caves & 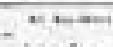 & $t=0$. & - \\
\hline 2. & 227699 & 1676 & $5 * 16$ \\
\hline$x$ & $9929 ?$ & 355 & 25214 \\
\hline-1 & 10987 & 222 & 949 \\
\hline
\end{tabular}

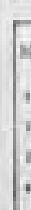

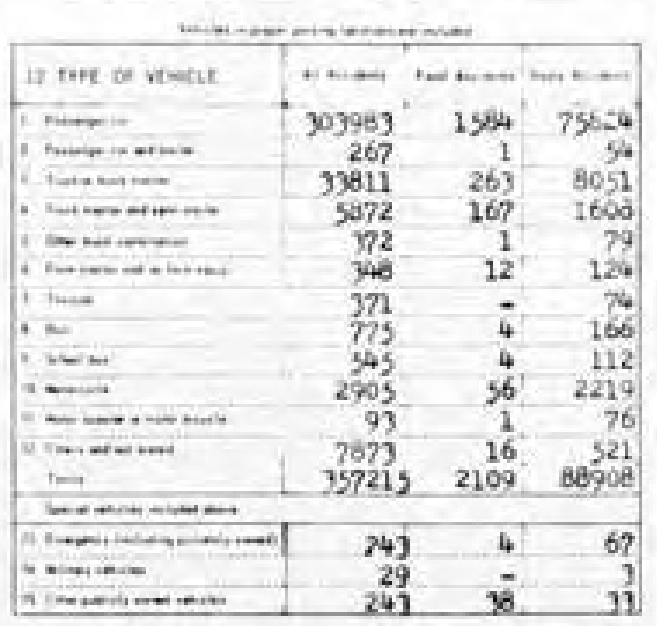

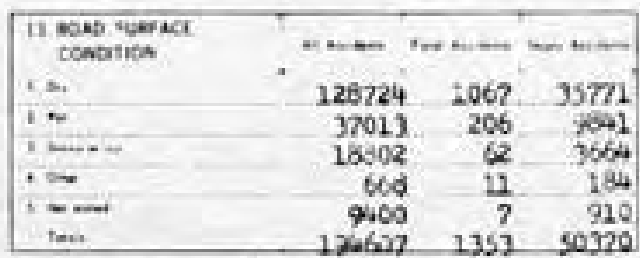

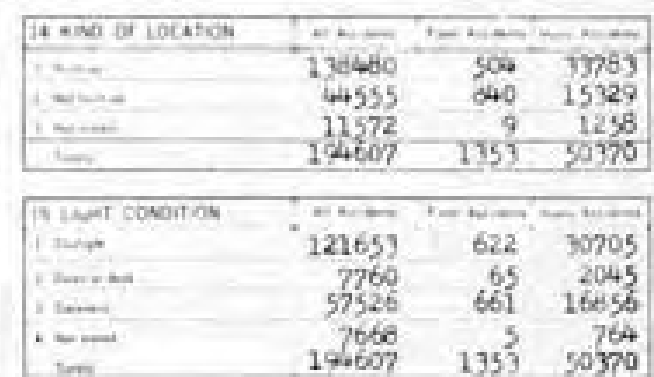

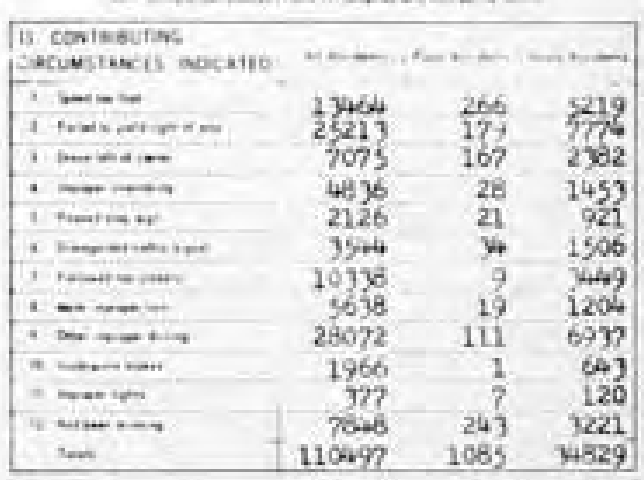




\section{Appendix B \\ Driving Regulations}

This Appendix includes excerpts from the Indiana Driver's Manual defining chauffeur's and public passenger chauffeur's licenses. The violation point system is also explained in this Appendix. 


\section{CHAUPFBURS AND PUHLIC PASSENGER CHAUPFBURS}

Every pernon whe is employed for hire by another for the principal purpose of eperating a motor vehicle, and every pernon who drives any motor vehicle upon a public highway. when in use for the tranaportation of properiy, for hire, muat have a Chaufleur's License.

The applicant for a chauffeur's license must be eighteen (18) years of age with one (1) year's licensed driving experience. He mest past the vision test and written examination every four (4) yean.

Every peraon whe operates a moter vehicle shile in we an a sched bus for the transportalioe of pupils to er froen school, of to or from school athletic gumes or conlest, er any pernoen who operates a motor vehicle while in we as a pablic panespet-carrying vehicle mot have a PuMlic Panenger Chanffurt, License.

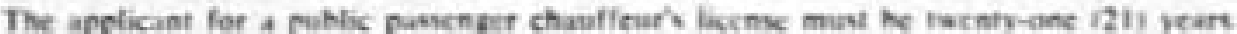

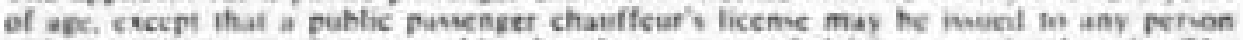
eighteen $(1 \times)$ yeurs of ake or older for the purpone of driving a tate cab suly. The

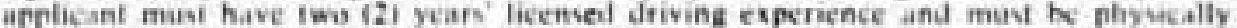
and mentally fil. He most pass the vision test and written examination and whmit a mestecal sxanianatue report each year. The report forms are avalable at any licsne branch

A chaufleur's revponvibility is crester-much ereater-than that of other driven. The

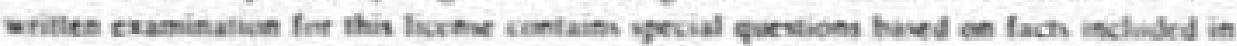
the VEHICIS AND HQUIPMINT sctire and in other parts of this Marnal.

\section{VIOLATION POTNT SYSTHA}

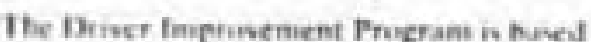

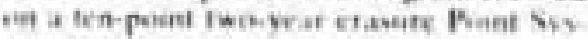

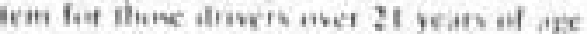
and an eught poent two year erasufe losist Sosem for a Fesicutionaty I isenve fthome onder 21 veare of ape s as diantrated

Derer improvement

Actien

Paint Lene:

Under 21 21 4 Oner

Atmontrative

Hearing

$3 \pi$

$10 \mathrm{st}$

mon mais

Prant values refleci the serumasnew of the offenve in relatiein tos harafous mesving vislatioms and hased. as neatly as pomitile, on actident stativation indisating the major caine of aculents

The licrhoe en permit of a druer can. valled ed drivinge while under the influsencet

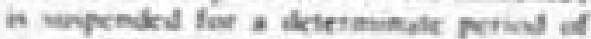
time AND UNIII he fllo and fumters

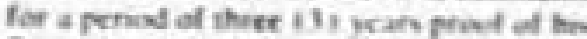
Sienncul respomikality ifurm SK :22) with the lluteas of Mator Vehicles.

Fafure to appear in sourt at the trquired time and plase will revilf in sus pension of your driving privilege until you appear in court, and a final deterimination of the charges against you is made

points assesseo pon conviction or Meckiess drivino Speet Conlege ipens Anacingl

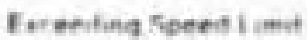
I is muk ovet is 7 th mph gres 16. and over

Ohair Hazarifous Mering Vindatinns:

Caturs Teathe Wistabions

Cav Gidenance

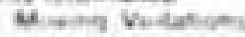

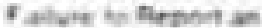
A. is abes

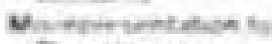
Denurithent

$z$ panints

3 pounts

6 points

3.4.5 points

1.3 pounts.

2 pounts

Miraning

Nearing

undatoar suspension on conviction or:

Ist Oblense at Driwing While under the influencet

2 Mos to I Year"

Znd and Subsequent Otiense

of Diring while unde?

ihe intluencet

Unnsianghier or Anckiess

Homicide

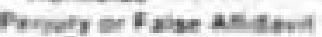
is Debaltant

Cribes invelting war at o Uober Wetiple

Yest to 2 Years:

Cenricthans of Rinckiess Driving in 12 Nones Prived

chaving Screne of Acrident lOve: 1100 orobeity damage iniury or Dealni

Diming whale Suabended

Out-of state Conviction - Petiod of Suspension carrying a Mandatory Suspension in indian.

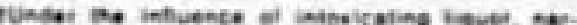

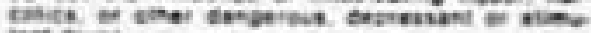
liat tinge

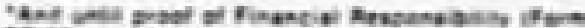

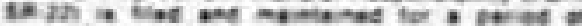

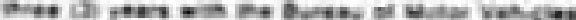

\section{PIGURE 5 EXCERPTS FROM INDIANA DRIVRR'S MANUAL}




\section{Appendix C \\ Data Collection Forms \\ and Related Information}

The forms in this Appendix are sample copies of those used to collect driver and accident records. Included in this appendix is a brief explanation of the "Soundex Code". 


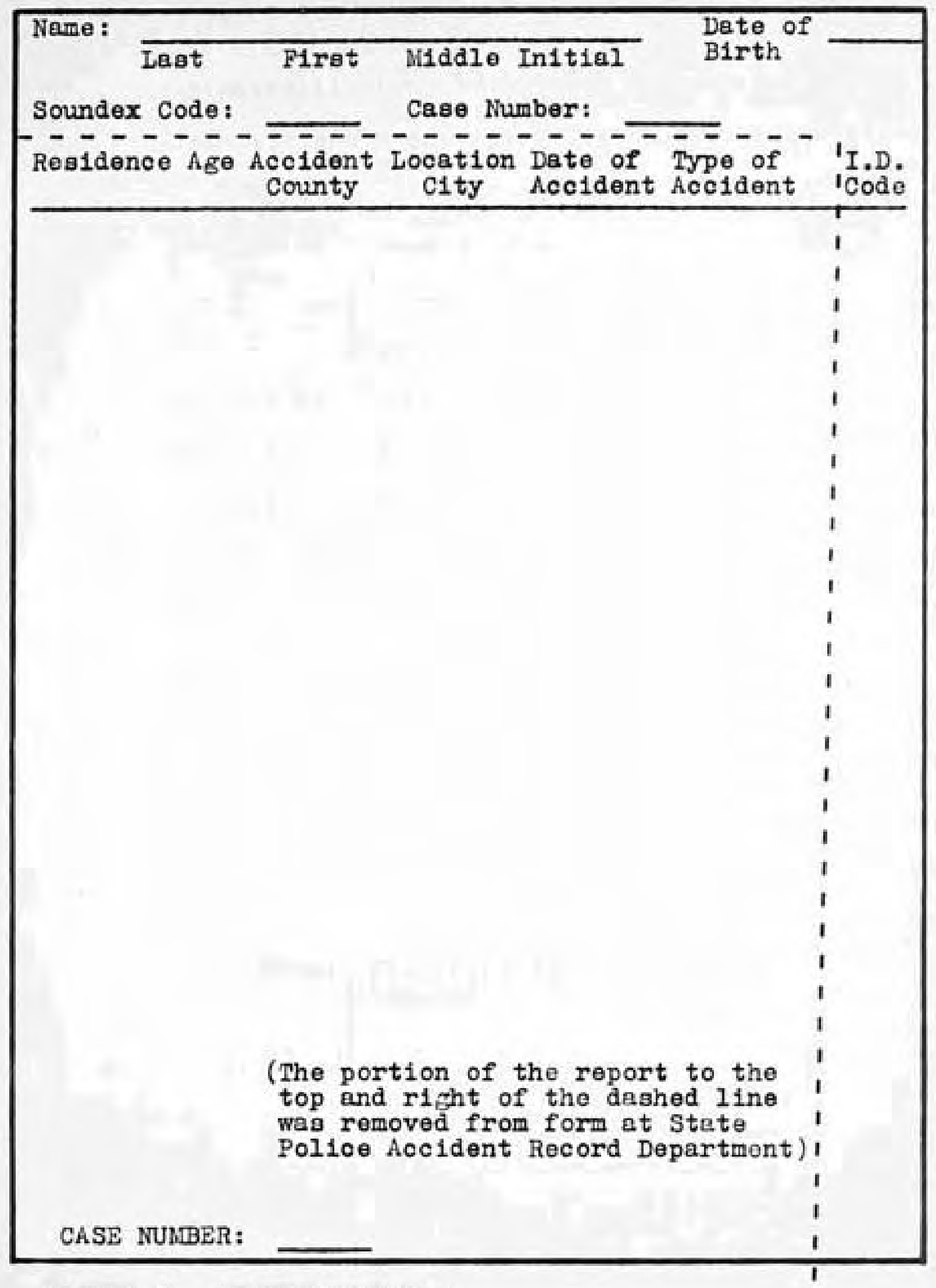

FIGURE 6 ACCIDENT RECORD 

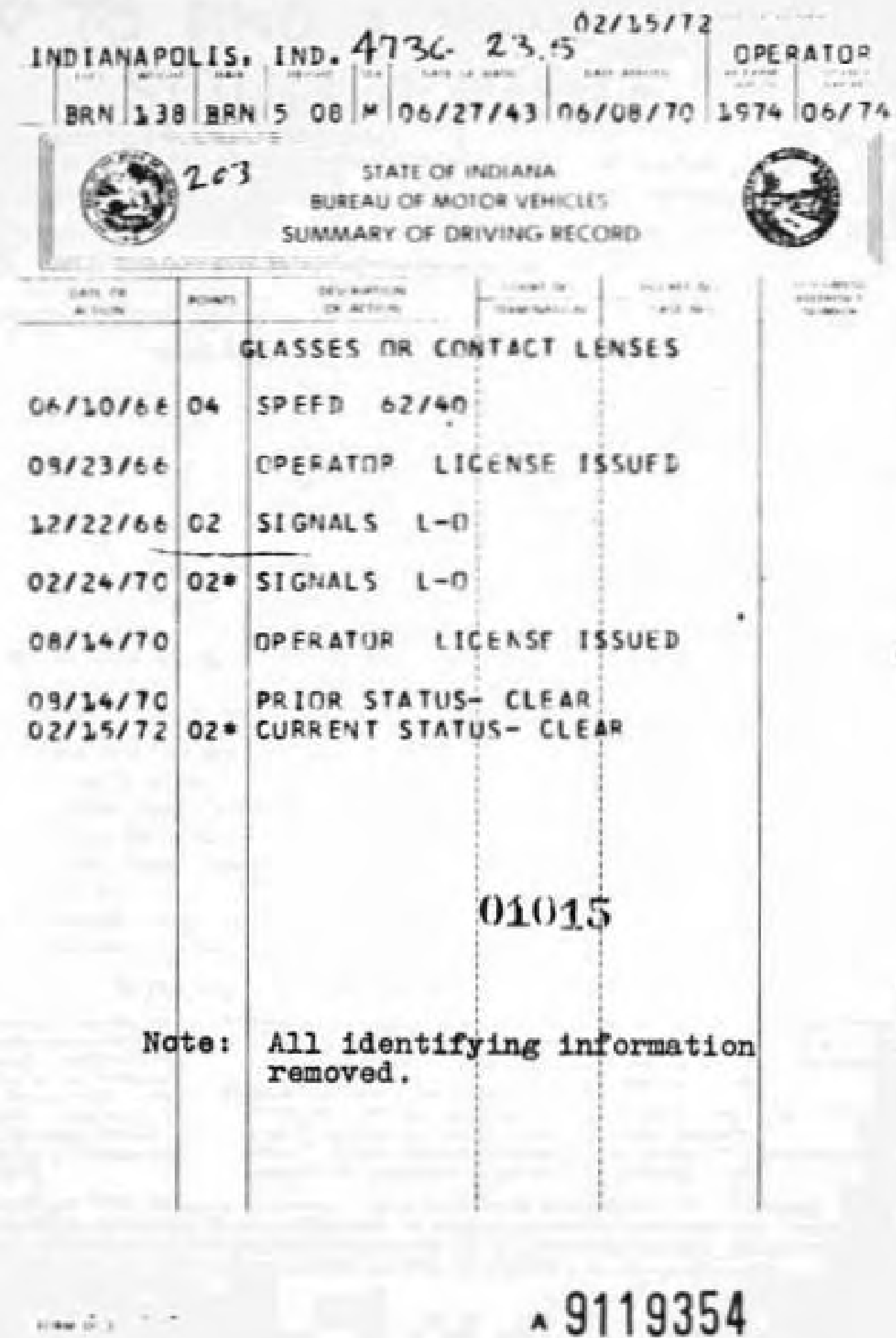

\section{^9119354}




\section{HOW TO FIND A NAME IN YOUR SOUNDEX FILE}

Go to the file section containing the letter of the alphobet in which you are interested; for example, B for Bayer; $K$ for Kauffmann, $S$ for Schneider. Code the remaining letters in the name in occordance with the following Soundex code. Never attempt to code the first letter of the surnome.

Koy letters, codes and equivalents are os follows:

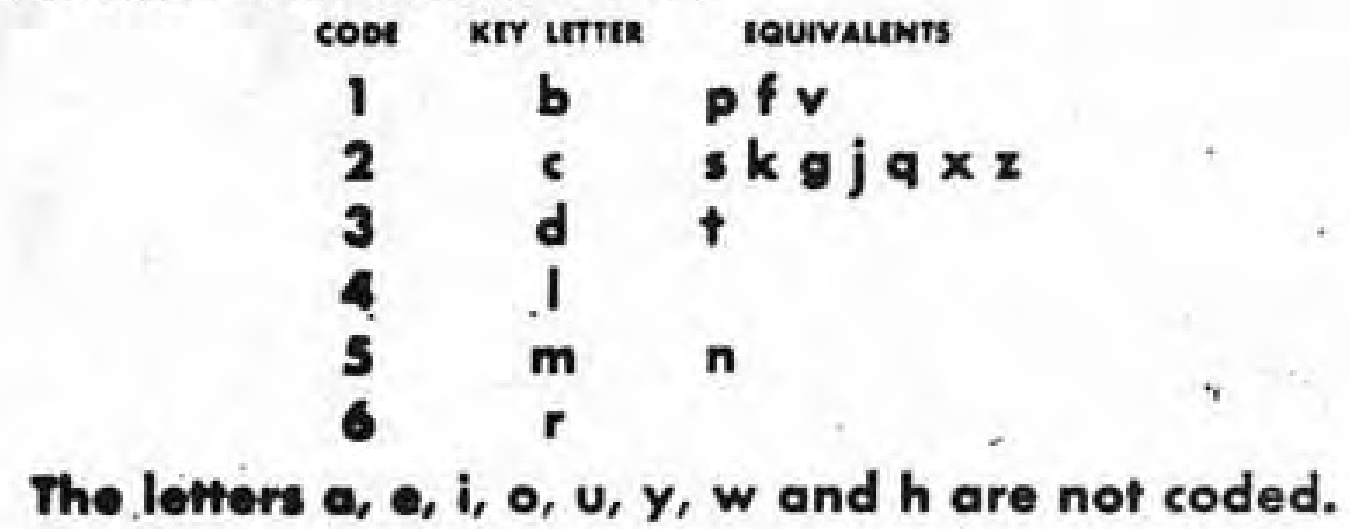

The following examples shew how Soundex controis the fling of diferent spelings of the same surnore

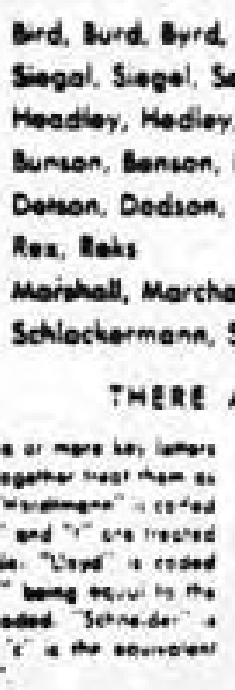

Brd. Burd. Byrd, Bard

Siegal, Si.epel, Segal, Siogie

Headioy, Hodier, Hudiey, Hutiey

Bumion, Bonion, Bunian

Domon, Dedsen, Detwen, Dudven

Rex, Rehs

Morikall, Marchall, Maruchal

Schlockermann, Siekerman

\begin{tabular}{|c|c|}
\hline$" \Delta$ "file section - guide & id 630 \\
\hline "S" file section - guide & e 240 \\
\hline "H" kile rection-guide & di 340 \\
\hline "a" file section-tuide & mem 525 \\
\hline "D" file section-guide & $\mathrm{dcm} 32 \mathrm{~s}$ \\
\hline "R" file secrien - guide & $=200$ \\
\hline " $M$ " file vection - guide & tel o24 \\
\hline " $5^{\prime \prime}$ file section - guide & ler 420 \\
\hline
\end{tabular}

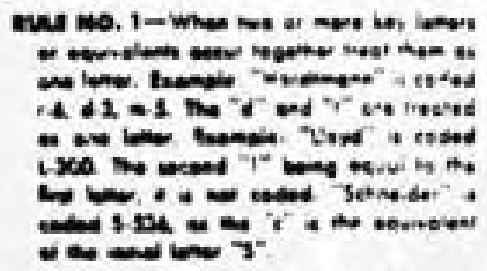

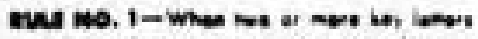

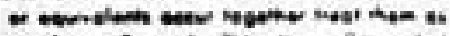

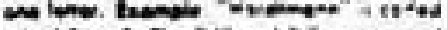

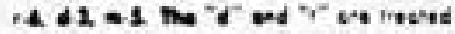

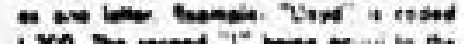

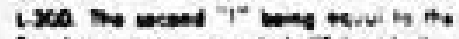

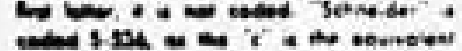

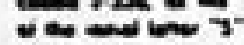

QE FIVE SIMPLE RULES TO KEEP IN MIND

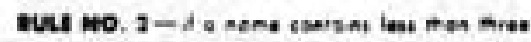

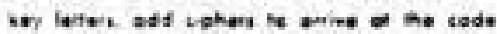

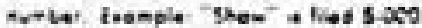

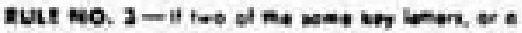
un letier and th equitulaw, ore uperaled by

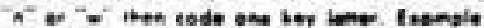

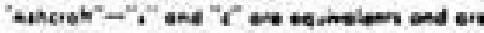
teperaied by " $\mathrm{n}$ ", therders, sede "Auhureh" ist

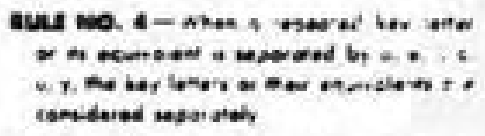

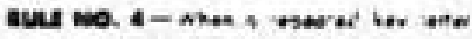

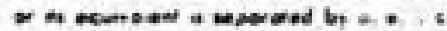

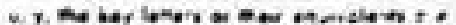
comberad near atoh

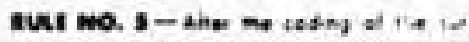

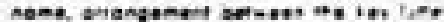

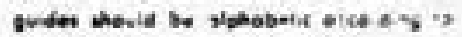
pinen nom

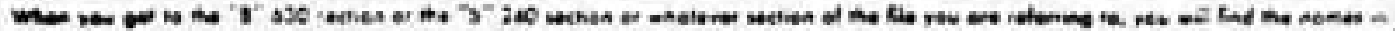

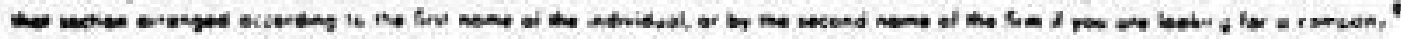

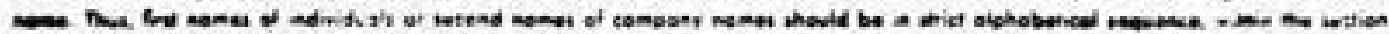

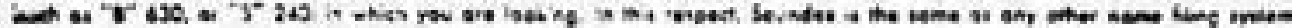




\section{Appendix D}

\section{Driver Characteristics}

The tables in this Appendix identify characteristics of different accident groups studied in this report. 
Table 18. Age and Sex Related to Total Accident Involvement

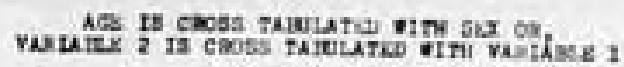

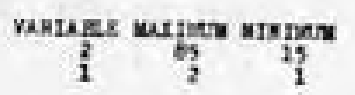

inf $1=\operatorname{mez}, 2$ - rauls

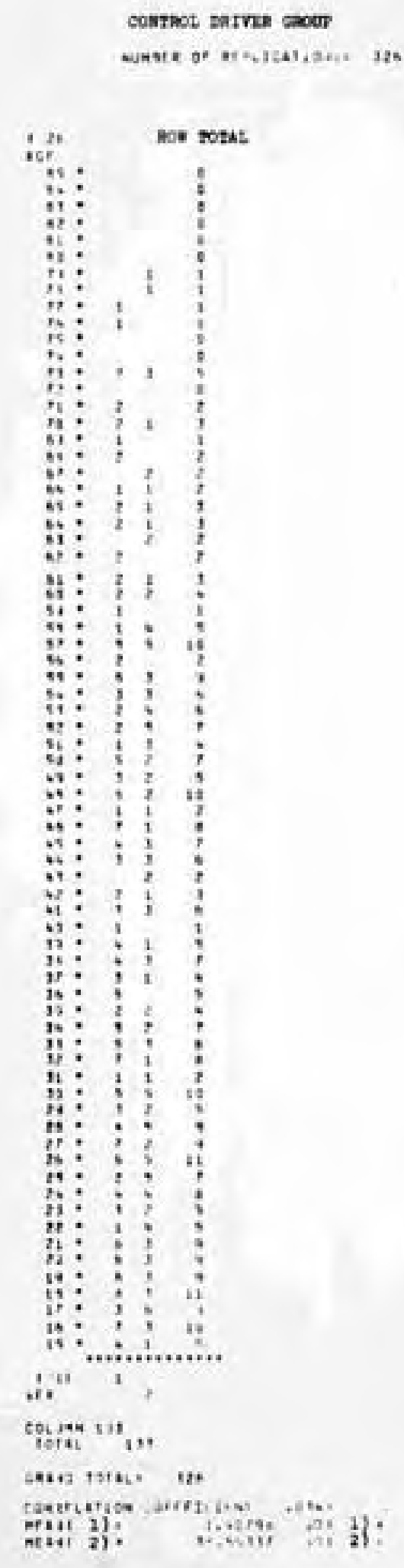

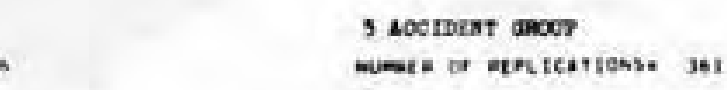

isi nor sotes

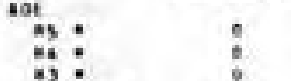

$3:$

$1: 1$

$\because:$

:

in:

i:

; :

i):

:

$\because:$

of:

*t: 1

$\because:$

3 :

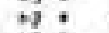

$\because:$

: :

, : i

, : 12

31

$3:$

3!:

?:

an 1

$\because:$

$\because:$

$3: 3$

$\because$ :

$\because:$

305

II:

3: :

is:

; :

3: 1

30:

: :

: : i

it: io

$\therefore:$ :

I;:

a: 11

it:

is: is

i..

19:

is: :

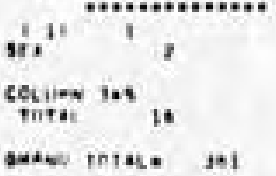

sotse thrace joi

coustatisa cetreicion at ats

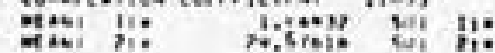




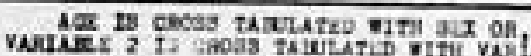

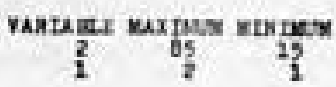

sai 2 - wLE, 2- raus

6-7 100temen anow

neate of apticapionse ras
Le nocterent abcus

mueta of athicariemse izT
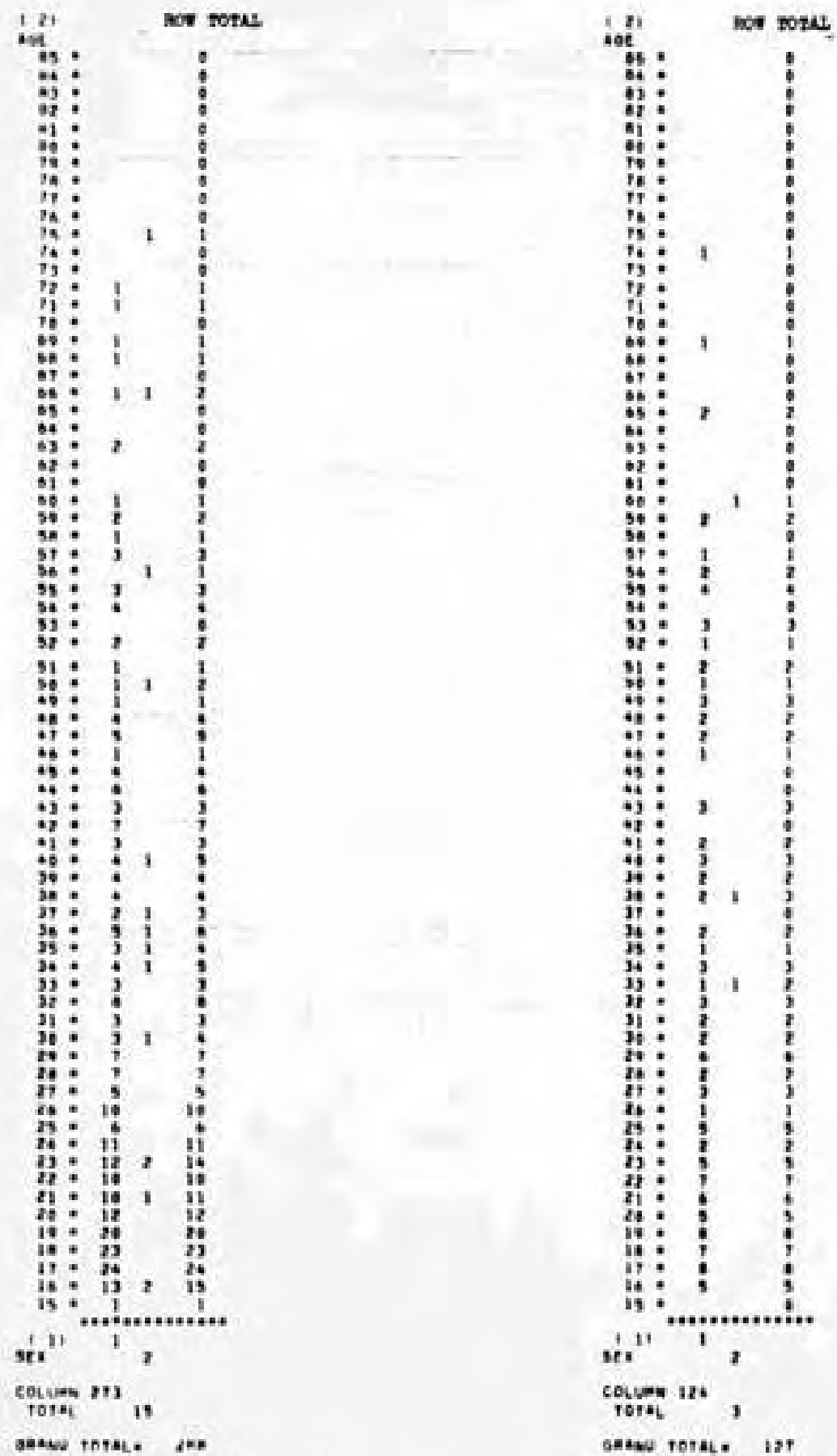

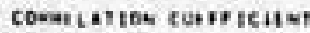

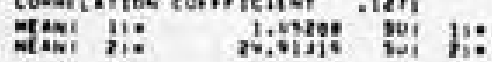

\section{1}


Table 19. License Restrictions Related to Total Accident Involvement.

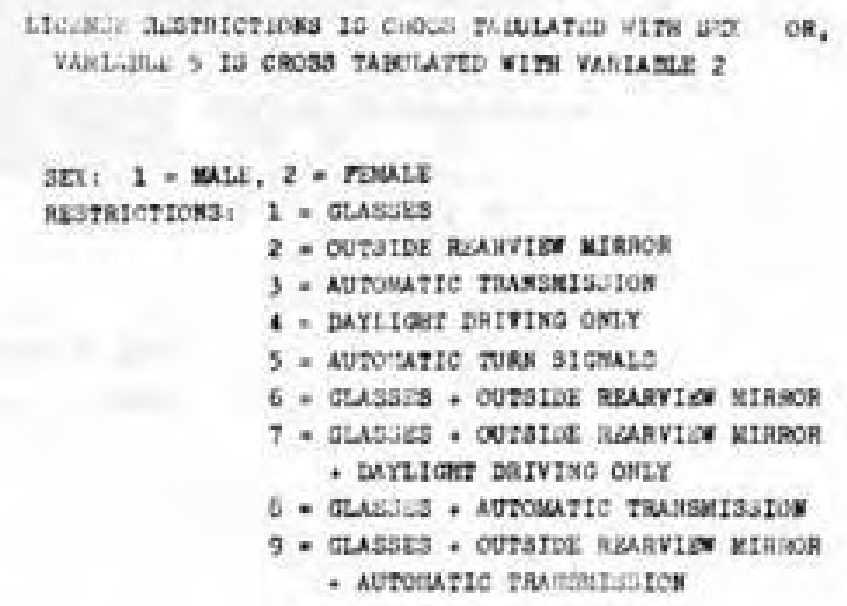

Conthot Darvas gacor

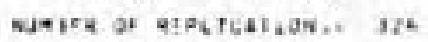

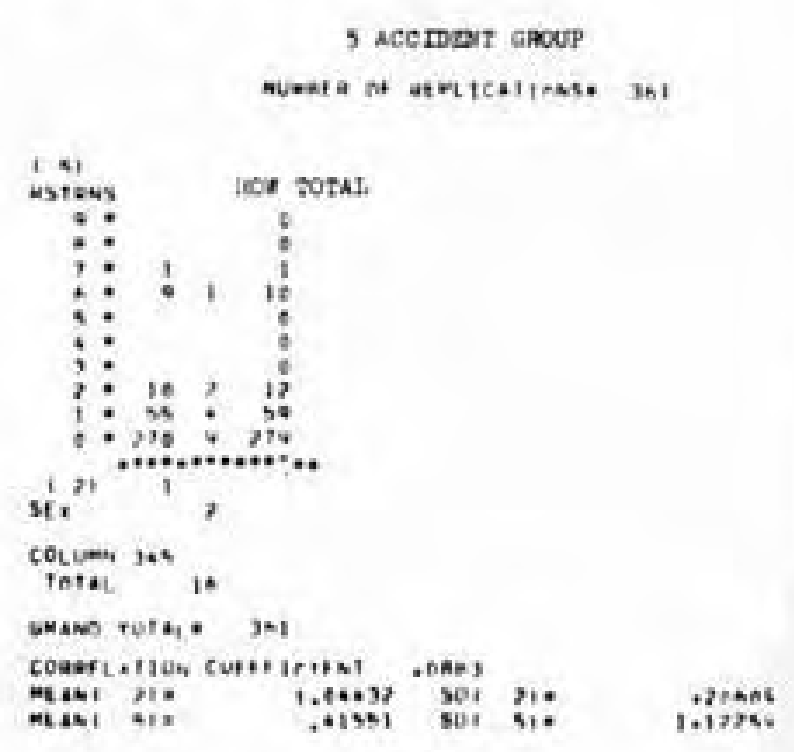

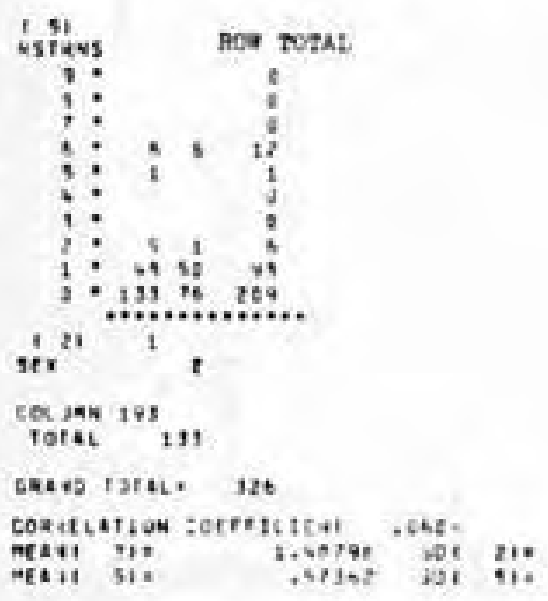

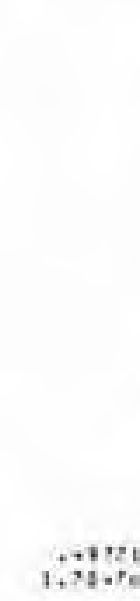


Table 19. (Continued)

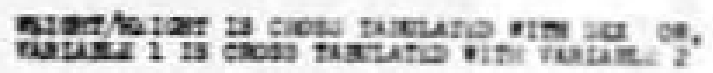
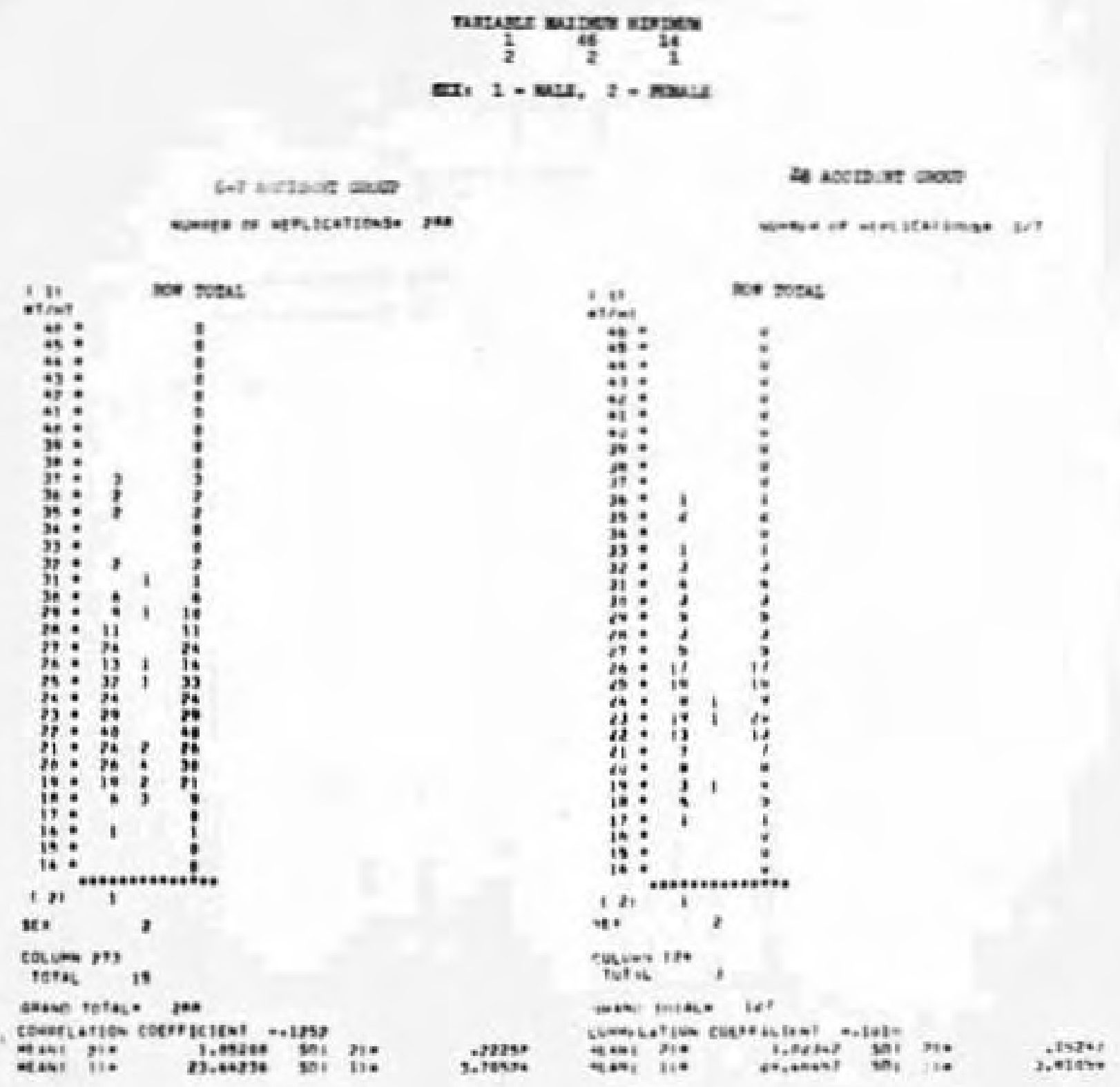
Table 20. Weight/Height Index in Relation to Total Accident Involvement.

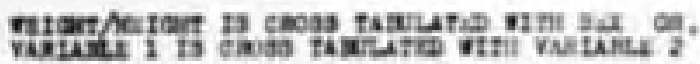

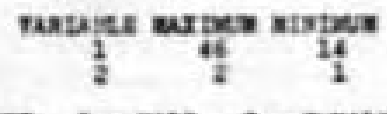

ari 1 - wer, 2 - nase

cotres patra bax?

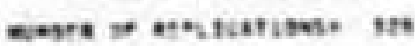

5 actuent ters

avela of athicafiate as!
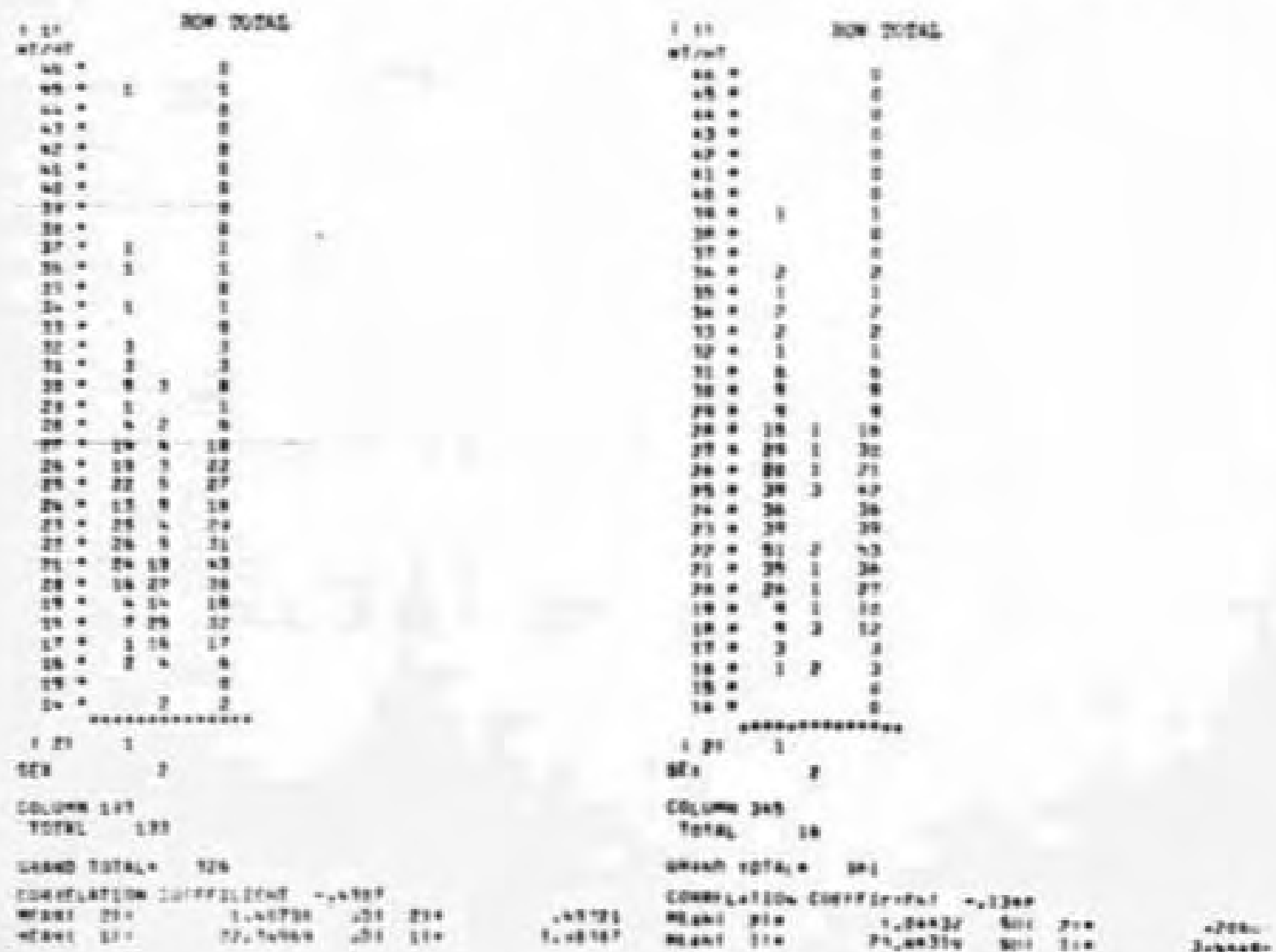
Table 20. (Continued)

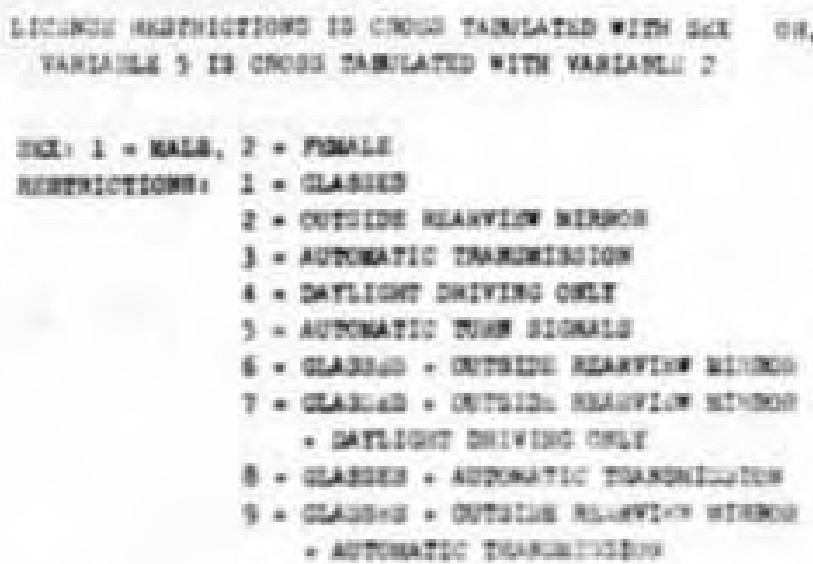

6-7 aeifiut dive:

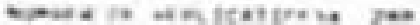

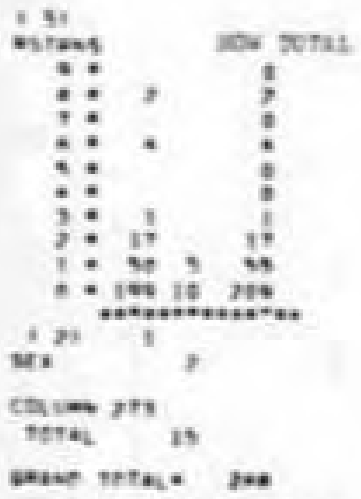

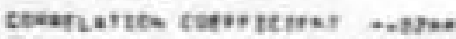

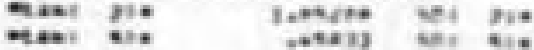

ea.

ent




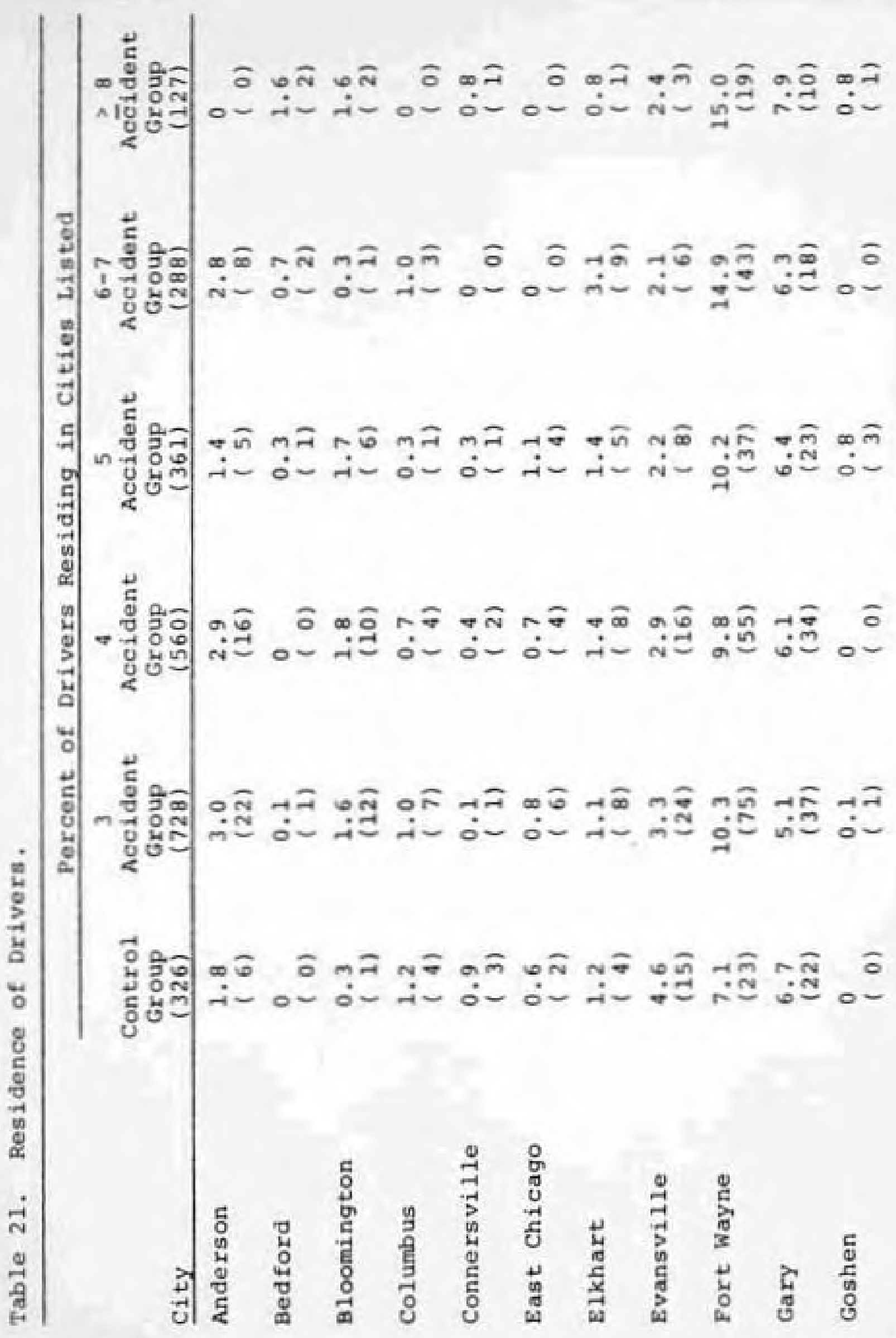




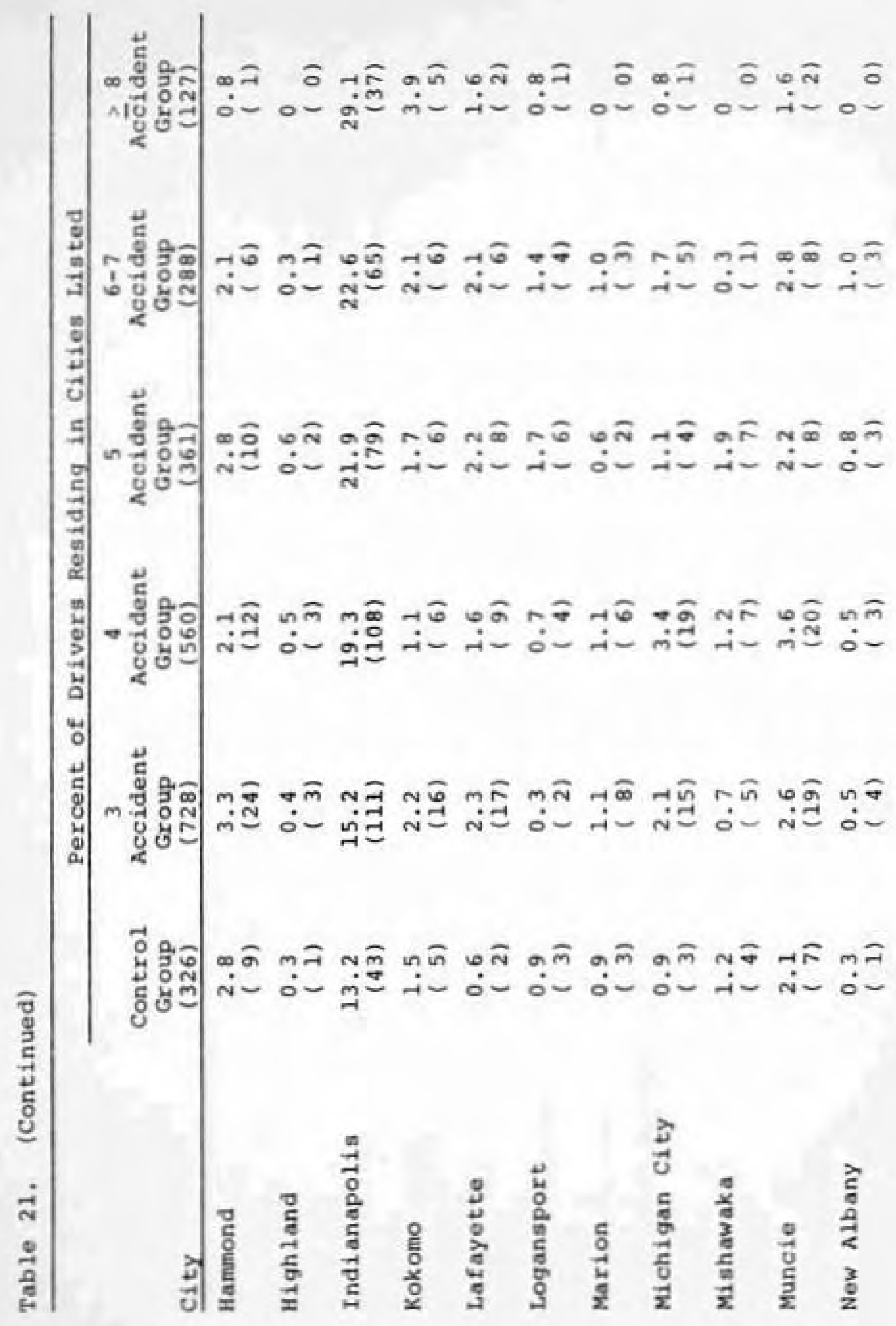




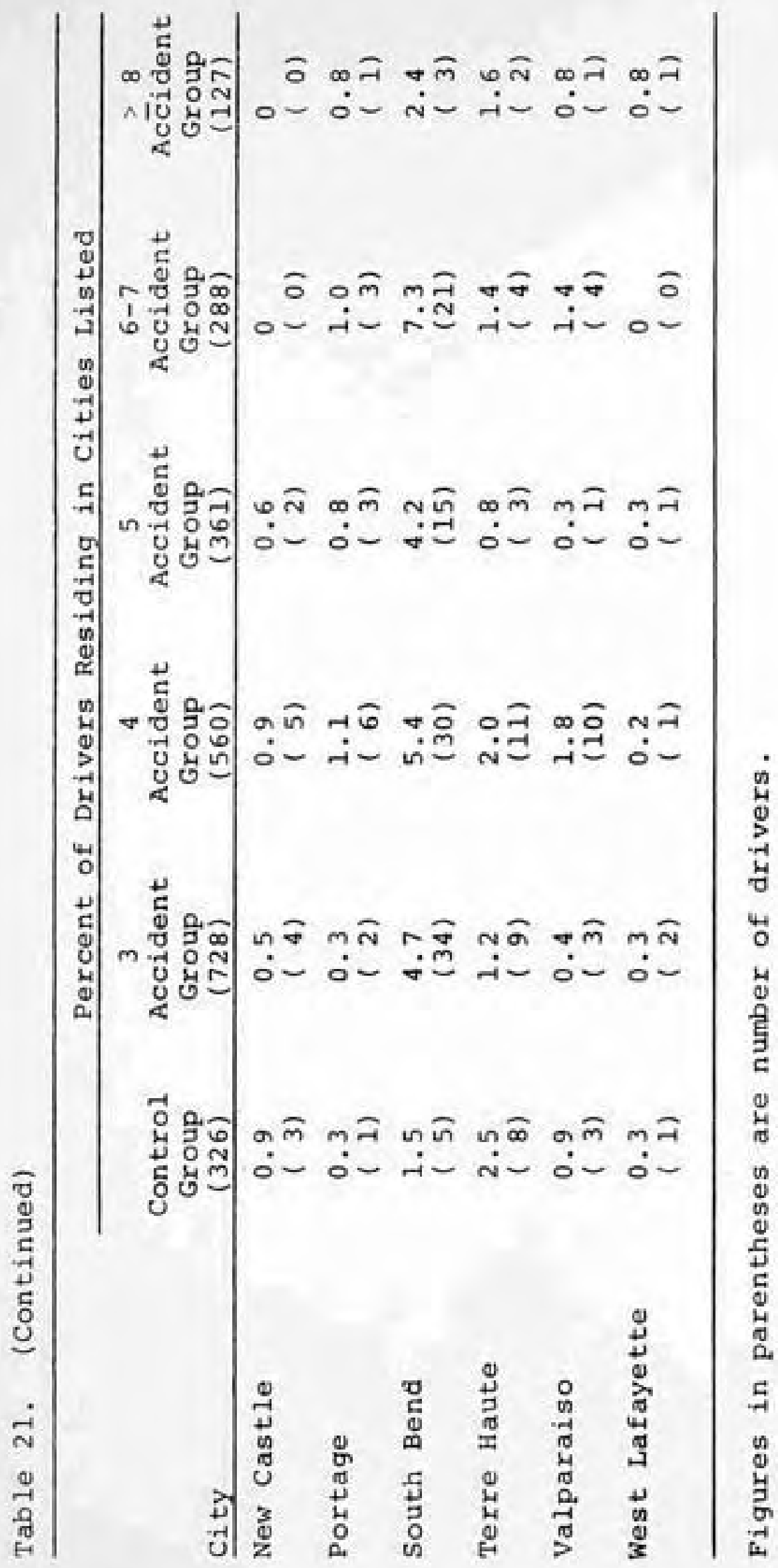




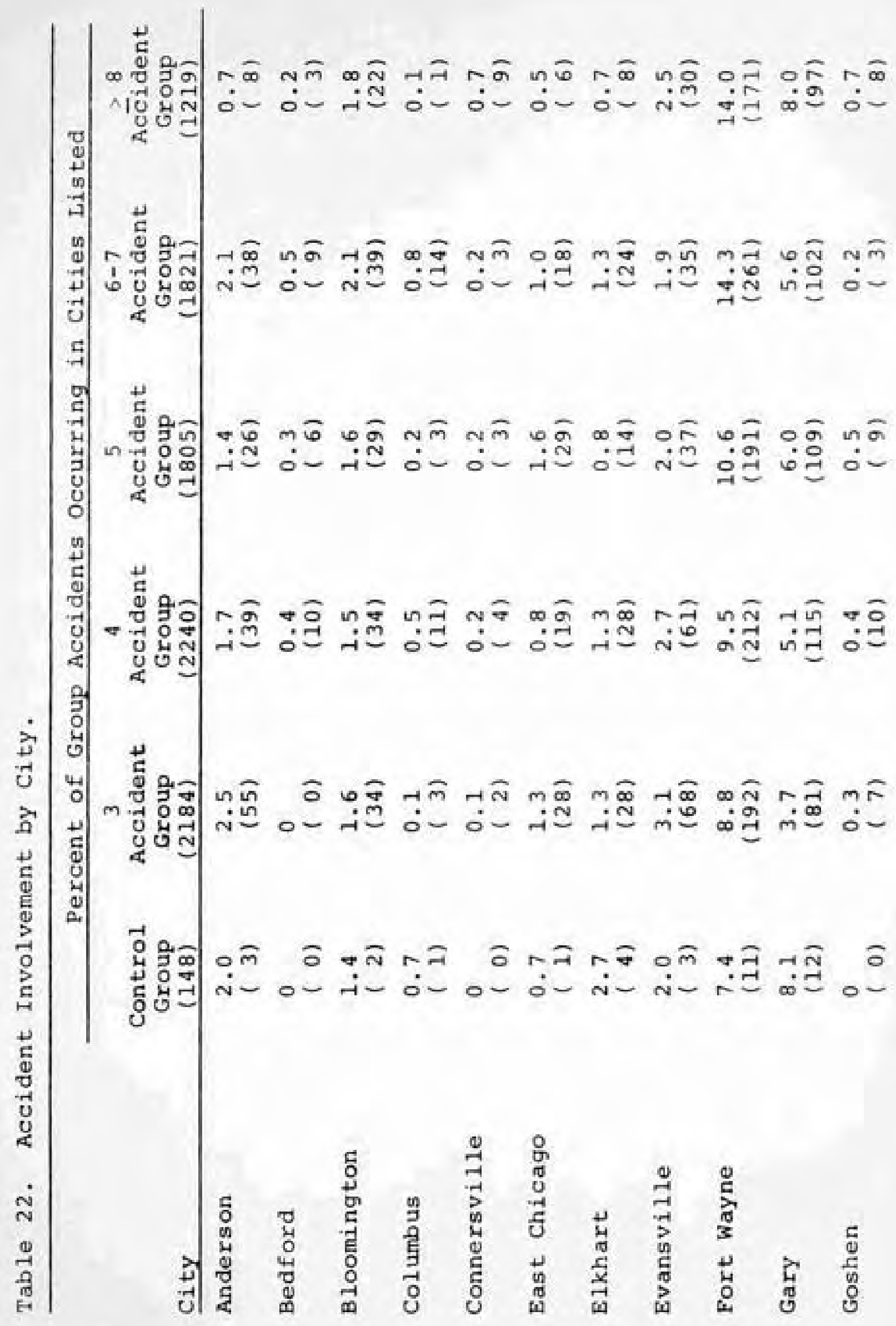




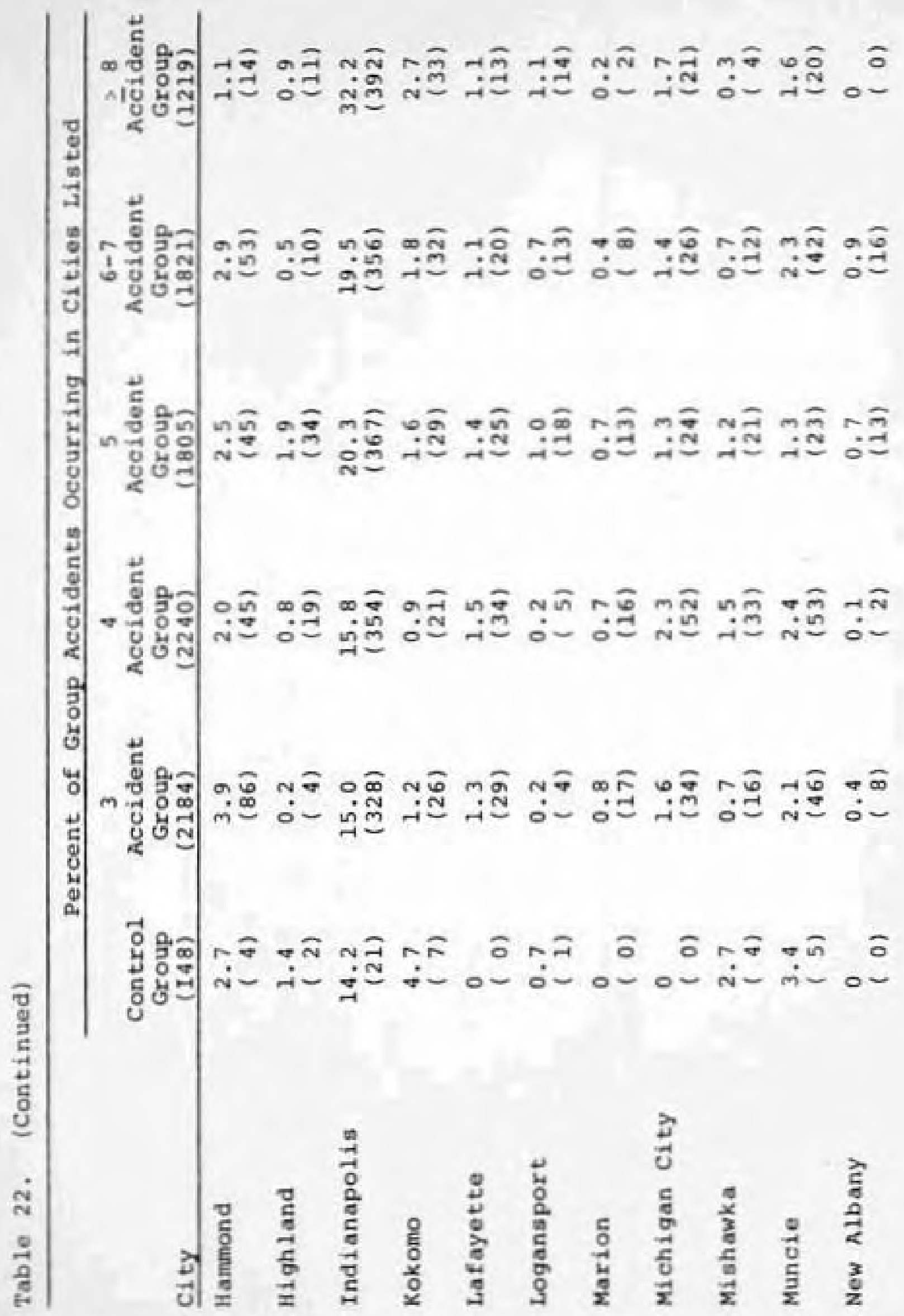




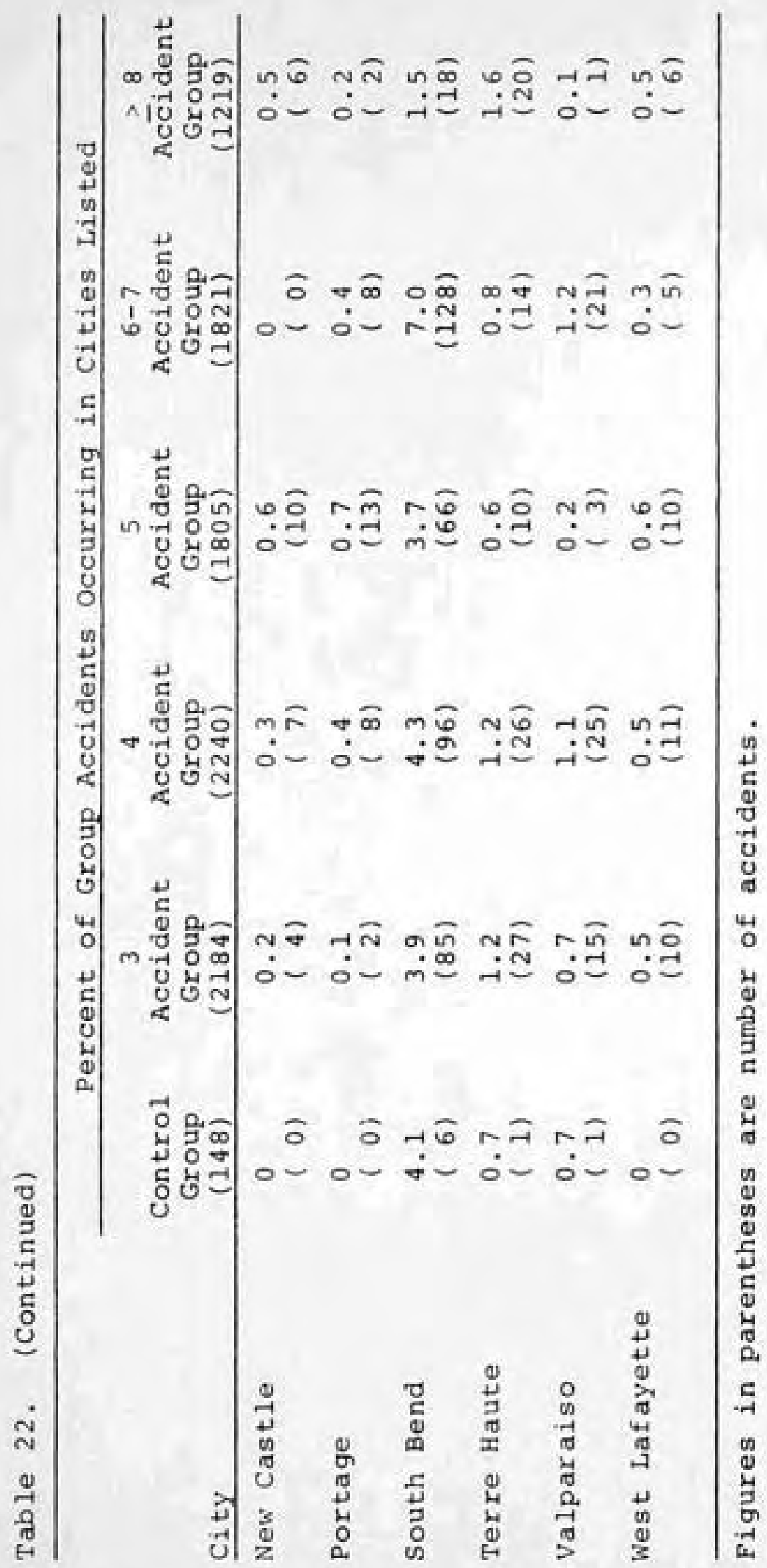

